$\frac{10}{211318978(1)}$

UCID- 21444

\author{
NUMERICAL MODELING OF THE THERMAL AND \\ HYDROLOGICAL ENVIRONMENT AROUND A \\ NUCLEAR WASTE PACKAGE USING THE EQUIVALENT \\ CONTINUUM APPROXIMATION: HORIZONTAL EMPLACEMIENT
}

John J. Nitao

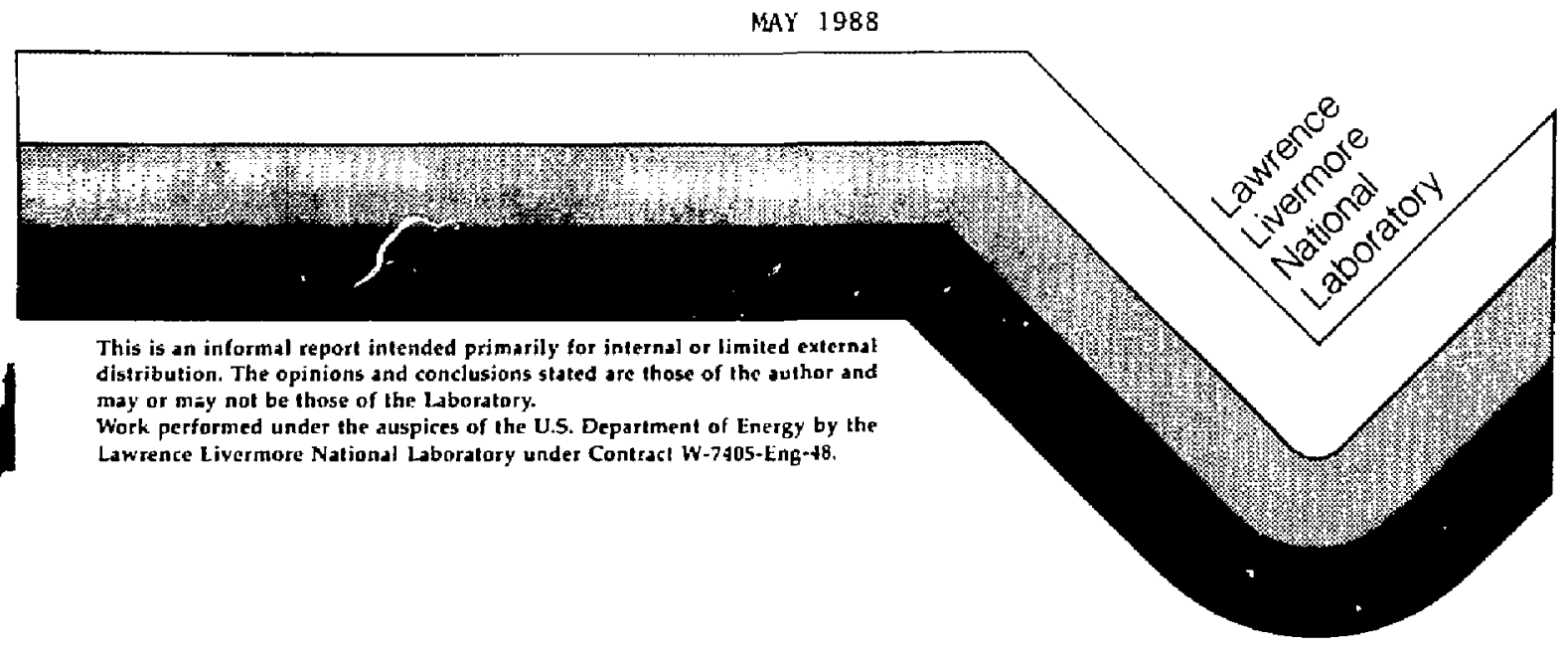

REPRODLICED FROM

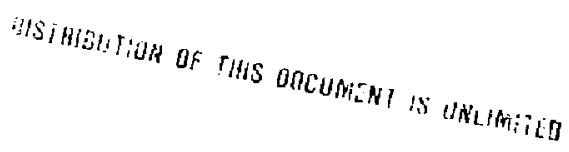


This document was prepared as an account of work spananed by an agenry of the United Statea Government. Neither the United States Government nor the Univeralty of Califarnia nor any of their employees, wakes any waranty, express or implied, do ansumes any legal liability of reaponsibility for the accuracy, completences, or u7cfulaess of any information, apparafus, product, of procews dicloned, or represents that its wie would not Infringe priwately owned tights. Refetence herein lo miy specific cammercial productu, procest, or service by trade name, twademark, manufactures, or atherwise, does not necenarity constitute ar imply ils endorueacni, recnmenendation, of favoring by the United Siater Govesngient or the University of Californta. The views and opinians of authors exprewsed herein do not necesarily slate or reflect those of the Uniled States Government or the University of Callfornia, and ahall nol be uned for adverttelng or product endorienenl purposes.

\author{
I'rinild in the Unhlosl Siates al Amprica \\ Avellatitr Irom

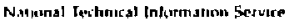

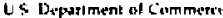 \\ 5265 Tort ketyal Rns \\ Spangheld, in zatol
}

\begin{tabular}{l} 
Price \\
Code \\
\hline
\end{tabular}

A01

Microfiche

Papercopy Prices

$\begin{array}{ll}\text { A02 } & 001-050 \\ \mathbf{A 0 3} & 051-100 \\ \text { A04 } & 101-200 \\ \text { A05 } & 201-300 \\ \text { A06 } & 301-400 \\ \text { A07 } & \$ 01-500 \\ \text { A0B } & 501-600 \\ \text { A09 } & 601\end{array}$

Prepared by Yucca Mountain Project (YMP) participants as part of the Civilian Radioactive Waste Management Program. The YMP project is managed by the Waste Management Project Office of the U.S. Department of Energy, Nevada Operations Otfice. YMP Project work is sponsored by the DOE Otfice of Civilian Fadicactive Waste Management. 


\title{
Numerical Modeling of the Thermal and Hydrological Environment around a Nuclear Waste Package using the Equivalent Continuum Approximation: Horizontal Emplacement
}

\author{
Solin J. Nitao \\ Earh Sciences Department \\ Lawrence Livermore National Laboratory \\ UCID -21444 \\ DE89 006802
}

\begin{abstract}
In support of the investigations for all underground high-level nuclear waste repository at Yucca Mountain, Nevada, we have performed computer simulations of the immediate themal and hydrological environment around a nuclear wasle package. Calculations of this type will be needed for waste package design, performance assessment, and radionuclide transport analyses. Two dimensional computer simulations using a modified version of the TOUGH code were run for an idealized configuration derived from thic COVE3 tenchmarking effon consisting of a single spent fuel waste package with laterally periodic boundary conditions. The model domain exiended downward to the water table and upward to the ground level. Fluid behavior in the rock was modeled using the the cquivalent continuum approximation. Runs were made with surface water influx rutes at the surface set to $0.1,0.5$, and 1.0 $\mathrm{mm} / \mathrm{yr}$. A significant amount of code modification and devciopment was reeded in order to develop the capability to nu these types of problems out to the Jong time spans required.
\end{abstract}

Since arıy significant transpon of non-gaseous radionuclides will involve liquid water as at main vehicle of movement, and since liquid water, if present, will also contribute to tn wasts package cnmosion. its presence is of vital concem. Initiat heating from the radiouctive decay will vaporize the liquid pore water around the waste package. Of major interest to waste container design 
is the time at which possible wetting of the package occurs during the subsequent cooldawn period. Our simulations showed that vapor transport and capiliary condensation are the the major mechanisms of water movement early in the cool-down period. However, the amount of liquid water in the rock next the waste package during this time is very small and will have very low mobility, although the diffusive transpon propenics of this water ate not exactly known. In our simulations the main front of water retums to the borchole wal] at approximately 1000 years from emplacement as it is drawn in by capillary imbibition. Al no time during the 2600 year time span of our simulation docs the water saturation of the rock next to the borchole wall increase above initial native saturation. The values of these two time periods as well as the other predictions reponted in this paper are highly preliminary due to the current uncertainty in the model input parameters and the sub-models used in our simulations. However, it is seen that the effect of the hydrological fluid flow on the thermal history may be significant. Considerable work needs to be done to develop better models of fluid behavior in panially fractured rock and more experimental data is needed to accurately model the waste package environment. 


\section{Table of Contents}

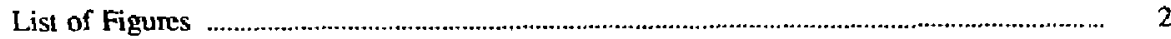

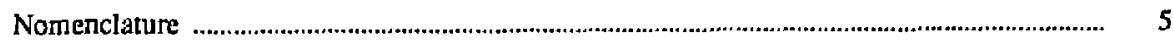

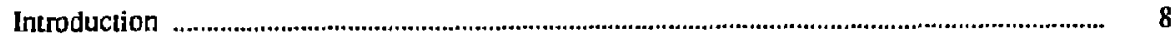

1.0 Equivalent Continuum Approximation .................................................................... 10

2.0 Description of the Problem and Model Input Parameters ............................................ 13

3.0 Discussion of the Physical Assumptions ....................................................................... 21

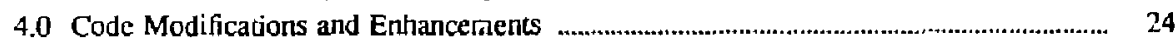

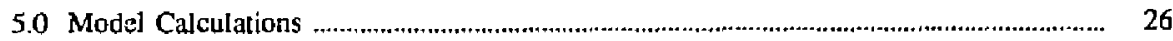

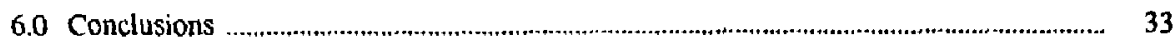

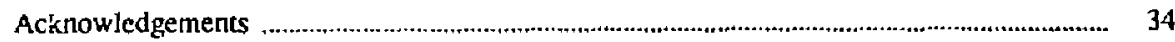

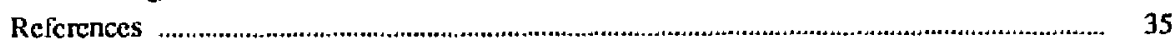

Appendix: Description of Goverting Equations in TOUGH .............................................. 38

Figures ................................................................................................................................... 41

\section{DISCLAIMER} This eepont was prepared as an account of work sponsored by an agency of the Uniled State
Government. Neithes the United States Government nor any agency thercol. nor any of thei
employees, makes any warranty, express or implied, or assumes any lege process the accuracy. completeness, of usefulness of any informy legal liability or responsiprocess disclosed. or represents that its use would of any information, apparatus, pruduct, ur manue hein to any specific commercial product, process, of serve privatsiy owned rights. Refer manufacturer. or otherwise does not necessarily constilus or ite by Irade name, trademark. and apin, or lavoring by the United States Goversment or imply its endorsement, recomand rpinions of authors expressed herein do not necessar any agency thereor. The views United Stales Government or any agency theseof necessarily state or reflect those of the 


\section{List of Figures}

Figure 1. Capillary Curves for Matrix, Fracture, and Bulk at $25 \mathrm{deg}$. C,

Figure 2. Bulk Relative Permeability Curves ( $\mathrm{Log}-\mathrm{Log})$

Figure 3. Bulk Liquid Relative Pemeability (Linear Scalc)

Figure 4. Malrix and Fracture Liquid Saturation vs. Bulk Liquid Saturation

Figure 5. Matrix and Fracture Relative Permcability

Figure 6. COVE3 Problem Geometry

Figure 7. Computational Mesh around Waste Package

Figure 8. Comparison of Temperature at Waste Packagc, 0-200 years

Figure 9. Comparison of Temperature at Waste Package, 0-2000 years

Figure 10. Temperature Profile along Verical through Waste Package at 100 years

Figure 11. Temperature Profile along Vertical through Waste Package at 400 years

Figure 12. Temperature Profiles along Vertical through Waste Package at Various Times, $0.1 \mathrm{~mm} / \mathrm{yr}$ recharge

Figure 13. Temperature Contours at 50 years, $0.1 \mathrm{~mm} / \mathrm{yr}$

Figure 14. Tenperature Contours at 400 years, $0.1 \mathrm{~mm} / \mathrm{yr}$

Figure 15. Temperature Contours at 50 ycars, $0.5 \mathrm{~mm} / \mathrm{yr}$

Figure 16. Temperature Contours at 400 years, $0.5 \mathrm{~mm} / \mathrm{yr}$

Figure 17. Temperature Contours at 50 years, $1.0 \mathrm{~mm} / \mathrm{yr}$

Figure 18. Temperature Contours at 400 years, $1.0 \mathrm{~mm} / \mathrm{yr}$

Figure 19. Liquid Saturation versus Time at Borchole Wall

Figure 20. Liquid Saturation Profiles along Vertical through Waste Package, $0.1 \mathrm{~mm} / \mathrm{yr}$

Figure 21. Liquid Saturation Profiles along Vertical through Waste Package, $0.1 \mathrm{~mm} / \mathrm{yr}$

Figure 22. Liquid Saturation Profiles along Vertical through Waste Package, $0.5 \mathrm{~mm} / \mathrm{yr}$

Figlie 23. Liquid Saturation Profiles along Vertical through Waste Package, $0.5 \mathrm{~mm} / \mathrm{yr}$ 
Figure 24. Liquid Saturation Profiles along Vertical through Waste Package, $1.0 \mathrm{~mm} / \mathrm{yr}$

Figure 25. Liquid Saluration Profiles along Vertical through Waste Package, $1.0 \mathrm{~mm} / \mathrm{yr}$

Figure 26. Ratio of Water Vapor Mass Flow Rate to Liquid Flow Rate, Profile above Waste Package at 400 years, $0.1 \mathrm{~mm} / \mathrm{yr}$

Figure 27. Gas Phase Darcy Velocities at 400 years. $0.1 \mathrm{~mm} / \mathrm{yr}$

Figure 28. Water in Fracture at 29 years, $0.1 \mathrm{~mm} / \mathrm{yr}$

Figure 29 Water in Fraciure at 39 years, $0.1 \mathrm{~mm} / \mathrm{yr}$

Figure 30. Water in Fracture at 50 years, $0.1 \mathrm{~mm} / \mathrm{yr}$

Figure 31. Water in Fracture at 100 years, $0.1 \mathrm{~mm} / \mathrm{yr}$

Figure 32. Water in Fracture at 29 years, $1.0 \mathrm{~mm} / \mathrm{yr}$

Figure 33. Water in Fracture at 50 years, $1.0 \mathrm{~mm} / \mathrm{yr}$

Figure 34. Fracture Liquid Saturation along Vertical Line through Waste Package Center, 29 years

Figure 35. Fracture Liquid Saturation along Vertical Line through Waste Package Center, 39 years

Figure 36. Fracture Liquid Saturation along Vertical Line through Waste Package Center, 100 ycars

Figure 37. Liquid Saluration Contours at 50 years, $0.1 \mathrm{~mm} / \mathrm{yr}$

Figure 38. Liquid Saturation Contours at 400 years, $0.1 \mathrm{~mm} / \mathrm{ys}^{\mathrm{y}}$

Figure 39. Liquid Saturation Contours at 50 ycars, $0.5 \mathrm{~mm} / \mathrm{yr}$

Figure 40 . Liquid Saturation Contours at 400 ycars, $0.5 \mathrm{~mm} / \mathrm{yr}$

Figure 41. Liquid Saturation Contours at 50 years, $1.0 \mathrm{~mm} / \mathrm{yr}$

Figure 42. Liquid Saturation Contours at 400 years, $1.0 \mathrm{~mm} / \mathrm{yr}$

Figure 43. Waler Vapor Mass Fractions versus Time at Borehole Wall

Figure 44. Water Vapor Mass Fraction Profiles along Vertical through Waste Package renter, $0.1 \mathrm{~mm} / \mathrm{yr}$

Figure 45. Water Vapor Mass Fraction Profiles along Vertical through Waste Package Center, $0.1 \mathrm{~mm} / \mathrm{yr}$ 
Figure 46. Gas Phase Pressure Profile at 1 year

Figure 47. Gas Phase Pressure Profile at 10c years

Figure 48. Gas Phase Pressure Profile at 400 years

Figure $49 . \quad$ Gas Phase Darcy Velocitics at 400 years, $0.1 \mathrm{~mm} / \mathrm{yr}$

Figure 50. Gas Phase Darcy Velocities at 1500 years, $0.1 \mathrm{~mm} / \mathrm{yr}$

Figure 51. Gas Phase Darcy Velocities at 2000 ycars, $0.1 \mathrm{~mm} / \mathrm{yr}$

Figure 52. Liquid Phase Darcy Velocities at 400 years, $0.1 \mathrm{~mm} / \mathrm{yr}$

Figure 53. Liquid Phase Darey Velocitics at 400 ycars, $0.1 \mathrm{~mm} / \mathrm{yr}$

Figure 54. Liquid Phase Darcy Velocities at 1500 years, $0.1 \mathrm{~mm} / \mathrm{yr}$

Figure 55. Liquid Phase Darcy Velocitics at 2000 years, $0.1 \mathrm{~mm} / \mathrm{yr}$

Figure 56. Ratio of Water Vapor Mass Flow Rate to Liquid Mass Flow Ratc at 100 years, $0.1 \mathrm{~mm} / \mathrm{yr}$

Figure 57. Ratio of Water Vapor Mass Flow Rate to Liquid Mass Flow Rate at 400 years, $0.1 \mathrm{~mm} / \mathrm{yr}$

Figure 58. Liquid Phase Velocity Vectors at 400 years, $0.1 \mathrm{~mm} / \mathrm{yr}$

Figure 59. Gas Phase Velocity Vectors at 400 years, $0.1 \mathrm{~mm} / \mathrm{yr}$ 


\section{Nomenclature}

Greck Symbols

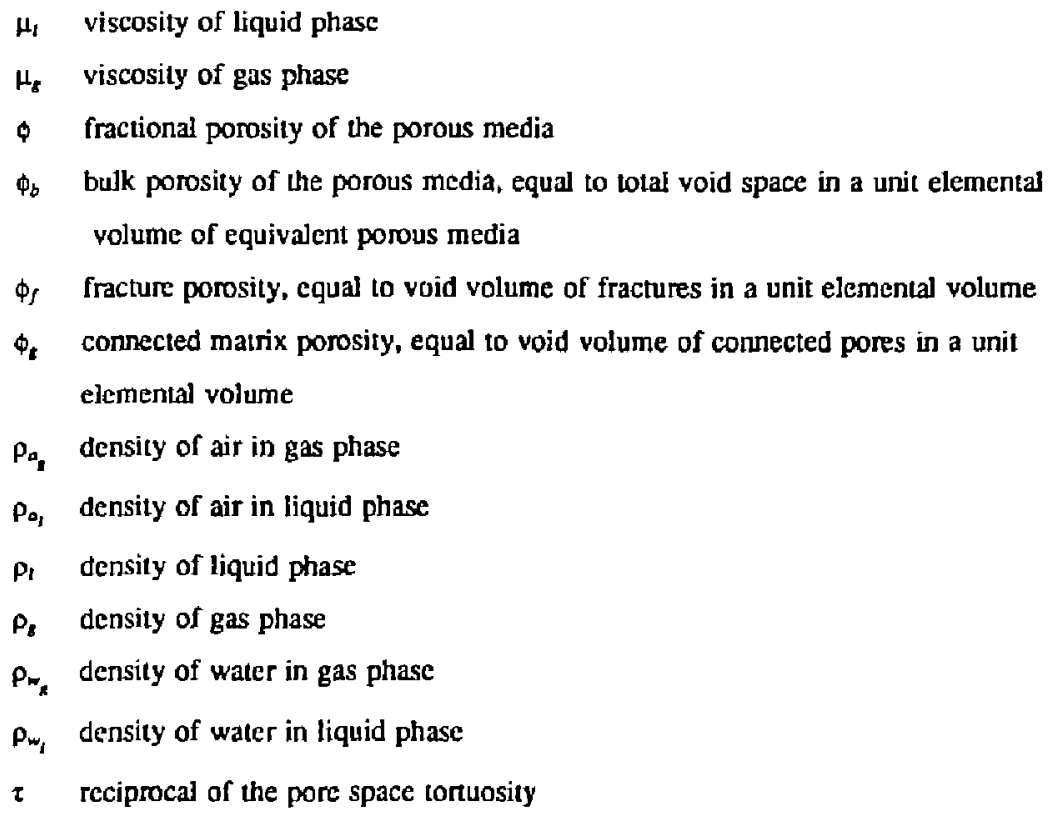

Roman Symbols
$C_{p} \quad$ unsaturated specific heat of the bulk porous media
g gravitational acceleration
$h_{a_{s}}$ speciitic enthalpy of air in gas phase
$h_{a_{l}} \quad$ specific enthalpy of air in liquid phase
$h_{\mathrm{g}} \quad$ specific enthalpy of gas phase
$h_{1} \quad$ specific enthalpy of liquid phase
$h_{w_{g}}$ specific enthalpy of water in gas phase
$h_{w_{1}}$ specific enthalpy of water in liquid phase


$K \quad$ absolute permeability of the porous media

$K_{h}$ thermal conductivity of the bulk porous media, a function of fluid saturation

$\dot{k}_{r_{1}} \quad$ relative permeability of liquid phase

$k_{r} \quad$ relative permeability of gas phase

$M_{1}$ molecular weight of the liquid phase

$p_{c} \quad$ capillary pressure

$p_{i} \quad$ liquid phase pressure

$P_{t} \quad$ gas phase pressure

$p_{\text {sal. }}$ saturation pressure of water, function of temperature, obtained from stcan tables

$p_{v} \quad$ vapor pressure

$R \quad$ gas constant

$Q_{a}$ sounce term for air component

$Q_{n} \quad$ source term for non-convective heat

$Q_{w}$ source term for water component

qeond heal flow rate due to conduction

$q_{a}$ dff flow rate of air in gas phase due to binary diffusion

$q_{8}$ flow rate of gas phase due to Darcy low

q! flow rate of liquid phase due to Darcy flow

$q_{w}$ diff flow rate of water vapor in gas phase due to binary diffusion

$s_{1} \quad$ liquid saturation

$s_{8} \quad$ gas saturation

$T$ absolute temperature of the fluid and porous media

1 time

$u_{a_{*}}$ specific intemal energy of air in gas phase

$u_{a_{i}}$ specific internal energy of air in liquid phase

$u_{b} \quad$ specific intemal energy of gas phase

$u_{i} \quad$ specific intemal energy of liquid phase

$u_{w_{t}}$ specific internal energy of water in gas phase

$u_{w 1}$ specific intemal energy of water in liquid phase

$x_{a}$ mass fraction of air in liquid phase

$x_{w}$ mass fraction of water in liquid phase 
$y_{a} \quad$ mass fraction of air in gas phase

$y_{w}$ mass fraction of water in gas phase

$\hat{z} \quad$ unit vector in downward direction

Subscripts

a air component

$b$ bulk

$f$ fracture

l liquid phase

g gas phase

$m$ matrix

w water component 


\section{Introduction}

The Topopah Spring unit at Yucca Meuntain, Nevada, is being evaluated by the Nevada Nuclear Waste Storage Investigations project (NNWSI) as a possible location for an underground high level nuclear wastc repository. Future license approval of such a site demands that scientific investigations and analyses be conducted to determine if the containment of the waste can meet the necessary environmental protection requirements. Lawrence Livermore National Laboratory has been given the responsibility for the design of the waste package at Yucca Mountain and for predicting the performance of the package with respect to the nearfield environment. Near-field hydrology plays an important facior in both of these lasks. Liquid water can act as a transport mechanism for radionuclides and chemical components found in soluble minerals in the host rock. Its presence is known to strongly influence the corrosion rates of the waste container.

The purpose of this repon is to review numerical simulations of the hydrologic and thermal waste package environment as well as to describe the capabilities that we have developed that will aid us in fiture studies. Our results should only be viewed as preliminary at this time because many of the physical input parameter: io the model as well as the exact conditions in Yucca Mountain are cither not known or have a high degree of uncertainty and many idealizations and approximations of complicated physical and chemical behavior have been made. Chemical effects, such as possible increased concentration and redistribution of silica by dissolution in hot water moving toward the waste package via "heat pipes" and deposition where water evaporates, are not taken into accolnt. Better knowledge of the site and the physical processes involved and their mathematical representation will lead to more accurate predictions in the future.

The Topopah Springs formation consists of welded tuff that is believed to be highly fractured. Due to the low surface recharge rate, the rock is only partially saturated. Multiphase flow of air and liquid water in both matrix and fracture is therefore possible. Heat from the radioactive waste can lead to vaporization of the water and vapor flow in the fractures and matrix around the waste package. Some specific items of interest to package design and performance are the temperature history, time to rewetting of the container, radionuclide transport, and mechanisms, if any, for directing water to any opening in the container. In this 
report we will restrict ourselves to the first two of these items.

Significant progress has been made in the numerical modelling of the near-waste package environment in partially-saturated media [Pruess and Wang, 1984; Pruess, et. al., 1986; Travis et. al., 1984; Bixler, 1985]. Our goal was to perform simulations out to the extended time spans needed by container design and performance assessment applications using current knowledge and conceptual models of the proposed site. Numerical modelling was based upon LLNL's madified version of the TOUGH code. The original version of this code was developed by Karsten Pruess at the Lawrence Berkeley Laboratory [Pruess, 1985]. The goveming equations appear in the appendix. The problem that was run has its origins in the COVE3 benchmarking exercise [Langkopf, 1985]. 


\section{Equivalent Continuum Approximation}

The conceptual model for flow that we have used is based upon the equivalent continuum approximation which lumps the fracture and matrix into a single porous medium equivalent The equivalent continuum approach assumes that the matrix and fracture system is in themodynamic equilibrium, i.e. phase pressures and temperatures between the matrix and fractures are continuous and equilibrate inslantancously. This assumption is valid as long as the source tems that drive the model change sufficiently slowly in time so as to allow the matrix and fracture to come to equilibrium. In reality, as the waste package gives off heal, a pressure buildup occurs in the matrix relative to the pressure in the fractures that is caused by the expansion of liquid water to steam. If the rock is highly fractured this pressure difference is low because the steam has only a short distance to escape to a fracture and equilibrium is attained relatively quickly. For our simulations to be valid it is essential that the rock be sufficiently fractured and that the matrix permeability be sufficienly high. High liquid lluxes in the fracture would be anather case where the equilibrium assumptica is violated.

The work in [Pruess and Tsang, 1986] describes simulations to investigate the validity of the assumption under non-isothermal conditions. Using discrete fracture modelling they simulated partially saturated flow in a fracture orthogonal to the longitudinal axis of a waste package container with periodic boundary conditions representative of an infinite array of fractures with an equal spacing of 0.22 meters. The effects of gravity and surface fluxes were ignored. The simulations showed that the equivalen! continuum model is adcquate for matrix permeabilitics greater than $32.6 \times 10^{-18} \mathrm{~m}^{2}$. However, simulations out to 0.1 years using a smaller permeability of $1.9 \times 10^{-18} \mathrm{~m}^{2}$ showed significant differences in the saturation and gas pore pressures between the discrete fracture model and the equivalent continuum model. Agreement with the temperatures and air humidity were good. The smaller permeability is the one used in our simulations because it is close in magnitude to those expected at Yucca Mountain. Hence, we would expect to see some differences from the discrete fracture model in the saturations and gas phase pressures. However, since they only ran their cases for a relatively shor time span, it is not clear how important these differences are at later times since much of the disequilibrium can be expected to occur at early times where temporal temperature changes are the 
greatest. Further comparisons with discrete fracture models at larger times are needed. Also, higher fraciure densities may lead to near equilibrium conditions. Additional work by Wang and Narasimhan [1986] and Klavelter and Peters [1986] indicated the validity of the equivalent continuum approach in isothermal infiltration problems with low surface recharge rates.

Within the equivalent porous medium approach, it is useful to consider how the bulk hydraulic quantities and parameters are defined. We wish to identify a representative elementary volume of the rock-fracture system large enough so that a meaningful continutim fracture porosity $\phi_{f}$ can be defined. This porosity is just the ratio of the fracture volume to the total bulk rock volume. The term "matrix" will be used to signify that portion of the elementary volume occupied by the bulk rock excluding the fracture void space. The matrix porosity $\phi_{m}$ is defined as the ratio of the volume of the voids in the matrix to the volume of the matrix. A bulk, equivalent porosity $\phi_{b}$ can then be defined as the total void space fraction within ine volume.

$$
\phi_{b}=\phi_{f}+\left(1-\phi_{j}\right) \phi_{m}
$$

Given the fracture and matrix saturations $s_{f}$ and $s_{m}$, the equivalent bulk saruration is given by

$$
s_{b}=\frac{s_{f} \phi_{f}+s_{m}\left(1-\phi_{f}\right) \phi_{m}}{\phi_{f}+\left(1-\phi_{j}\right) \phi_{m}}
$$

It is imponant to recognize that the balance equations used in our TOUGH simulations (sce appendix) involve hydraulic quantities and parameters representative of bulk behavicr that occurs within the fracture malrix elementary volume. A pore velocity predicted by TOUGH will not necessarily represent a velocity observed in either the matrix or fractures; it is a bulk average. By partitioning the flow areas within elementary volumes, an equivalent bulk conductivity of the equivalent medium has been used by Klavetter and Peters [1986], Pruess [1986], and Wang and Narasimhan, [1986] as

$$
\boldsymbol{K}=K_{m}\left(1-\phi_{I}\right)+K_{I} \phi_{I}
$$

This expression assumes that there are enough fractures of varied oricntation to ensure isotropic behavior. Since we are assuming equilibrium between the matrix and the fracture, the liquid and gas phase pressures in the matrix and fracture are assumied to be equal such that the capillary pressures are also equal: 


$$
p_{c \notin f}\left(s_{b}\right)=p_{c q m}\left(s_{b}\right)
$$

Since TOUGH requires a capillary pressure as a function of bulk saturation, we need to solve this equation for the bulk saturation $s_{a}$. In our code we gen:sate a table of capillary pressure versus saturation and perform inverse linear interpolation to obtain the capillary pressure as a function of saturation. At the same time a table of relative permeability based on the van Genuchten [1980] rclationships are also generated.

Figures 1 is a plot of the equivalent continuum capillary pressurc versus bulk liquid saturation while figure 2 shows the relative permeability curves as a function of bulk gas saturation. These curves are based on the characteristic curves for the matrix and the fraclures that were used in our simulations (see section 2 for description of the characteristic curves that were used). Figure 3 is a liquid relative permeability curve in linearly scaled axcs. Note that the value of the liquid relative permeability becomes nearly zero at about 0.984 bulk liquid saturation. This value is the point at which the fracture nearly desaturates and the rict liquid permeability, which is the product of the bulk absolute permeability times the relative permeability, becomes close to that of the matrix. At each value of bulk liquid saturation there corresponds a bulk suction pressure based on equilibrium: of the matrix and fractures. and at each such suction pressure there will be a liquid saturation value for the matrix and a separate value for the fractures.

In figure 4 we have plotted the relationship between the saturations in the fracture and matrix as a function of bulk saturation. Note that below the critical bulk saturation of about $0 .: 34$ the fracture saturation is zero or nearly zero. Above this value the fracture begins to have a significant liquid saturation. The behavior of these curves rely entirely on the characteristic curves that ase used. The fracture suction curves that we have used have low values relative to the matrix suction over most of the saturation range (figure 1). Suction equilibrium of the matrix and fracture can only occur at higher matrix saturations where the matrix suction curve is lower. If the fractures had. suction curve that was higher, the critical bulk saturation crossover point where the matrix begins to saturate would be lower. 


\section{Description of the Problem and Model Input Parameters}

The current problem considers a two-dimensional domain transverse to a single horizontally emplaced cylindical waste package (see figure 6). The two vertical edges are treated as no-flow boundaries to simulate an infinite periodic array of containers with 37.8 meters spacing. The waste package is represented by a cross-sectional half-circular element. The inpul parameters used in our simulations are primarily those that were collected during the COVE3 code benchmasking exercise [Langkopf, 1985]. The original COVE3 problem is no longer part of the benchmarking effort and has been replaced by a simpler heat pipe problem exercise which is called COVE3a. The original COVE3 problem domain was limited to a region $20 \mathrm{~m}$ above and below the waste package. The domain has been extended to include the $348 \mathrm{~m}$ above the waste package to the ground level and $225 \mathrm{~m}$ below the package to the water table for this problem. The matrix-rock fluid model is based upon the equivalent continuum approximation as described in the previous section. The heat loading of the container was based on that of 8.6 year old PWR spent fuel. The boundary conditions at the top and bottom of the model were constant temperature and phase pressures with no fluid influx at the water table and a constant non-zero surface recharge rate of water at the surface. Runs were made out to 2600 years for turee different surface water inlluxes of $0.1 \mathrm{~mm} / \mathrm{year}, 0.5 \mathrm{~mm} / \mathrm{year}$, and 1.0 $\mathrm{mm} / \mathrm{ycat}$.

The input parametcrs to our problem are given in the following. Those items marked with an asterisk ane in variance to the original COVE3 exencise input parameters.

\section{Rock Propenties}

- fraclure pemeability 1.x $10^{-11} \mathrm{~m}^{2}$

- matrix pemeability $3.9 x \mathrm{I} 0^{-18} \mathrm{~m}^{2}$

- fracture porosity $1.8 \times 10^{-3}$

- malrix porosity 0.11

- thermal conductivity in formation within $20 \mathrm{~m}$ bejow and above waste package: 
(linear in saturation between wet and dry values)

wet themal conductivity: $2.30 \mathrm{~W} / \mathrm{m}-\mathrm{K}$

dry themal conductivity: $\quad 1.74 \mathrm{~W} / \mathrm{m} \cdot \mathrm{K}$

- density of rock: $2580 \mathrm{~kg} / \mathrm{m}^{3}$

- specific heat of rock: $\quad 840 \mathrm{~J} / \mathrm{kg}-\mathrm{K}$

- thermal conductivity $20 \mathrm{~m}$. above waste package: $1.82 \mathrm{~W} / \mathrm{m}-\mathrm{K}$

- thermal conductivity $20 \mathrm{~m}$. below waste package: $1.56 \mathrm{~W} / \mathrm{m}-\mathrm{K}$

\section{Binary Diffusion}

- The binary diffusion coefficient is given in units of $\frac{\mathrm{m}^{2}}{\mathrm{sec}}$ by the correlation

$$
D=\frac{4.40 \times 10^{-6} T^{2.334}}{p}
$$

where $T$ is in degrees Kelvin and $\mathrm{p}$ is in Pascals.

\section{Liquid Relative Permeability and Capillary Pressure Curves}

- In the van Genuchten correlation [Pcters et al., 1984] the capillary head $h$ is related to the saturation by

$s_{\varepsilon}=\left[1+(\alpha h)^{\beta}\right]^{-\lambda}$

where

$s_{\varepsilon}=\frac{\left(s_{t}-s_{r}\right)}{\left(1-s_{r}\right)}$

$s_{r}=$ residual saturation

$\lambda=1-1 / \beta$

$\alpha, \beta=$ two correlating parameters found by curve fitcing with experimental data

- The liquid relative pem.eability is given by

$k_{r}=\frac{\left\{1-(\alpha h)^{\beta-1}\left[1+(\alpha h)^{\hat{\beta}}\right]^{-\lambda}\right\}^{2}}{\left[1+(\alpha h)^{\beta}\right]^{\alpha / 2}}$ 
- for the fractures. $\alpha=1.2851 \mathrm{~m}^{-1}, \beta=4.23$,

- for the matrix, $\alpha=5.67 \times 10^{-3} \mathrm{~m}^{-1}, \beta=1.798$,

- matrix residual liquid saturation ${ }^{*} s_{r}=0.0$ (the original COVE3 value was 0.0801 , personal communication with R. Peters [1987] indicates that a value of 0.0 is closer to experimental data)

- fracture residual liquid saturation ${ }^{*} s_{r}=0.0$ (the original value was 0.0395 ; results for the equivalent continuum model used in this report are not sensitive to this parameler; they would be if there were a high suclion gradient in the fractures near the residual value)

However, note that due to the functional form of the curves used, the relative permeability carve for the fractures (figure 5 ) becomes essentially non-conductive at a fracture saturation of 0.3 , and, similarly, at a matrix saturation of 0.1 for the matrix curve (figure 5)

In figure 1 we show the plots of the capillary curves for the fracture, the matrix, and for the bulk continuum. Note that due to the low suction of the fracture curve over most of its range, equilibrium between the fracture and matrix can only occur when the matrix is nearly saturated wilh liquid.

\section{Equivalent Continuum Relative Permeability}

$$
k_{r l}=\left[K_{f} k_{r i_{f}} \phi_{f}+K_{m} k_{r l_{m}}\left(1-\phi_{f}\right)\right] / K_{\mathrm{b}}
$$

where

$K_{f}, K_{m}=$ fracture and matrix saturated permeabilities

and the saturated bulk liquid permeability is given by

$$
K_{b}=K_{f} \phi_{f}+K_{m}\left(1-\phi_{f}\right)
$$

A plot of the buik relative permeabilities is given in figure 2.

Gas re]ative permeability

$$
k_{r p}=1-k_{r}
$$

- Capillary pressure cutorr*

The original van Genuchuen correlation for the capillary pressure goes to infinity at 
the liquid residual saturation and is undefined below this value. In order to use the correlation below residual saturation a capillary cutoff at a liquid saturation of 0.12 was specified in COVE3, i.e. the capillary pressure evaluated at points below 0.12 was set to the value computed by the van Genuchten formula at 0.12 saturation. The resulting derivative discontinuity at this cutoff point was found to cause numerical problems during the cool-down phase. We therefore replaced the cutoff by a more gradual linear one that intersects the $y$ axis at a capillary head egual to the largest measured in [Peters et al.,1984]. Furthermore, a matrix residual saturation of 0.0 instead of the previous value of 0.0801 appears to be closer to the experimental data [R. Peters, personal communication]. Therefore, the actual portion of the curve that needs to be smoothed is very small in extent. The actual capillary curve modification used in tems of head is

$$
\begin{aligned}
& h=h_{0}+\left(h_{1}-h_{0}\right) / s_{1} \\
& \text { for } 0.0 \leq s<s_{1} \\
& \text { where } \\
& s_{1}=0.0432 \\
& h_{1}=1.89 \times 10^{6} \mathrm{~m} \\
& h_{0}=9.1 \times ; 0^{3} \mathrm{~m}
\end{aligned}
$$

A plot of the capillary curve is given in figure 1 .

\section{Wase Package Configuration}

$348 \mathrm{~m}$ below surface

$225 \mathrm{~m}$ above water table

Spacing between container: $37.8 \mathrm{~m}$ based on $57 \mathrm{~kW} / \mathrm{acre}$ initial average heat load based on 8.555 year old PWR spent fuel container [Langkopr, 1985]

\section{Boundary Conditions*}

- ground surface $348 \mathrm{~m}$ above container:

$286^{\circ} \mathrm{K}$ constant temperature and $1.0 \times 10^{5} \mathrm{~Pa}$ gas phase pressure with zero capillary pressure and zero water saturation at the topmost element representing the surface; constant water inllux rate of $0.1 \mathrm{~mm} / \mathrm{ycar}, 0.5 \mathrm{~mm} /$ year, or $1.0 \mathrm{~mm} /$ year into first 
element below ground surface element

- water table

$225 \mathrm{~m}$ below container: fixed temperature of $304 \mathrm{~K}$, constant gas phase pressure of $1.0422 \times 10^{5} \mathrm{~Pa}$ with saturation fixed at 1.0

- lateral boundaries

$18.9 \mathrm{mI} \hat{i}: 0 \mathrm{~m}$ container: no lateral flow

Waste Package Heat Source Term

$5.05 \mathrm{~m}$ long container of 8.555 PWR spent fuel

$$
\begin{aligned}
& H(r)=\sum_{i=1}^{6} b_{i} \exp \left(-a_{i} t\right) \text { (Watts) } \\
& t=\text { years emplacement }
\end{aligned}
$$

$$
b_{1}=31.7 \quad a_{1}=2.82 \times 10^{-5} \text { year }^{-1}
$$$$
b_{2}=48.6 \quad a_{2}=1.29 \times 10^{-4} \text { year }^{-1}
$$$$
b_{3}=443.3 \quad a_{3}=1.76 \times 10^{-3} \text { year }^{-1}
$$$$
b_{4}=2123 . \quad a_{4}=2.0 \times 10^{-2} \mathrm{ycar}^{-1}
$$$$
b_{5}=431.5 \quad a_{5}=6.35 \times 10^{-2} \text { year }^{-1}
$$$$
b_{6}=321.9 \quad a_{6}=4.4 \times 10^{-1} \mathrm{year}^{-1}
$$

- container average heat capacity: $325 \mathrm{~J} / \mathrm{kg}-\mathrm{K}$

- container average density: $2535 \mathrm{~kg} / \mathrm{m}^{3}$

- container radius (set to borehole radius): $0.36 \mathrm{~m}$

\section{Mesh Geametry of Numerical Model}

Originally a rectangular mesh was used to perform our simulations, but 1-D and 2-D grid sensitivity nus showed the need for finer radial resolution with respect to distance from the waste package. This could not be achicved using a recrangular mesh due to the large bandwidths that result in the system of linear equations that are solved in TOUGH. We thereforc implemented a curvilineat mesh (fgure 7) allowing for a fine radial resolution to be achicved with minimal matrix bandwidths.

Since the space discretization method in TOUGH requires an orthogonal mesh, we wrotc a program that uses streamines and leycl curves of the hamonic potentials 
resulting from an array of line sources in order to generate our grid lines. Further grid sensitivities need to be made in the future to see whether the fine resolution we used near borehole is really necessary for predicting parameters perinent to the waste package design and performance. In any case, the use of a curvitinear mesh is much more efficient than a rectangular mesh.

The mesh generation software was checked by running TOUGH on a thermal conduction problem and comparing the results with an analytic solution.

The particular mesh used for our nuns has a total of 1473 elements with 119 divisions in the radial direction and $\mathbf{1 2}$ divisions in the angular direction (figure 7). At distances farther than 22 meters above and below the wasle package the two dimensional mesh becomes a one-dimensional column of elements stacked on top of each other, extending to the ground surface and the water table.

Table 2.1 gives the thickness of the radial divisions in the radial direction with respect to the points where the grid lines intersect the $\mathrm{z}$ axis.

\begin{tabular}{|c|c|}
\hline \multicolumn{2}{|c|}{ Table 2.1 } \\
\hline mo.of divisions & size \\
\hline 1 & 0.3588 m (borchole) \\
\hline 30 & 0.07 \\
\hline 40 & 0.1 \\
\hline 1 & 0.11 \\
\hline 1 & 0.12 \\
\hline 1 & 0.13 \\
\hline 1 & 0.14 \\
\hline 1 & 0.15 \\
\hline 1 & 0.16 \\
\hline 1 & 0.18 \\
\hline 50 & 0.20 \\
\hline 1 & 0.22 \\
\hline 1 & 0.24 \\
\hline 1 & 0.26 \\
\hline 1 & 0.28 \\
\hline 1 & 0.30 \\
\hline 4 & 0.4 \\
\hline 1 & 0.8 \\
\hline 1 & 1.6 \\
\hline
\end{tabular}

The original COVE3 problem was limited to only $20 \mathrm{~m}$ above and below the waste package. In our simulations we have extended the domain to include the region of rock 
up to the surface and down to the water table to provide what we think are more realistic boundary conditions. Although in reality the thermal and hydrologic propenties vary significantly over this extended domain, we have, except for the thermal conductivities which are spatially averaged values, used the same property values as those that are expected to occur at the repository level. For the effects of this approximation see below under "Initial Conditions".

\section{Initial Conditions}

TOUGH uses gas phase pressure, temperature, and mass fraction or gas saturation as slate variables (see appendix). The initial conditions lor these variables were obtained by making runs with no container heat flux unlil steady state fluid and thermal conditions were attained. This was done for each of the surface recharge rates: $0.1 \mathrm{~mm} / \mathrm{year}, 0.5$ $\mathrm{mm} /$ year, and $1.0 \mathrm{~mm} / \mathrm{year}$. These initialization nuns were non-isothermal.

It is possible that the variakilities in the rock properties which are not considered in our model, but which are known to occur at the different horizons above and below the repository formation, could lead to saturation conditions being in significant error from currenty predicted repository conditions. However, it turns out that our calculated steady values at the repository level were close to those obtained by Wang and Narasimhan [1986] who did take the spatial variability of the rock properties into account. Because of this fact and since the perturbations due to the waste package will be localized around the waste package the use of uniform properties is justified when modeling conditions near the waste package.

The initial values that occur in the rock immediate to the waste package are given in Table 2.2.

\begin{tabular}{|l|c|c|c|}
\hline \multicolumn{5}{c|}{ Table 2.2 } \\
\hline surface influx & gas phase pressure & liquid saluration & temperature \\
\hline \hline $0.1 \mathrm{~mm} / \mathrm{yr}$ & $1.026 \times 10^{5} \mathrm{~Pa}$ & 0.854 & $23.18^{\circ} \mathrm{C}$ \\
\hline $0.5 \mathrm{~mm} / \mathrm{yr}$ & $1.026 \times 10^{5} \mathrm{~Pa}$ & 0.980 & $23.14^{\circ} \mathrm{C}$ \\
\hline $1.0 \mathrm{~mm} / \mathrm{yr}$ & $1.026 \times 10^{5} \mathrm{~Pa}$ & 0.985 & $23.9^{\circ} \mathrm{C}$ \\
\hline
\end{tabular}


Note that the $1.0 \mathrm{~mm} / \mathrm{yr}$ case in Table 2.2 is above the critical bulk saturation of

$$
\frac{\left(1-\phi_{f}\right) \phi_{m}}{\phi_{f}+\left(1-\phi_{f}\right) \phi_{m}}=0.98387
$$

which was discussed at the end of section 1 and is the point at which the matrix becomes nearly saturated and significant amounts of fracture water begins to exist. The value of 0.985 bulk liquid saturation converts to a saturation of 0.085 in the fractures. A look at the fracture relative permeability curve (figure 5) indicales that the water is essentially immobile in the fracture at this saturation. The bulk saturation for the $0.5 \mathrm{~mm} / \mathrm{yr}$ case is just below the critical value. Also note that the slight diffenences in initial temperature are due to the cooling effects of the surface recharge water that has a temperature of $12.85^{\circ}$ Celsius, the same as the constant ground surface temperature used in our boundary conditions. 


\section{Discussion of the Physical Assumptions}

It is important to keep in mind the many assumptions, eslimalions, and approximations present in our model. These are reviewed below.

- The equivalent continuum model for fracture flow in a partially saturated porous medium is based upon the assumption that thermodynamic equilibrium between matrix and fractures is atlained over sufficiently small times relative to the time constants of the physical phenomena of interest. The degree of accuracy of this approximation is, as mentioned previously, not completely known. The continuum approximation is also based in sone sense upon the exisience of a sufficient fracture density. If fracture spacings are too large in comparison with the scatc of the problem, the cffective bulk hydrallic behavior will be predicted on too large a scale. In other words, the behavior will likely be inconsistent with that which is measured in the near-field enviranment. Thus, the model results used in this report may not be accurate if the rock at the repository tevel is fractured less than is believed or if the fracture density is highly variable over space. Our continuum model also assumes that the individual fractures are sufficiently oriented such that their bulk hydraulic behavior can be described as isotropic. One other factor that has not been addressed is the extent to which fractures act as capiliary barriers or conduits for crossfr-clure flow [Wang and Narasimhan, 1986].

- The boundary conditions chosen represent, by symmetry, an infinite array of waste packages. Comparison of this approximation with that of a finite array has been done by Montan [1987] using puse thermal conduction models. His work indicates that for times greater than 600 years the infinite array assumption can lead to the prediction of higher temperatures duc to the contribution of the "image" sources located beyond the finite extent of the array.

- The repository configuration is currently planned to have different kinds of waste in altemating rows [Schelling, 1987]. We have assumed that our waste package contains cypical PWR spent fuel that is 8.55 years old. We have adjusted the spacing in order for 
the heat load per acre to be representative. The spacing of the various rows of waste packages will likely have a strong effect on the hydrological and thermal bchavior as will the emplacement scheduling of the containes on the amount of heat given off by the various kinds of waste.

- In our simulations we have assumed constant rock preperties around the waste package; i.e., variations in matrix as well as fracture properties have been neglected. Future simulations may have to consider inhomogeneities such as highly nubblized shear zones found in the G-tunnel complex at the Nevada Test Site which has formatio:s similar in origin to those at Yucca Mountain.

- Our model ignores any thermal effects due to the large scalc convection cells that may exist over the repository [Pruess, 1986].

- The madel does not address the effects of the gap between the waste package container and the bore hole wall. In particular if this gap is empty, preliminary runs that we have done show that a significant amount of steam can escape through this pathway assuming that the borehole is not completely sealed from the drifts. The extensive drift ventilation that will be present before repository closure [Hopkins,1987] will also reduce the moisture conent in the rock. Thus, our simulations are conservative in this regards in overpredicting the amount of water in the rock around the package.

- The thermal effect of a borehole air gap, which we have neglected, is to insulate the container to some degree. The temperature of the container we predict will be lower than if this effect is incorporated, especially at early times, but the rest of the system should not be affected significantly.

- Capillary pressure is one of the main mechanisms that affect the time for the wetling front to recede and reach the bore hole wall. Our model does not have capillary hysteresis. The curves that we used are from Peters et al. [1984] who varied saturations in their core by drying in a microwave oven thus resulting in measurements that are under 
mixed drainage and imbibitory conditions. Use of pure imbibition curves would be more appropriate for our modeling during the cooldown rewelling phase and could significantly increase the predicted time required to rewet the borehole. The proporional increase in time is approximately given by a factor which is equal to the average ratio of the drainage to imbibition suction pressure over the saturation range of interest [Buscheck and Nitao, 1988].

- Yapor pressure lowering, as given by the Kelvin law or its variants, is due to the surface energy present at the liquid-gas interface. Its effecls are significant at the strong matric potential that exists in tuff at low liquid saturations. Because the mean pore radii in Topopah tuff are on the order of 40 nanometers [Klavetler, 1986], there is reason to kelieve that the high potentials are caused by surface adsorbed water. Experimental evidence indicates that the amount of adsorbed water decreases as temperature increases [Derjaguin, 1981]. This leads one to believe that the amount of water that is adsorbing onto the rock due to vapor pressure lowering is being overpredicted since the curves being used are measured at room temperature. Capillary curves need to be measured at different temperatures and different saturation histories.

- It is importan! to realize that the characteristic curves for the fractures are escinates [Wang and Narasimhan, 1986]; no experimental curves are available. Priess has shown that different characteristic curves in the fractures can lead to highly different hydrothernal behavior -.- film flow in the fractures under high suction gradicnts could lead to a heat pipe that has a strong cooling effect on the container which would then allow liguid water to remain close to the borchole. It is clear that more experimental work needs to be performed in this area. The matrix relative permeabilities that have been used are not from direct experimental data. They were derived fronl the capillary curves of Peters et.al. [1984] using the theoretical method of Mualem [1976]. 


\section{Code Modifications and Enhancements}

Several modifications to the TOUGH code were necessary in order to be able to nu the problems described in this repon. The modifications to the physical process models included the incorporation of vapor pressure lowering and the characteristic curves for the the equivalent continuum approximation. (Some versions of the code at Lawrence Berkeley Laboratories have vapor pressure lowering but the release version dous not since for most applications vapor pressure lowering is negligible and would increase computational time.)

The TOUGH code is written in FORTRAN and encompasses about 7,000 lines of source code. The original code that we obtained had a limitation of 500 elements and had to be converted to variably dimensioned format. It was converted to run on the CIVIC compiler at the NMFE Center in onder to allow us 10 make our nuns on the CRAY-2 which is able to handle larger problems because of its large memory. Other code changes were necessary in order to increase the speed of execution. A block banded matrix solver was coded to replace the general-purpose sparse matrix solver in TOUGH. The PVT funclions were replaced by a table lookup algorithm. An improved automatic time stepping algorithm was developed to allow long problems to be run more efficiendly without user intervention. Together with various other code optimizations, these changes accelerated the code by a factor of fivc. These changes were verifed by running test problems numbers 1 and 6 in the ToUGH manual. Further verification occursed in the COVE3a code benchmarking exercisc which is currently in progress.

Use of preconditioned conjugate gradient linear equation solvers [Behie, 1980], adaptive moving meshes, and more extensive vectorization are other changes that could further increase the code's efficiency. The implementation of these changes has been resisted, however, as it would probably require a major rewrite of the code and destroy its modularity. A more general porous media flow model is currenty being developed that will have there enhanced features. 
The original COVE problem specified a capillary curve that had a sharp cutoff at residual liquid saturation. If this curve is smoothed near the residual saturation level (section 2) the number of itcrations required for convergence is reduce.1. This procedure improves the computational efficiency by another factor of two, giving an overall improvement factor of 10 for the COVE problem. A COVE nu out to 2600 years now requires 4 cpu hours of CRAY-2 time as compared with 40 hours without these modifications.

In order to reduce the bandwidth of our solution matrix we have implemented a curvilinear mesh generator based on potentials. The TOUGH code is based on the integrated finite difference method and therefore requires orthogonal grid lines if a 5-spot computational molecule in rwo dimensions is used. It is a common procedure to generate such a grid using level curves and streanlines from harmonic potentials [Robertson and Woo, 1978]. The potentials we used were a superposition of logarithmic potentials with singularities at the periodic locations of the waste packages up to 15 on each side of the package being modeled. A preprocessor was written that creates the curvilinear mesh and generates TOUGH input parameters. In order to interpret the results we need to have graphical output of the physical variables. A postprocessing system was therefore developed on tt:e Sun Workstation that extracts data from TOUGH output, performs any necessary interpolations, and convens it into a form suitable for plotting. The graphs used in this report were performed using the SAC graphics software [Tull, 1987].

Most of the above enhancements have found use in other NNWSI hydrological modeling s.udics as in Buscheck and Nitao [1988]. 


\section{Model Calculations}

The calculations were carried out using the TOUGH code which uses the integrated linitc difference method [Preuss, 1985]. The govening cquations are given in the appendix.

As mentioned earlier, model simulations were made with surface recharge fluxes of 0.1 $\mathrm{mm} / \mathrm{yr}, 0.5 \mathrm{~mm} / \mathrm{yr}$, and $1.0 \mathrm{~mm} / \mathrm{yr}$. Typical cases took 4 CPU hours on the CRAY-2 wilh 350 time steps. In order to ascertain the effect of the porc water on the themal history, a case which considered only thermal conduction was also carried out by initializing the model with no water in the pores and setting hydraulic conductivities to zero. A rock thermal conductivity of $2.08 \mathrm{~W} / \mathrm{mC}$ was used for this case which is an average value of dry and wet themal conductivities, and the specific heat of the rock was set to equal to the dry rock value as given in section 2.

We now discuss the results of all of these cases. Times reported will always be with respect to the time at which the waste package is emplaced into the repository. Vertical distances are with respect to the waste package center, positive being above and negative below.

Table 5.1 summarizes the three cases that have fluid flow.

\begin{tabular}{|l|l|l|l|l|}
\hline $\begin{array}{l}\text { recharge } \\
\text { rate }\end{array}$ & $\begin{array}{c}\text { initial liq. } \\
\text { sat. at } \\
\text { waste pkg. }\end{array}$ & $\begin{array}{c}\text { time to first } \\
\text { presence of watcr } \\
\text { at bore hole wall }\end{array}$ & $\begin{array}{l}\text { time to } \\
\text { reach initial } \\
\text { liq. sat. }\end{array}$ & $\begin{array}{c}\text { max. } \\
\text { temperature } \\
\text { of wasle pkg. }\end{array}$ \\
\hline \hline $0.1 \mathrm{~mm} / \mathrm{yr}$ & 0.854 & $1400 \mathrm{yr}$ & $>2600 \mathrm{yr}$ & 202 deg. C. \\
0.5 & 0.980 & 1000 & $n$ & 199 \\
1.0 & 0.985 & 1000 & $n$ & 199 \\
\hline
\end{tabular}

\section{Temperature Field}

Figures 8-9 are a comparison of the temperature history of the container. The effect of the surface recharge rate is relatively small. The temperatures for the cases that included fluid How in the pores. as opposed to the case where only thermal conduction was considered, is significantly lower after the first 20 years. 'i his is due to the increased heat tsansfer of the 
"heat-pipes" that occur. Their effect is to flatten the temperature gradient at approximately 100

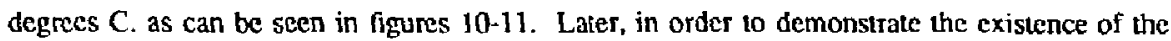
heat-pipe cffect we will show plots of the counterflow of vapor and liquid phases. The temperature profiles along the vertical line through the waste package are shown at different times in figure 12 where negative and positive values on the $x$ axis correspond to distance below and above the waste package center, respectively.

Figlires 13-18 are temperature contours at 50 and 400 years for different recharge fluxes. They show that increasing recharge fux results in the contours lying closer to the container. This difference is particularly pronounced between the $0.1 \mathrm{~mm} / \mathrm{yr}$ and $0.5 \mathrm{~mm} / \mathrm{yr}$ cases. However, there is only a slight difference between the 0.5 and $1.0 \mathrm{~mm} / \mathrm{yr}$ cases.

Our use of periodic boundary conditions, which in effect madel an infinite array of containers, result in slightly higher temperatures than in the case where a finite array is modeled. As demonstrated by Montan [1987] using models that consider only thermal conduction the temperature diffenence starts to become significant at 600 years from the time of container emplacement.

\section{Fluid Saturation Field}

In figure 19 we have the time history of the liquid saturation in the rock next to the borchole face. Watcr first retums at about 200 years. This water is due to vapor condensation. Figures 20-2l shows that water mass transfer near the waste package is due to the steam in the gas phase moving towards the container and condensing at temperatures higher than the nominal boiling point due to capillary condensation (vapor pressure lowering). Significant capillary condensation occurs only at liquid saturations below about 0.1 where the capillary tension is sufficiently high. Note that significant condensation wi[l, at this stage, oceur in the rock where the eapillarity is high and not significantly on the container itself since the container walls am. relatively smooth. The high capillary pressures at low soturations that have been measured for Topopah tuff could be due to surface adsorption phenomenon [Marshall, 1979]. Thus, at low saturations the "capillary condensation" may actually be condensation due to surface adsorption. It is imporant to note that the capillary curves used in our model were measured only at room temperature. To correct for higher temperatures only a simple adjustment factor based on the dependency of the interfluid surface tension on temperature was used. The curyes also 
do not include the dependence of surface adsorption on temperaturc. Some experiments iDerjaguin, 1981] indicate that surface adsorption effects may have a decreasing dependence with temperature. If this is so, our simulations would overpredict the condensation duc to surface adsorption.

In the vicinity of the waste package our plots show the liquid saturation in the rock during portions of thermal loading to be exactly zero. In actuality there will always he at least a small amount of water adsorted on the pore walls of the rock. The cause for this difference between theory and simulation is duc to our modification described in section 2 of the capillary curve which prevents the capillary pressure from going to the theoretical limit of infinity as the saturation tends to zero. This puts a lower limit on the vapor pressure lowering as given by the Kelvin type equation [Marshall, 1979]

$$
p_{v}=p_{\text {sat. }}(T) \exp \left(\frac{-p_{c} M_{I}}{p_{r} T R}\right)
$$

As this equation shows. the vapor pressure would go to zero if the capillary curve went to infinity, and therefore the saturation in our simulations would then go to zero. The effect of the capillary pressure at fow saturations has been confimed by previous runs that we have made which were initialized for a slightly different geometry but all other input parametcrs were the same as the present runs. They show that by increasing the capillary curve at smal] saturations one can produce simulations that have wa'er at the borehole walls at all times.

the amount of water we are underpredicting by our modification of the capillary curve is however very small, and depending on the pore size of tuff may consist of only a few molecular layers in thickness that is very tightly bound to the matrix porc walls. Investigations by Klavetter and Peters [1986] indicate that Topopah tuff may have very small pore sizes. It is known that the few layess of wates uixt to a pore wall ane tightly bound [Derjaguin, 1981] and would not be frec to advect although transfer by surface diffusion may be possible [Barner. 19411.

The water duc to capillary imbibition (for our purposes, a liquid saturation greatcr than 0.1) reaches the borethole wall at about 1000 years for the $0.5 \mathrm{~mm} / \mathrm{yr}$ and $1.0 \mathrm{~mm} / \mathrm{yr}$ cases and 
1400 years for the $0.1 \mathrm{~mm} / \mathrm{yr}$ casis. There are at least two factors that may actually increase these t:welting times. The first is the fact that the equivalent continuum model ignores the fact that fractures can retard the liquid flow movement as the liquid tries to cross a fracture. The second is that the capillary curves were measured under conditions closer to drainage conditions rather than the imbibition conditions of rewetting. Suction under imbibition is typically an order of magnitude of so lower than under drainage.

At no time within the 2600 year time span of our runs is the water able to enter the borehole space. This conclusion holds for even the $1.0 \mathrm{~mm} / \mathrm{yr}$ case which has a small amount of liquic water in the fractures. The liquid phase pressure is always less than atmospheric pressure due to the tensions in the matrix and fractures, and the liquid saturation remains below the initial saturation level during the entire 2600 year period. This conclusion is valid, of course, only under our modeling assumptions. For example, the effect of severe heterogeneities such as nubblized shear zones is urknown.

Figures 22-27 are saturation profiles along the vertical at different times. Note that during the heating period the vaporization of liquid water in the rock near the container and its subsequent condensation results in a transfer of water away from the container. At early times the condensed water increases the liquid sauration in the rock in the region ahead of the boiling zone causing a "hump" to occur in the saturation curve in figure 22 for the $0.1 \mathrm{~mm} / \mathrm{yr}$ case. This hump is hardly noticeable in higher recharge cases oecause the malrix is initially nearly salurated. The vaporization front is rather sharp during the heatup period as the front recedes from the waste package. Preliminary simulations with discrete fractures have stown that in actuality the bulk liquid saturation front would be significantly smeared because of the higher boiling point inside the matrix due to the higher gas pressures in the matrix than in the fractures; the boiling front propagates away from a fracture into the matrix. Such effects are, of course, not considered in our equivalent continuum model. The extent of the vaporized zone is greater in the $0.1 \mathrm{~mm} / \mathrm{yr}$ case than in the other two cases by about $2 \mathrm{~m}$. This is accounted for by the fact dhat the initial amount of the water in the rock as given by the initial saturation in th: $0.1 \mathrm{~mm} / \mathrm{yr}$ case is 0.854 which is about 15 percent lower than for the other two cases. The $0.5 \mathrm{~mm} / \mathrm{yr}$ and $1,0 \mathrm{~mm} / \mathrm{yr}$ cases have nearly identical initial saturations of 0.980 and 
0.985, respectively, and have nearly identical profites even though the latter case is above the critical saturation at which fracture flow occurs. The main effect of recharge rale may be its effect on raising steady state initial saturation levels near the waste container before heating begirs than in its transport properties.

Figures 28-33 show the regions where the fractures contain water al various times for the $0.1 \mathrm{~mm} / \mathrm{yr}$ and $1.0 \mathrm{~mm} / \mathrm{yr}$ cases. With our input parameters the significant liquid water saturation in the fractures occurs at a bulk liquid saturation of about 0.984 . The fracture watcr in the $0.1 \mathrm{~mm} / \mathrm{yr}$ case occurs as a halo about the waste package, wider bclow the waste package than above it due to gravity driven flow. The $1.0 \mathrm{~mm} / \mathrm{yr}$ case has, as expected. water in the fractures at all points behind the vaporization front since the initial saturation of 0.985 is above the critical value. The $0.5 \mathrm{~mm} / \mathrm{yr}$ case which bas jnitial saturation of 0.980 is close enough to the critical value so that it behaves like the $1.0 \mathrm{~mm} / \mathrm{yr}$ rase. The thermal effects of the water in the fractures is small due to the small gradients in the fracture capillary curves. However, if we had used different fracture characteristic curves with a high capillary gradient as would occur for surface films, a highly efficient heat pipe in the fracture would kcep the rock around the waste package at $100^{\circ} \mathrm{C}$. and would result in the water remaining close to the waste package [Pruess, Nov, 1984]. Clearly, more experimental work needs to be done to determine the possible existence of film flow in fractures.

In figures 34-36 we haye calculated the liquid saturation in the fracturcs based on the bulk saturation along a vertical line through the waste package center for the $0.1 \mathrm{~mm} / \mathrm{yr}$ case. Note that the saturations stay bclow a value of 0.2 .

Figures $37-42$ are contours of the liquid saturation at 50 and 400 years.

\section{Water Vapor}

Figure 43 is the water vapor mass fraction history at the borehole wall. The atmosphere around the waste package quickly becomes 100 percent steam and stays at this level until 600 years. After this point the water vapor continues to remain higher than the value before 
heating started of 2 percent. Figures $44-45$ shows the profiles at different limes.

\section{Gas Phase Pressure}

Figures $46-48$ show profiles of the gas phase pressure. They show very little rise from the injtial pressurc. For the tight matrix permeabilities used in these cases the equivalent continuum model is known to sevencly underpredict the gas pressures in the matrix. In actuality, simulations with discrete fracture models have shown that several atmospheres of pressure can build up in the marix.

\section{Darcy Veincities and Flow Rates}

Figures $49-51$ gives the vertical profile of the vertical component of the gas phase bulk Darcy velocitios above the waste package. Gas \%elocities an generally upwand except for a small downward flux near the container. In figure 49 a relatively high blip in the gas velocities is seen at the vaporization front where steam is carried outward and then is condensed. Figurcs 52-55 give the vertical profile of the verical component of bulk continuum iiquid phase Darcy velocities above the waste package. Liquid Darcy velocities are oriented downwand primarily in response to capillary suction. The pronounced blip seen in Figures 52 and 53 is due to the capillary imbibition from the sharp saturation gradient at the saturation halo, as predicted by the equivalent continuum model, into the vaporized zone. A discrete representation of fractures would likcly result in a more diffuse transition al the imbibition fronl.

In order to confinm that the heat pipe effect is the cause of the flat temperature profiles in figures 10 and 11 , we have plotied the profile of the vapor mass flow rate to liquid mass fow rate ratio along a vertical line passing through the waste package (figures 56-57). This plot covers only the par of the heat pipe above the waste package. A ratio value of negative one indicates a balanced coupter-cument of liquid to vapor flow. The region where the heat pipe necurs coinctides with the region where the temperature is flat. Note that this part of the heat pipe starts about $12 \mathrm{~m}$ above the containcr center and extends to about $19 \mathrm{~m}$, and evidendy lasts for several hundred ycars. Below the waste package the heat pipe is located lower due to the effect of gravity and stans from about $15 \mathrm{~m}$ below the package and ends at about $23 \mathrm{~m}$. 
Because of the low permeability of the matrix, liquid counter-current velacitics are very low. Therefore, thermal fluxes from the waste package will be greater than the amount that a heat pipe can handle unless the flux area is large. At small distances from the waste package the flux anea for a heat pipe across a cylindrical control volume are too low for a heat pipe to be sustained. But from the geomerry of the system, the effective flux area will increase. up to a point, as the drying front proceeds outward. At a sufficienty large flux area the convective flux of the counter-cument liquid will be balanced, and heal pipe is sustained. Note that at radii farther than $19 \mathrm{~m}$, which is the distance to the no-flow boundary, the flux area across the drying front can no longer increase radially but stays fixed.

The regions of counter current flow of the gas and liquid phases in the heal-pipes can be seen in figures 58-59 which show the vector fields of the phase velocities. The lengths of the vectors are normalized with respect to the maximum velocity in each separate plot. 


\section{Conclusions}

Within the approximations and assumplions utilized in the models our simulations showed the following:

1. At the surface recharge rates studied and during the 2600 year time span of our simulations the liquid saturation at the borchole wall next to the container did not retum to the initial native saturation after drying from the waste package waste heat began. Liquid pore pressures remain below the borchole pressure so that no liquid flow into the borchole is predicted.

2. Small amounts of water due to capillary condensation first reaches the borehole wall at about 200 years. This time is very sensitive to the capillary curves used at the low saturation range. Based upon the conservative surface recharge rate estimate of 0.5 $\mathrm{mm} . / \mathrm{yr}$. [Montazer and Wilson, 1984], bulk water (saturation $>0.10$ ) first reaches the borchole wall at about 1000 years from emplacement due primarily to capillary imbibition. Future incorporation of hystenetic capillary curves and improved models that take into account the reduced permeability of the flow crossing fractures would further delay the arrival of liquid water.

3. Predictions of temperatures near the waste package are significantly lower when flow is included as compared to the case where only thermal conduction and constant specific heat are considered.

4. Significant amounts of fracture water are predicted to occur due to the movement and condensation of water vapor in the fraclures during the heating period. However, there is no water in the fractures in the vicinity of the waste package due to the drying effects of the waste package heat. For the fracture capillary curves used in this study the effect of fracture water on the thermal response of the system is not significant. It must be kept in mind, however, that these curves are approximations and there is a need for experimental data belore any firm conclusions can be made.

Some of the important research areas that we believe should be pursued include:

1. The atcuracy and applicability of the equivalent continuum model needs to be rexamjned in light of wark done in Pruess [1986]. 
2. With regard to analyzing techniques for thermal predictions, comparisons necd to be made with heat conduction models that use variable specific heats to model latent heat, such as those used in Montan [1986], and, perhaps, recalibrating such models as necessary. The issue of the effect of using periodic boundary conditions necds to be considered.

3. The effect of container spacings and the placement of containers with different heal outputs needs to be studied.

4. Experimental data for the matrix and fracture characteristic curves is necded, including measurements at different temperatures, and under both drainage and imbibition conditions.

5. Discrete fracture modelling is: needed to study the effect of gravity driven flow in fractures, fracture orientation, fracture cross-flow, and highly permeable rubblized shear zones.

6. The effect of thermally stressed fracture closures on the near field hydrology is not known.

7. The possible effect of film flow in fractures should be investigated since its presence could possibly contribute to water movement toward the container.

8. Depending on the suction potential curves, therc may be significant anounts of surface adsorbed water in the matrix rock near the container even during the period when the matrix has been almost dehydrated by the waste package heal. The diffusive transpon properties of this water may have to be determined experimentally.

\section{Acknowledgments}

The author would like to acknowledge Ken Eggert who initiated this study and provided the environment and resources without which this work could not have been done. My appreciation also goes to Andy Tompson and Tom Buscheck for their fnuitful discussions. 


\section{Rcferences}

Barrer, R.M., Diffusion in and Through Solids. Cambridge University Press, (avail. through University Microfilms, Ann Artor), (1941).

Bchie, A. and Vinsome, P.K., Block Itcrative Methods for Fully Implicit Reservoir Simulation, Soc. Pet. Eng. paper no. SPE 9303, (1980).

Bixler, N.E., NORIA: A Finite Element Computer Program for Analyzing Water/ Vapor/Air/Energy Transpont in Porous Media, Sandia Nalional Laboratory repon no. SAND84-2057 (1985).

Buscheck. T.A., and Nitao, J.J., "Fluid Floy Modelling" in Institutional Research and Development, FY86 Annual Repon, URCL-535́89-86, Lawrence Livermore National Laboratory, pp. 48-49, (1987).

Buscheck, T.A., and Nitno, J.J., Estimates of the Hydrologic Impact of Drilling Water on Core Samples taken from Partially Saturated Densely Welded Tuff, submitted as a Lawrence Livermore National Laboratory report (1988).

Derjaguin, B.V. and Churaev, N.V., Structufe of the Boundary Layers of Liquids and its Influence on the Mass Transfer in Fine Pores, Progress in Surface and Membrane Science, vol. 14, Academic Press, 69-130,(1981).

Hopkins, P.L., Eaton, R.R., and Sinnock, S., Efrect of Drift Ventilation on Repository Hydrology and Resulting Solute Transpon Implications, Sandia National Laboratories repor no. SAND86-1571, (May 1987).

Klavetter, E.A and Peters, R.R., Estimation of Hydrologic Properties of an Unsaturated, Fractured Rock Mass, Sandia National Laboratories report no. SAND84-2642 (July 1986).

Langkopr, B.,Sandia National Laboratory Memo entitled: Status of COVE3, file 1.1.231, (Aug, 22, 1985).

Marshall, T.J. and Holmes, J.W., Soil Physics, Cambridge University Press, Chp. 2, (1979).

Montan, D.N., Themal Calculations pertaining to a Proposed Yucca Mountain Disposal, to be published as is Lawrence Livermore National Laboralory repor, 1987.

Montan, D.N., Thermal Calculations pertaining to Experiments in the Yucea Mountain Exploratory Shaft, Lawrence Livermorc National Laboratory report no. UCID-20780, 
(Mar. 1986).

Montazer, P. and Wilson, W., Conceprual Hydrologic Model of Flow in the Unsaturated Zonc. Yucca Mountain, Nevada, Water Resources Investigations, Report 84-4345, United States Geological Survey, Denver, Colorado, (1984).

Mualem, Y., A New Model for Predicting the Hydraulic Conductivity of Unsaturaled Porous Materials, Water Resources Res., vol. 12, no. 3, 513-522 (1976).

Peters, R.R., phone conversation, (Feb. 1987).

Peters, R.R., Klavetter, E.A., Hall, I.J., Blair, S.C., Heller, P.R., and Gee, G.W., Fracture and Matrix Hydrologic Characteristics of Tuffaceous Materials from Yucca Mountain, Nye County. Nevada, Sandia National Laboratories repon no. SAND84-1471, (Dec. 1984).

Pruess, K. and Wang, J.S.Y., TOUGH - A Numerical Model for Nonisothermal Unsaturated Flow to Study Waste Cannister Heating Effects, Mat. Res. Soc. Symp. Proc., vol. 26. Elsevier Science, (1984).

Pruess, K. Tsang, Y.W., and Wang, J.S.Y., Numerical Studies of Fluid and Heat Flow near High-Level Nuclear Waste Packages Emplaced in Parially Saturated Fractured Tuff, Lawrence Berkeley Laboratory report no. LBL-18552, (Nov. 1984).

Pruess. K., TOUGH User's Guide, Lawrence Berkeley Lab., LBL-20700, Draft Version, (Nov. 1985).

Pruess. K. Wang, J.S.Y., and Tsang, Y.W., Effective Continuum Approximation for Modelling Fluid and Heat Flow in Fractured Porous Tuff, Sandia National Laboratories repon no. SAND 86-7000, also Lawrence Berkeley Laboratory repor no. LBL-20778. (1986).

Roberson, G.E. and Woo, P.T., Grid-Orientation Effects and the Use of Orthogonal Curvilinear Coordinates in Reservoir Simulation, Soc. Pet. Eng. J., val. 18, no. 1, pp. 13-19. (Feb. 1978).

Schelling, F.J., The NNWSI Project Reference Information Base, Version 02.001, SLTR876001, (May 1987).

Tull, J.E., SAC Graphics User's Marsual, Lawrence Livermore National Laboratory intemal repon (1987).

Travis, B.J., Hodson, S.W., Nuttal, H.E., Cook, T.L., and Rundberg, R.S., Numerical Simulation of Flow and Transport in Fractured Tuff, Mat. Res. Sac Symp. Proc., vol. 26. 
Elsevier Science. (1984).

van Genuchten, M.T., A Closed Form Equation for Predicling the Hydraulic Conductivily of Unsalurated Soils, Soil Sci. Soc. Am. J., 44, 892-898, (1980).

Wang, J.S.Y. and Narasimhan, T.N., Hydrologic Mechanisms Goveming Fluid Flow in Partially Saturated Fractured, Porous Tuff at Yucca Mountain. Sandia National Laboratory report no. SAND84-7202, (1986). 


\section{Appendix: Description of Governing Equations in TOUGH}

The code we have used in our simulations was a version of the TOUGH simulator which we have modified. TOUGH was developed by K. Pruess at LBL [Pruess, 1985] and treats two-phase two-component flow in porous media including themal flow and water-steam interphase mass transfer. Both liquid and gas phases are considered. The liquid phase contains a mixlure of water and dissolved air and the gas phase a mixture of water vapor and air. The solid phase of the host poious medium is included in the energy balance but is otherwise passive and immobilc. Binary wiffusion of the air and waler vapor is included. The conservation equations that are solved per are those for total water, air, and energy. Hydrodynamic dispersive fluxes of the individual components in each phase are neglected as is the dispersion of themal energy in each of the advecuing phases. The partial differential equations solved by the TOUGH code have been discussed in Pruess [1985]; for completeness they are given by

Water

$$
\frac{\partial}{\partial t} \oplus\left[p_{l} s_{1} x_{w}+p_{q} s_{q} y_{w}\right]+\nabla \cdot\left[x_{w} q_{l}+y_{w} q_{g}+q_{w d j / r}\right]=Q_{w}
$$

Air

$$
\frac{\partial}{\partial t} \phi\left[\rho_{t} s_{1} x_{a}+\rho_{s} s_{g} y_{a}\right]+\nabla \cdot\left[x_{a} q_{1}+y_{a} q_{g}+q_{a d d f f}\right]=Q_{a}
$$

Thennal Encrgy

$$
\begin{aligned}
& \frac{\partial}{\partial t}(1-\phi)\left[C_{p} T\right]+\frac{\partial}{\partial t} \phi\left[\rho_{i} s_{1} u_{l}+\rho_{g} s_{g} u_{s}\right]+
\end{aligned}
$$

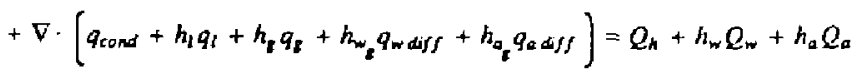

Thesc equations are spatiafly discretized using a finite volume, or integrated finite difference, approach and discretized in time by the fully implicit backward Euler method. The resulting set of discretized algebraic equations are non-linear and are solved itetalively using the Newton-Raphson meibod. The set of primary variables that are solved depend on which phases are present in a grid block: 


\begin{tabular}{|c|c|}
\hline state & primary variable set \\
\hline $\begin{array}{ll}\text { no liquid } & s_{1}=0.0 \\
\text { no gas } & s_{l}=1.0 \\
\text { liquid and gas } & 0.0<s_{l}<1.0\end{array}$ & $\begin{array}{l}p_{\ell}, T, y_{a} \\
p_{e}, T, x_{a} \\
p_{e}, T, s,\end{array}$ \\
\hline
\end{tabular}

We note again several of the main assumptions made in the above conservation equations and in their implementation in TOUGH:

1. Thermal equilibrium between the pore fluid and the rock

2. Hydrodynamic dispersion is neglected

3. Equilibrium themodynamies is assumed

We now give the constitutive equations that are necessary to close the partial differential equations.

Ilcal and Mass Transfer Relations

$$
\begin{aligned}
& q_{l}=p_{l} K \frac{k_{r l}}{\mu_{1}}\left(\nabla p_{J}+g p_{I} \tilde{z}\right) \\
& \text { Darcy's Law } \\
& q_{g}=p_{z} K \frac{k_{r g}}{\mu_{g}}\left(\nabla_{p_{g}}+g p_{z} \hat{z}\right) \\
& q_{c o n d}=K_{h} \nabla T \\
& \text { Fourier's Law of Heat Conduction } \\
& q_{w d i f f}=\tau \phi s_{g} D \rho_{g} \nabla y_{w} \\
& \text { Fickian Law for Binary Diffusion } \\
& \varphi_{a d i f f}=\tau \phi s_{d} D \rho_{a} \nabla y_{a} \\
& D=\frac{D^{0}(T+273.15)^{\theta}}{p}
\end{aligned}
$$

\section{Characteristic Curves}

The characteristic curves that we used are described in section 2. They are of the general form:

$$
\begin{array}{lr}
k_{r t}=k_{r l}\left(s_{l}\right) \quad k_{r g}=k_{r g}\left(s_{g}\right) & \text { Relative Permeabilities } \\
p_{g}-p_{l}=p_{\mathrm{g}}\left(s_{\mathrm{g}}, T\right) & \text { Capillary Pressure }
\end{array}
$$


In COVE3 the capillary curves ane multiplied by a temperature dependent watet surface tension factor.

\section{Mixing Relations}

The properties of the phases are obtained from those of the component PVT values by

$$
\begin{aligned}
& \rho_{g}=y_{* t+} \rho_{w_{d}}+y_{0} \rho_{a_{g}} \quad \rho_{1}=x_{w+} \rho_{w_{i}}+y_{a} \rho_{a_{1}} \\
& h_{g}=y_{w} h_{w_{g}}+y_{0} h_{a_{s}} \quad h_{l}=x_{w} h_{w w_{j}}+x_{a} h_{a_{i}} \\
& u_{g}=y_{w} u_{w}+y_{a} u_{a_{g}} \quad u_{l}=x_{w} u_{w_{f}}+x_{a} u_{a_{l}} \\
& \mu_{1}=\mu_{i}\left(\mu_{w_{1}}, \mu_{a_{1}}, x_{m}\right) \quad \mu_{d}=\mu_{g}\left(\mu_{w_{g}}, \mu_{a_{g}}, y_{m}\right)
\end{aligned}
$$

Tables of component propenics are available as functions of temperature and pressure.

Interphase Mass Transfer

The mass fraction of air dissolved in the liquid phase is given by

$$
\frac{x_{a}}{y_{a}}=\text { canstant }
$$

Henry's Law

The mass fraction of waler vapor in the gas phase when the two phases are present is a function of pressure and temperature based on Dalton's Partial Pressure Law, steam table saturation pressure, and vapor pressure lowering

$$
y_{m}=f\left(\rho, T, s_{4}\right)
$$

The equation in TOUGH incorporates a more nigorous relationshjp than the more common approximation

$$
y_{w+}=\frac{p_{v}}{p_{8}}
$$

The vapor pressure lowering due to the suction potential is given by

$$
p_{v}=p_{x a t}(T) \operatorname{cxp}\left(\frac{-p_{c} M_{l}}{\rho_{l} T R}\right) \quad \text { vapor pressure lowering based on Kelvin rype law }
$$


$-41$.

Matrix (salld line), Fracture (doshed line),

and Equivolent cont. (dotled Ine) Copillary Pressures

Curves vs. Liquid Soluration

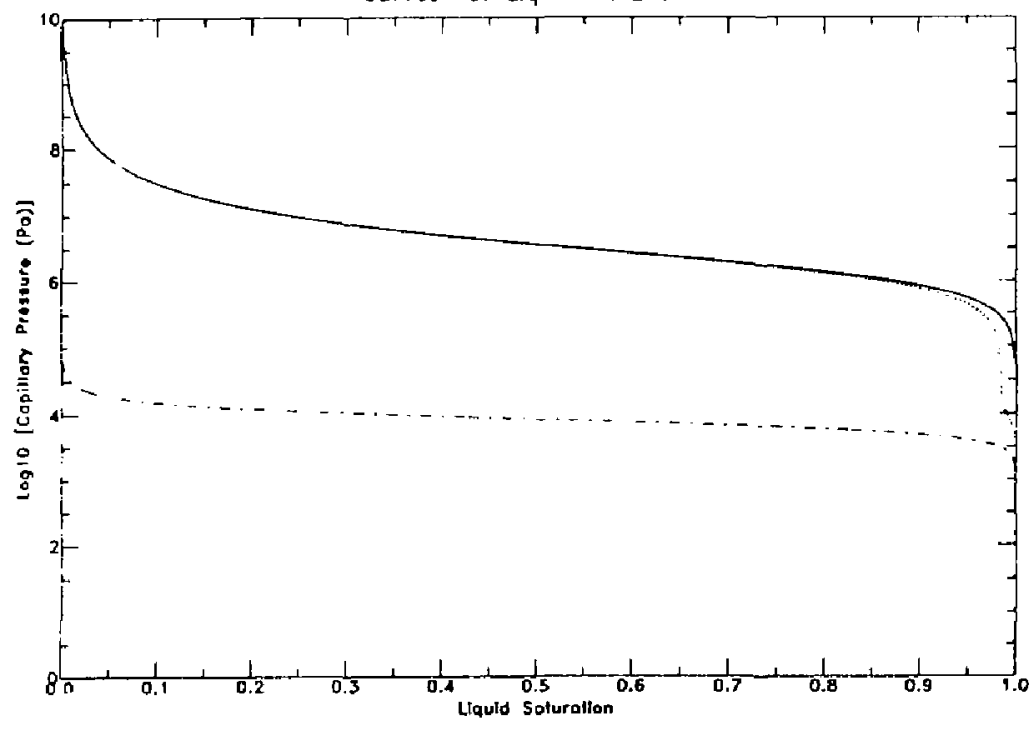

Figure 1. Capillary Curves for Matrix, Fracture, and Bulk at 25 deg. C.

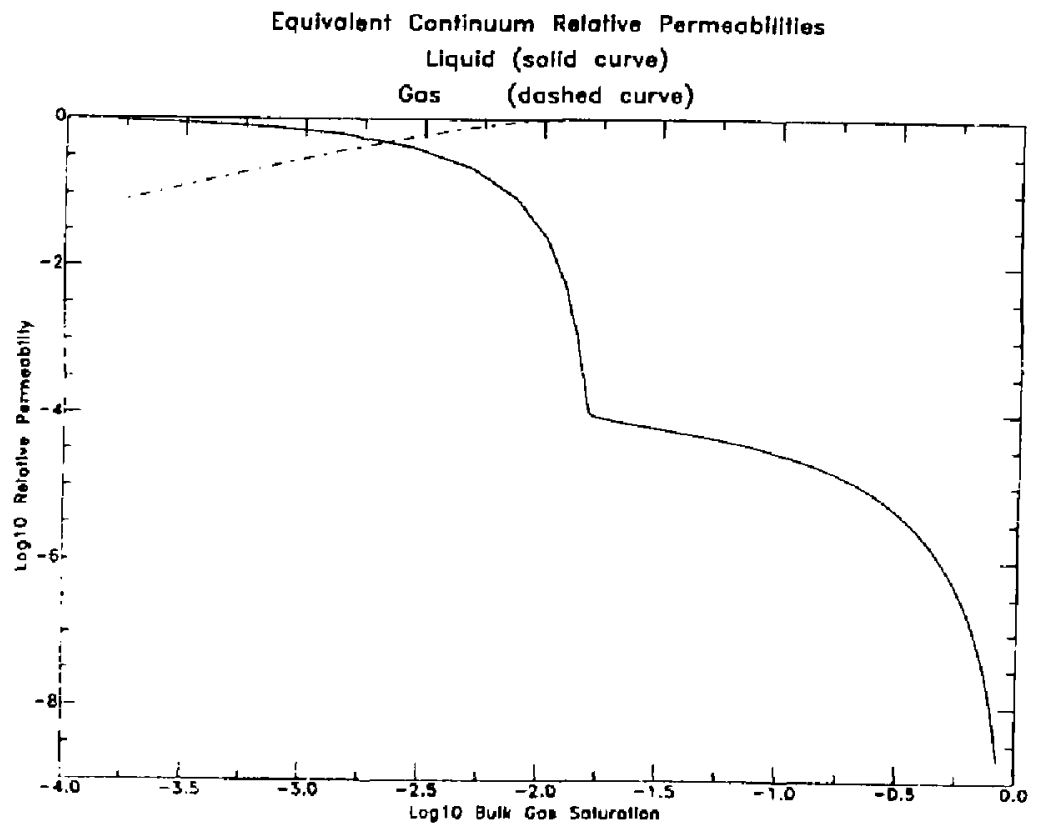

Figure 2. Bulk Relative Permeability Curves (Log-Log) 
$-42-$

Equivolont Contlnuum Relotive Permeobility

чs. Bulk Liquid Soturation

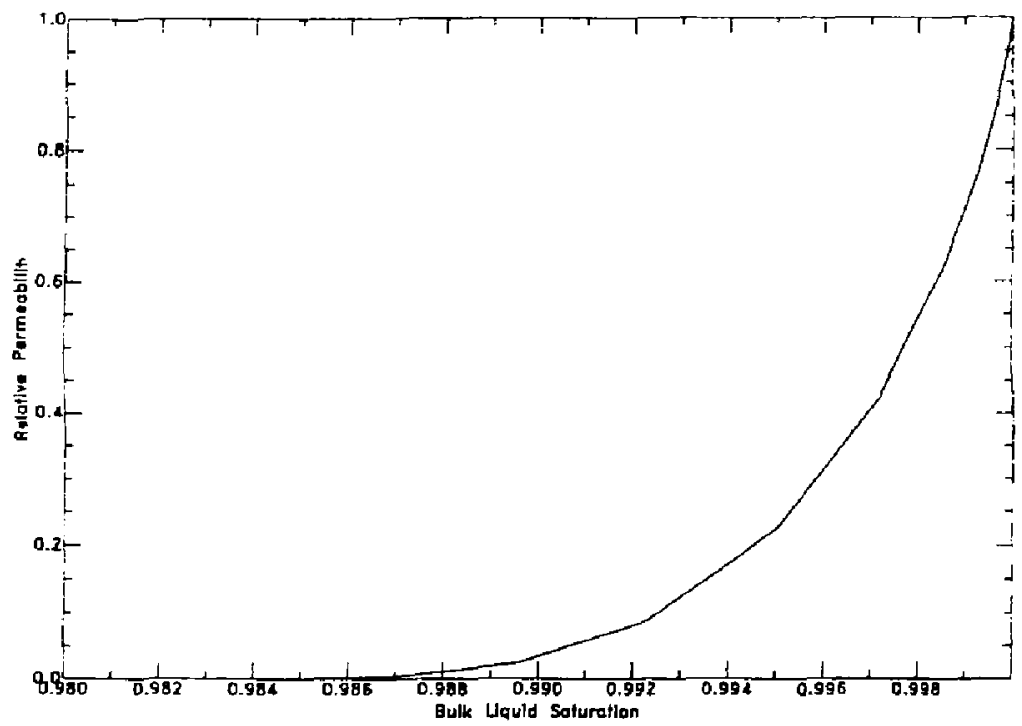

Figure 3. Bulk Liquid Relative Permeability (Linear Scale)

Matrix (solid line) and Frocture (doshed $\operatorname{lin} \theta$ )

Liquld Saturolion vs. Bulk Liquid Soturation

of Equiyalent Confinuum Model

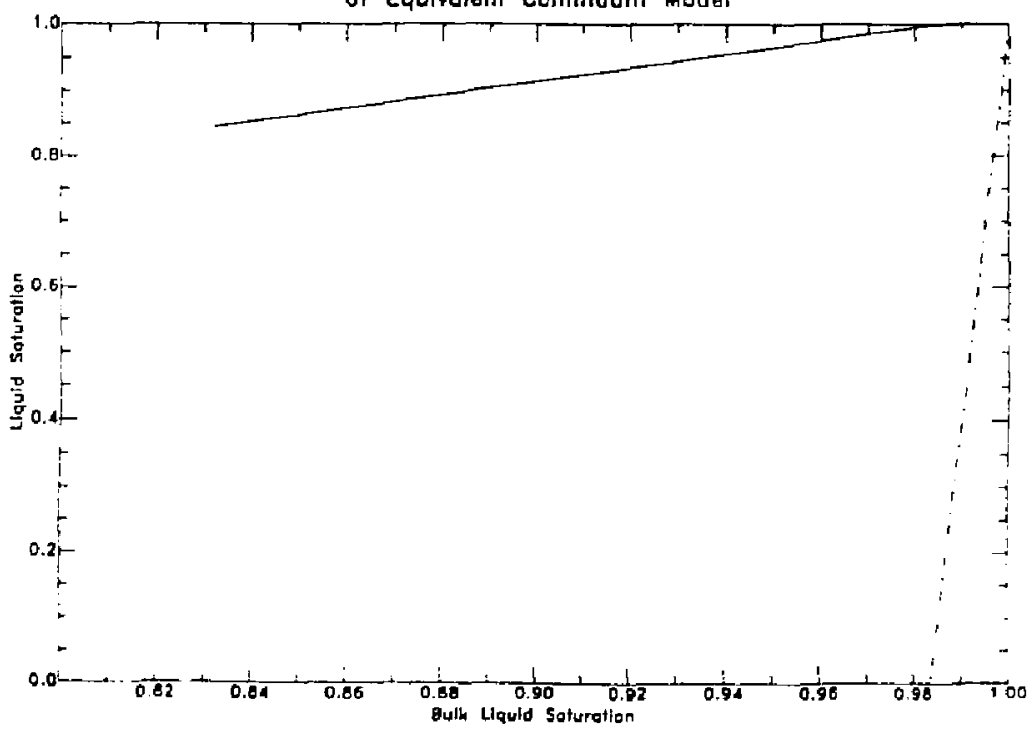

Figure 4. Matrix and Fracture Liquid Saturation vs. Hulk Liquid Saturalion 
$-43-$

Matrix (solid line) and Frocture (doshed line)

Liquid Relative Permeability vs. Liquid Saturation

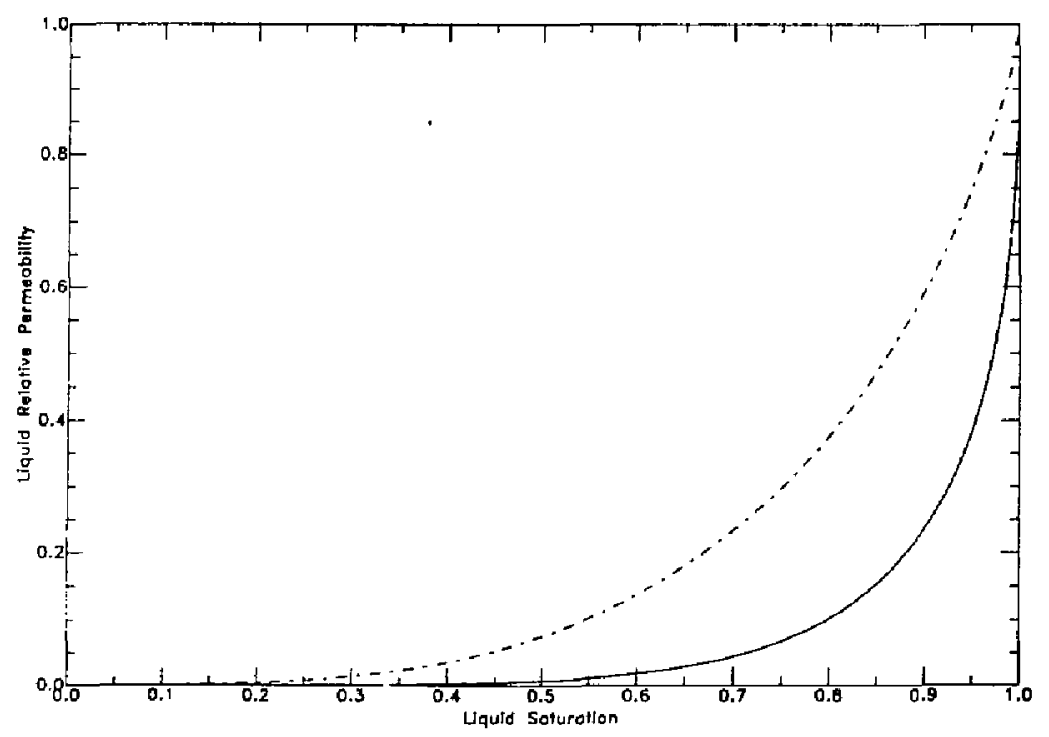

Figure 5. Matrix and Fracture Relative Permeability 
Ground Surface

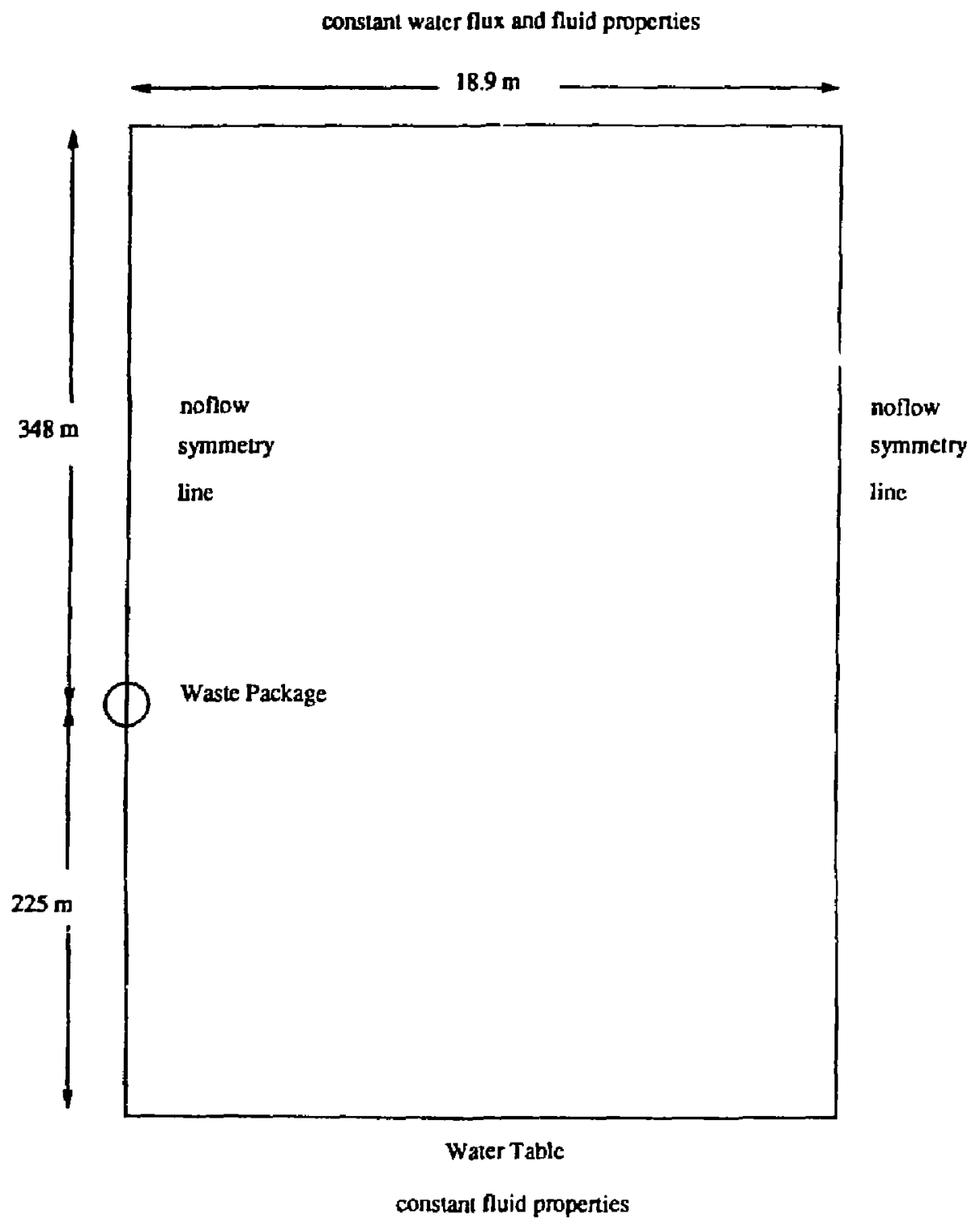

Figure 6. COVE3 Problem Gcometry

(not to scale) 


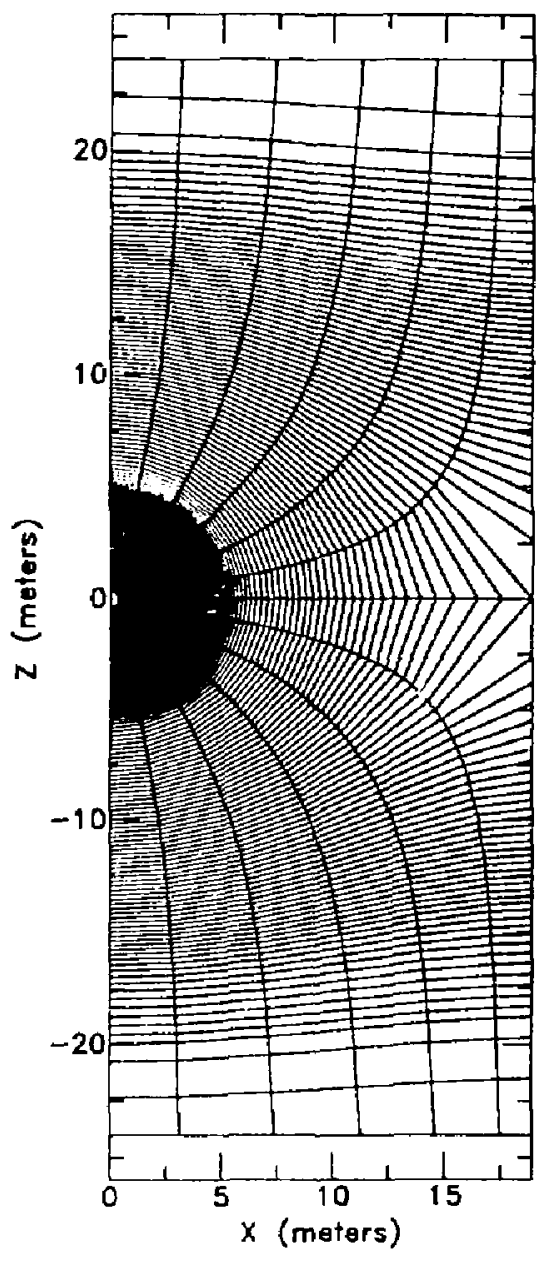

Higure 7. Computalimal Mylish arand Waste Package 
$-46-$

Comporison of Temperature of Waste Package

$0.1 \mathrm{~mm} / \mathrm{yr}, 1.0 \mathrm{~mm} / \mathrm{yr}$, and no pare fiuid

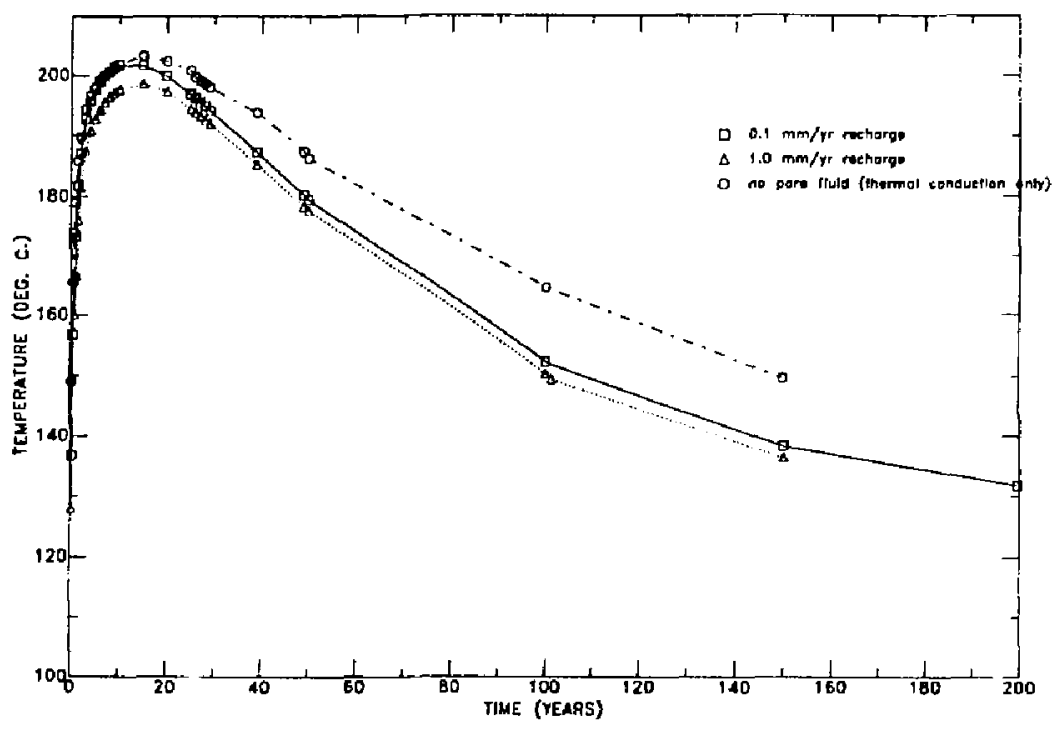

Figure 8. Comparison of Temperature at Waste Package, 0-200 years 
Comparison of Temperature at Wasto Package

$0.1 \mathrm{~mm} / \mathrm{yr}, 1.0 \mathrm{~mm} / \mathrm{yr}$, and no pore fluid

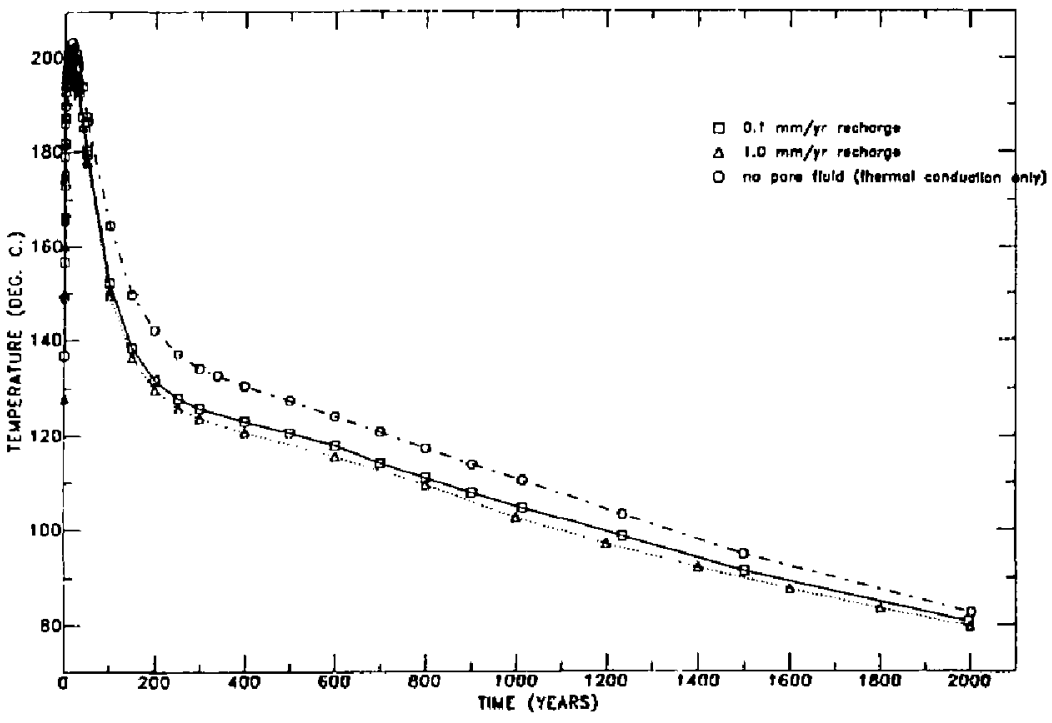

Figure 9. Comparisun of Temperatare at Waste Package, 0.2000 years

TEMPERATURE along VERTICAL THROUGH WASTE PACKAGE CENTERLINE AT 100 yrs.

$0.1 \mathrm{~mm} / \mathrm{rr}$ (solid lir.i) and $1.0 \mathrm{~mm} / \mathrm{yr}^{\circ}$ (dotted lina) recharge. no fluid flow (doshed) (runs: cove20b, cove21b. ther13)

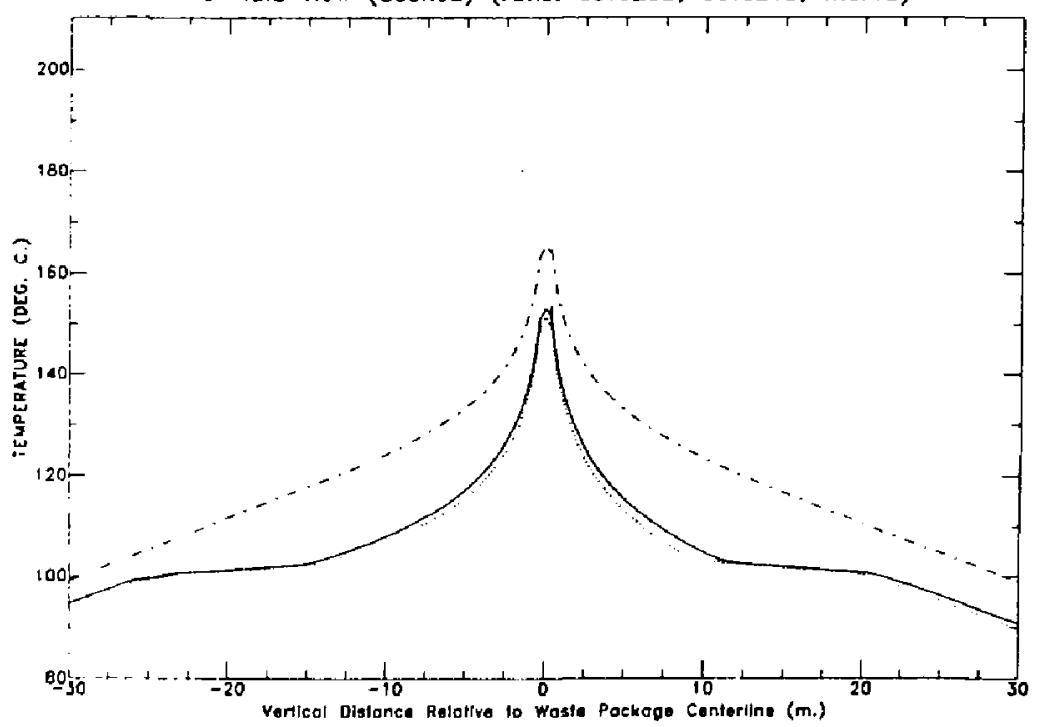

Figure III. Temperature Profile along Vertical through Waste Package at 100 years 
$-48-$

TEMPERATURE ALONG VERTICAL THROUGH WASTE PACKAGE CENTERLINE AT 400 YRS.

$0.1 \mathrm{~mm} / \mathrm{yr}$ (solld line) and $1.0 \mathrm{~mm} / \mathrm{yr}$ (datled line) recharge.

no fluid flow (dashed) (runs: cove20b, cove21b, ther13)

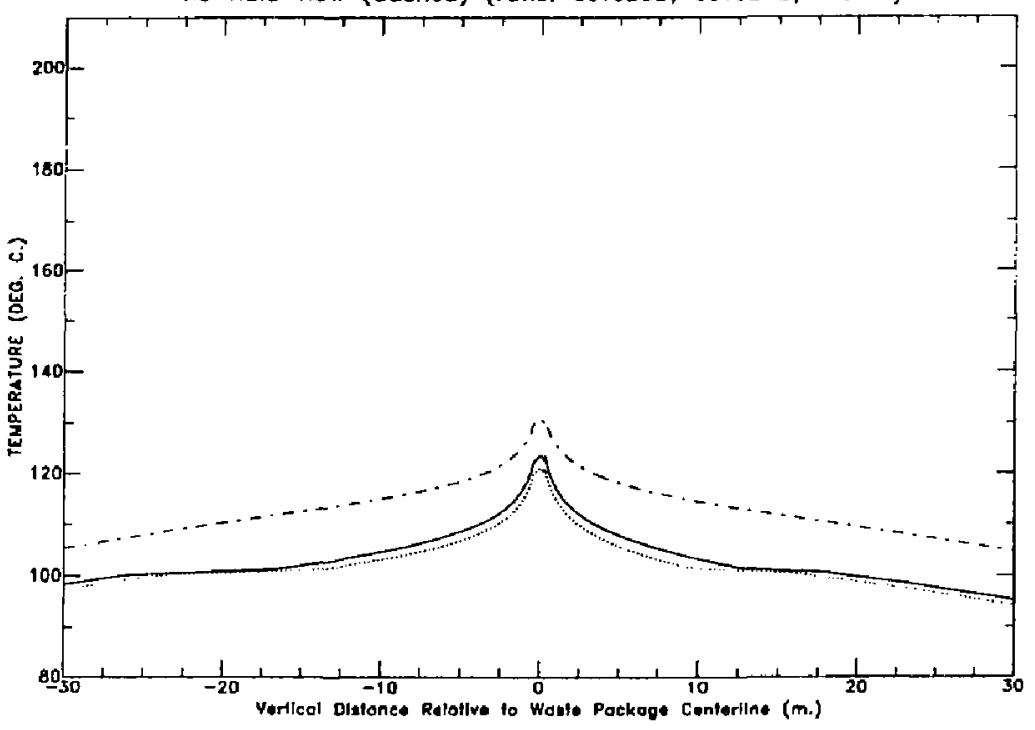

Figure 11. Temperature Profile along Vertical through Waste Package at 400 years

TEMPERATURE ALONG VERTICAL THROUGH WASTE PACKAGE CENTERLNE

$0.1 \mathrm{~mm} / \mathrm{yr}$ rechorgo

(run: cove20b)

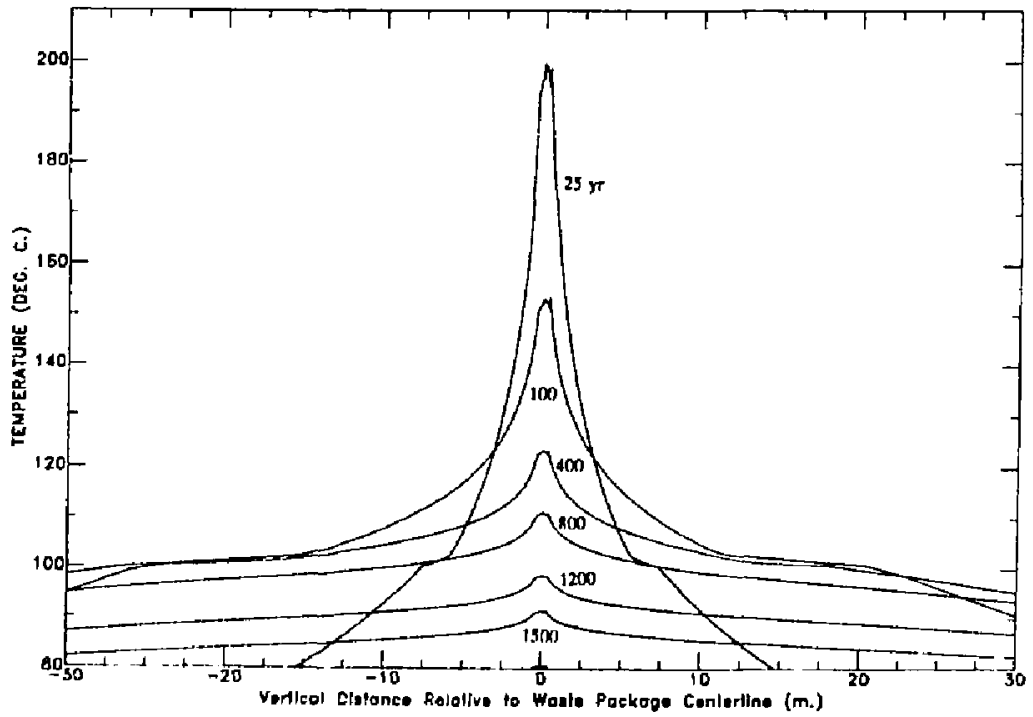

Figure 12. Temperature Profiles along Vertical through Waste Package at Various Times, $0.1 \mathrm{~mm} / \mathrm{yr}$ recharge 


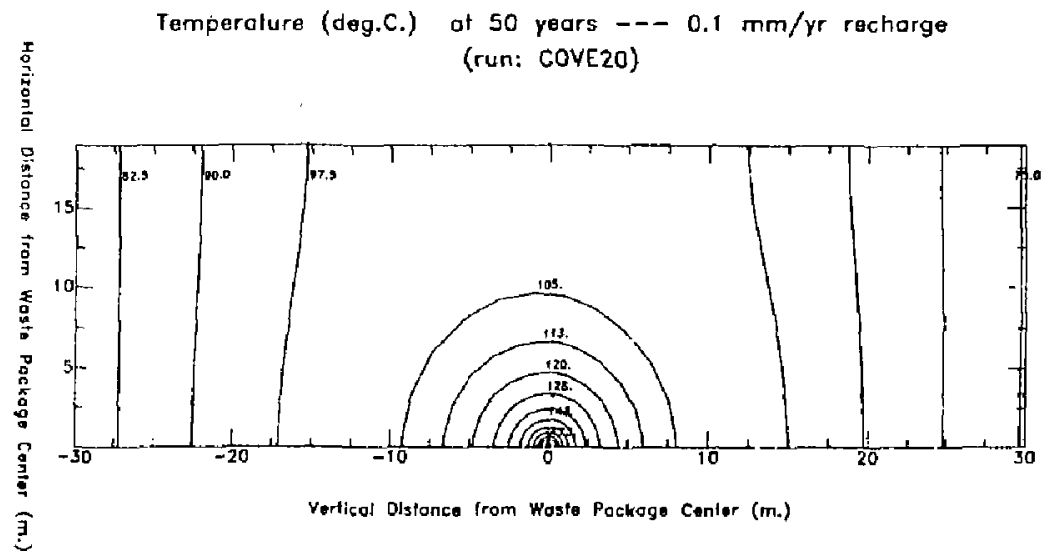

Figure 13. Temperature Contours at 50 years, $0.1 \mathrm{~mm} / \mathrm{yr}$

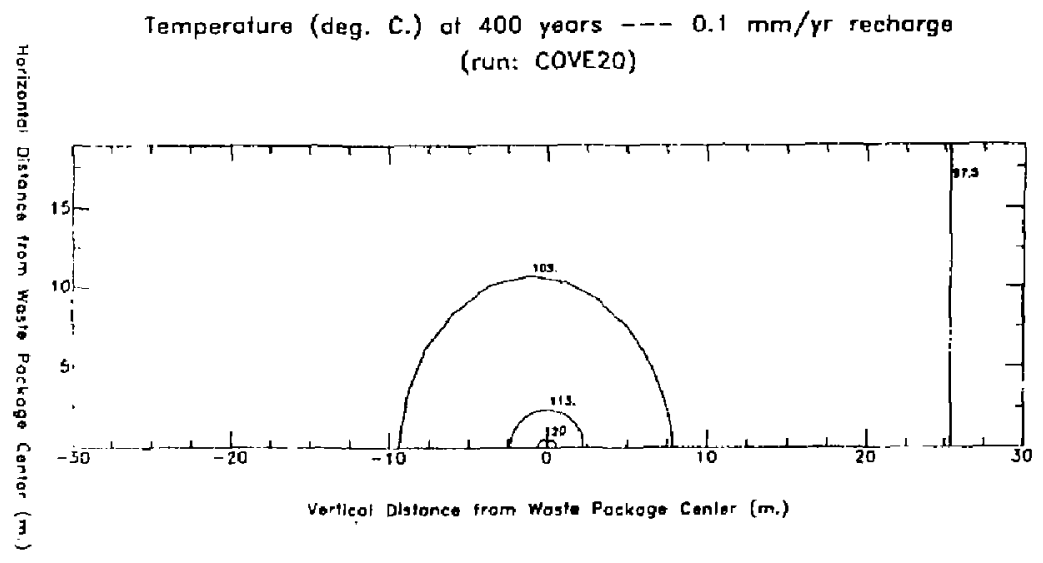

Figure 14. Temperafure Contours at 400 yeass, $0.1 \mathrm{~mm} / \mathrm{yr}$ 


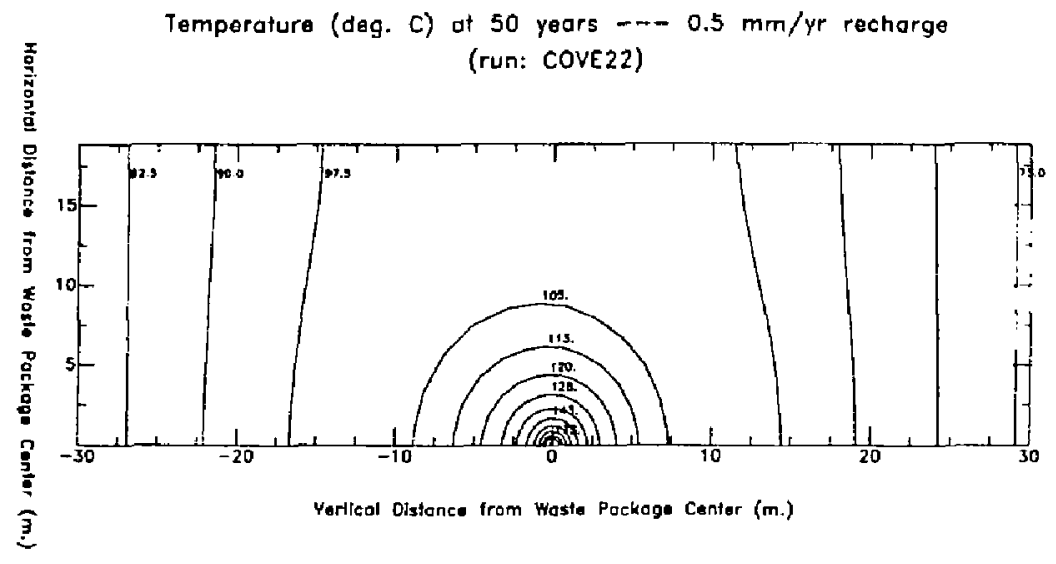

Figure 15. Temperature Contours at 50 years, $0.5 \mathrm{~mm} / \mathrm{yr}$

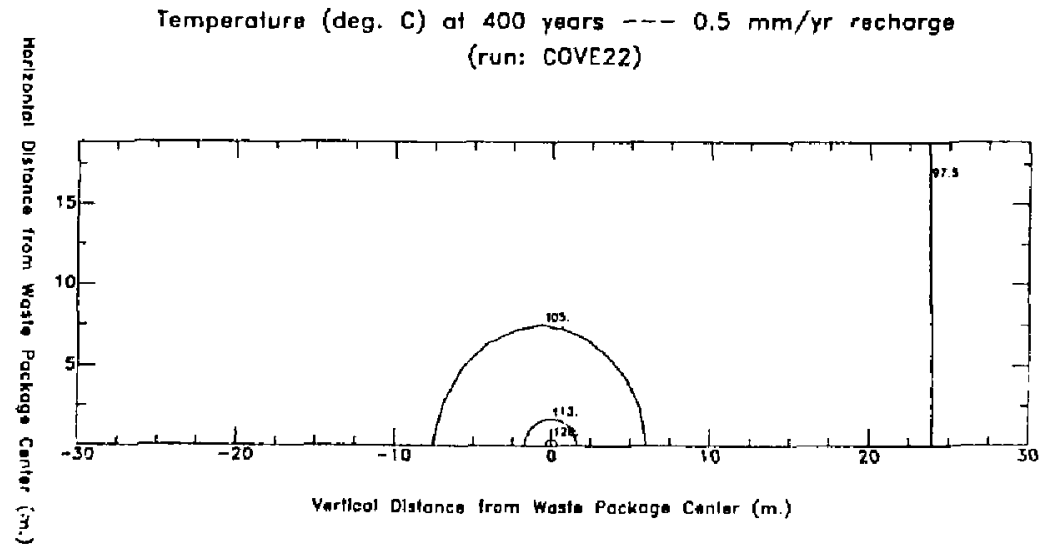

Figure 16. Temperature Contours at 400 years, $0.5 \mathrm{~mm} / \mathrm{yr}$ 


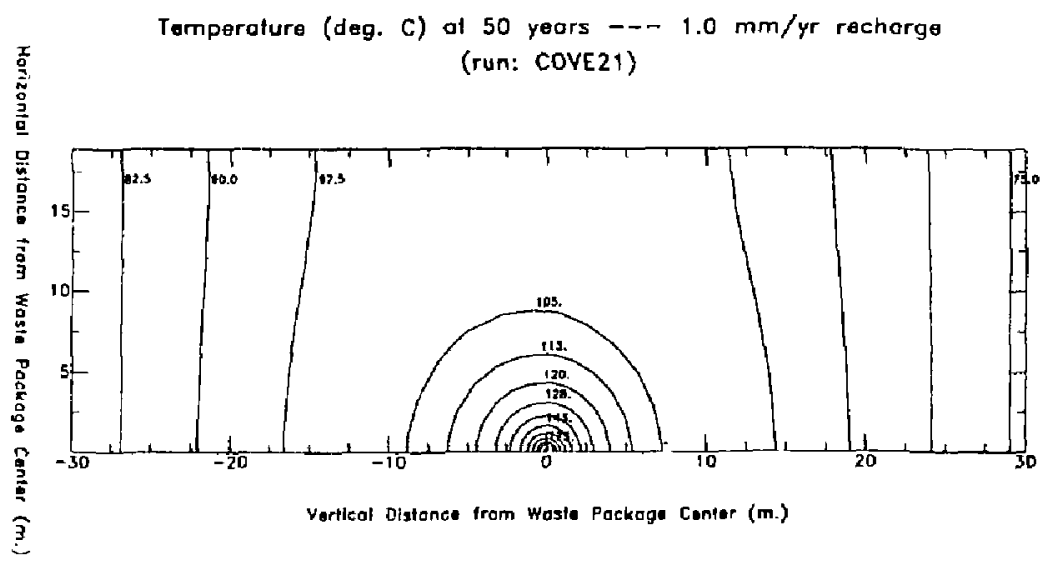

Figure 17. Temperature Contours at 50 years, $1.0 \mathrm{~mm} / \mathrm{yr}$

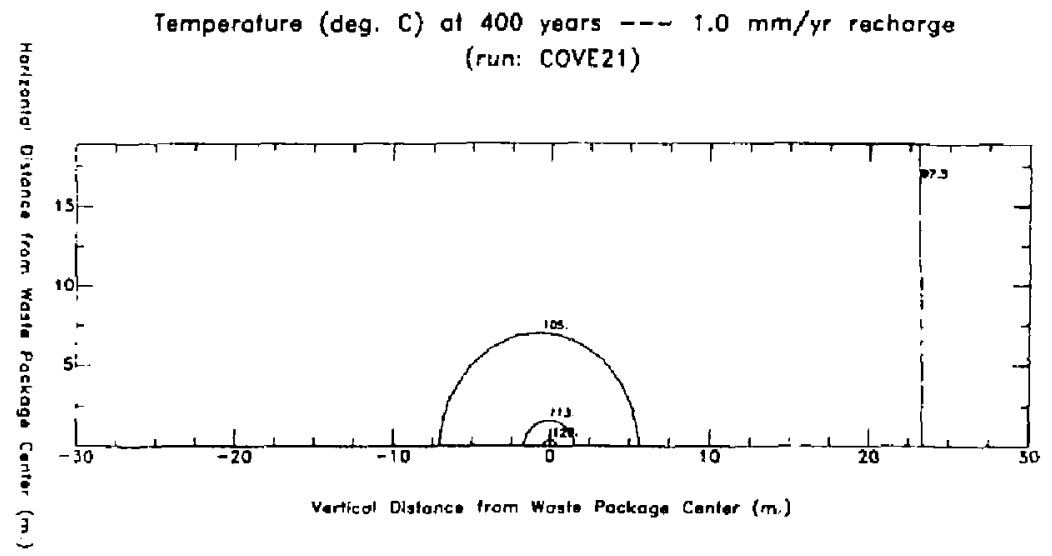

Figure 18. Temperature Contours at 400 years, $1.0 \mathrm{~mm} / \mathrm{yr}$ 
Comparison af Liquid Saturation At Barehola Wall $0.1 \mathrm{~mm} / \mathrm{yr}, 0.5 \mathrm{~mm} / \mathrm{yr}$, and $1.0 \mathrm{~mm} / \mathrm{yr}$

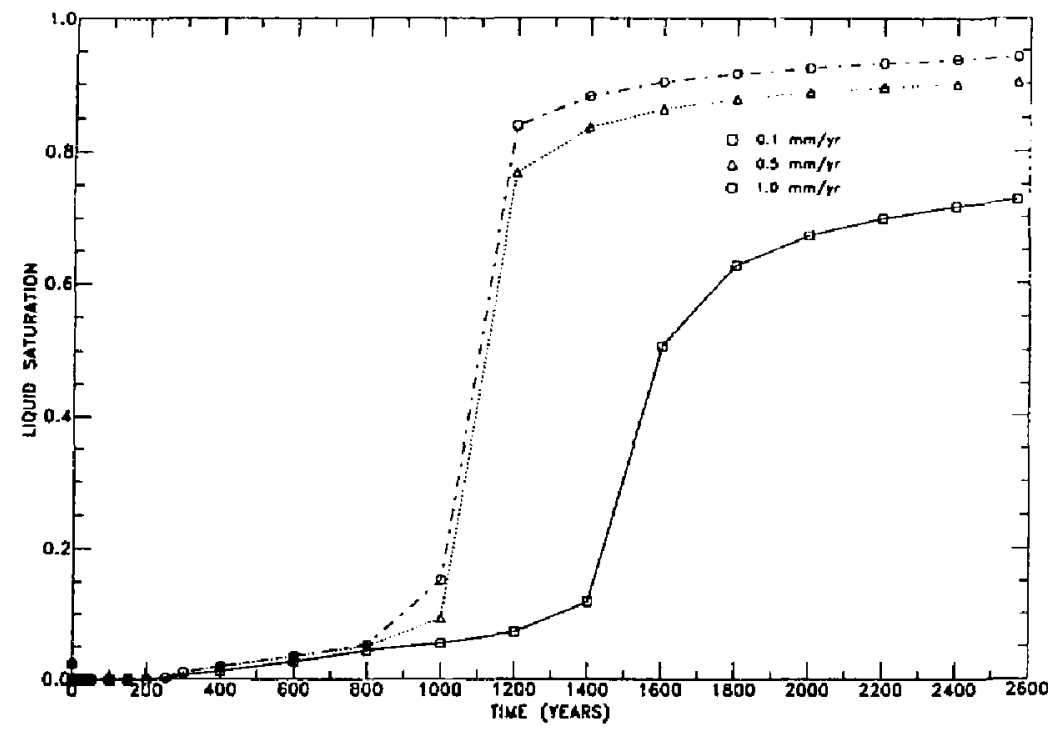

Figure 19. Liquid Saturation versus Time at Borehole Wall

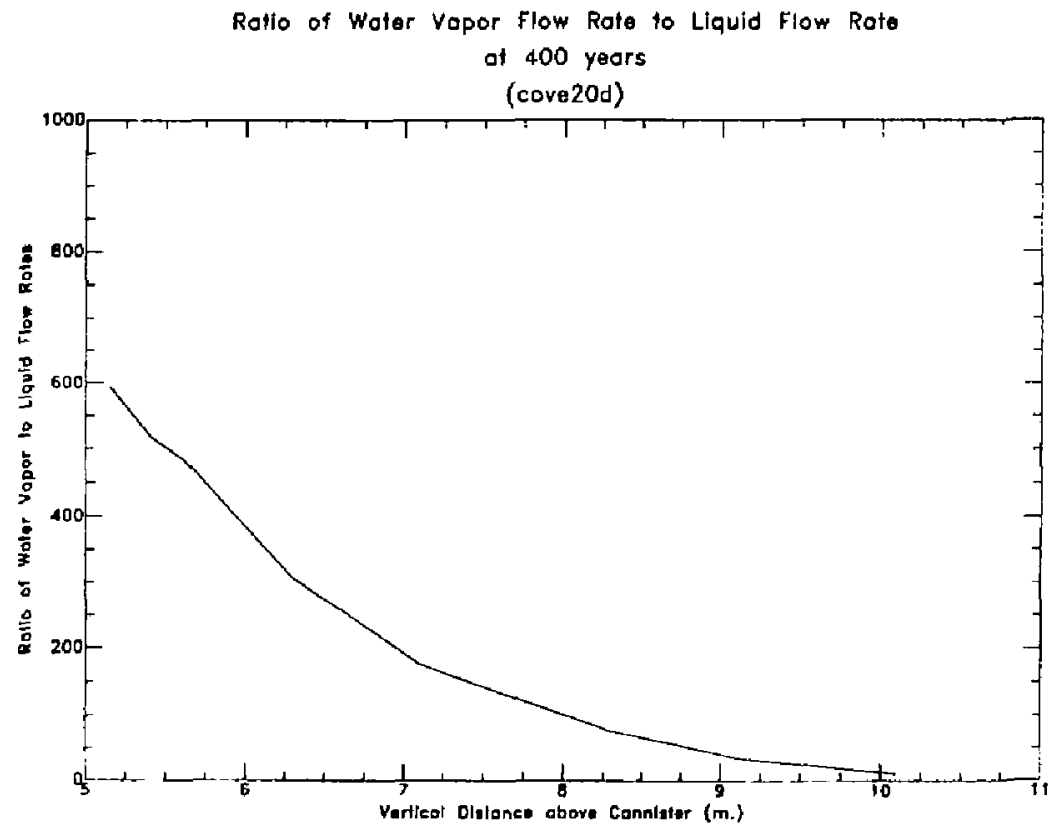

Figure 20. Ratio of Water Vapor Mass Flow Rate to Liquid Flow Rate, Profile above Wuste Package at 400 years, $0.1 \mathrm{~mm} / \mathrm{yr}$ 
$-53-$

Gas Phose Darcy Velocities at 400 years

$0.1 \mathrm{~mm} /$ yr recharge

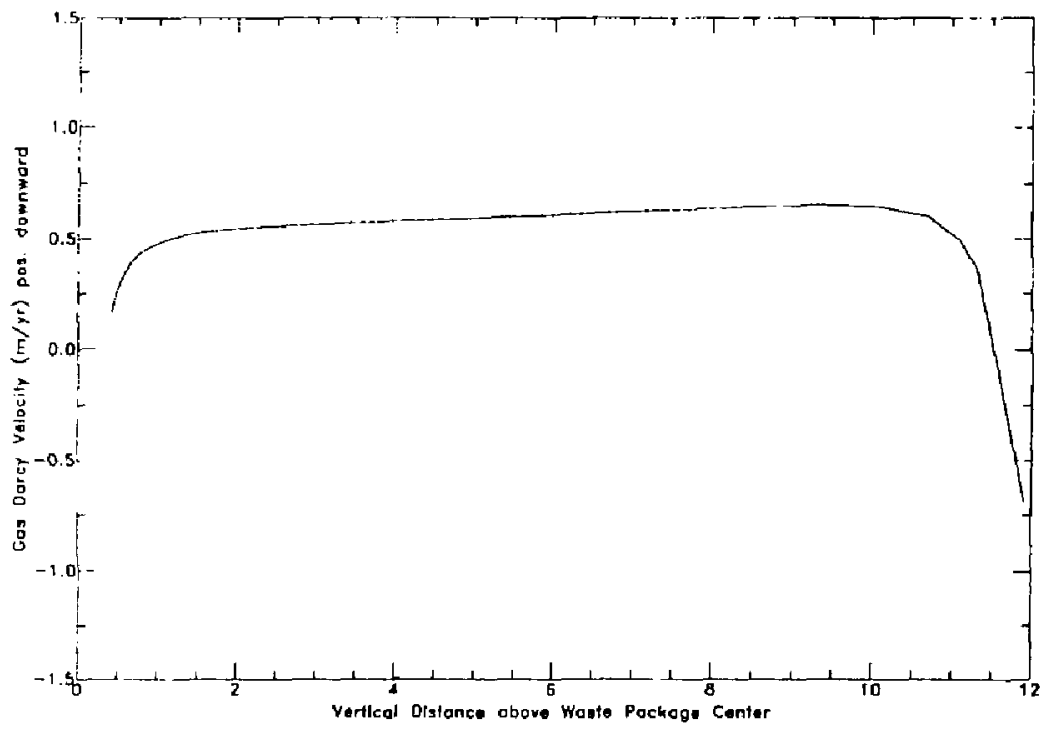

Figure 21. Gas Phase Darcy Velocities at $\mathbf{4 0 0}$ years, $0.1 \mathrm{~mm} / \mathrm{yr}$

LIQUID SATURATION PROFILES ALONG VERTICAL LINE THROUGH WASTE PACKAGE CENTER $0.1 \mathrm{~mm} / \mathrm{yr}$ recharge

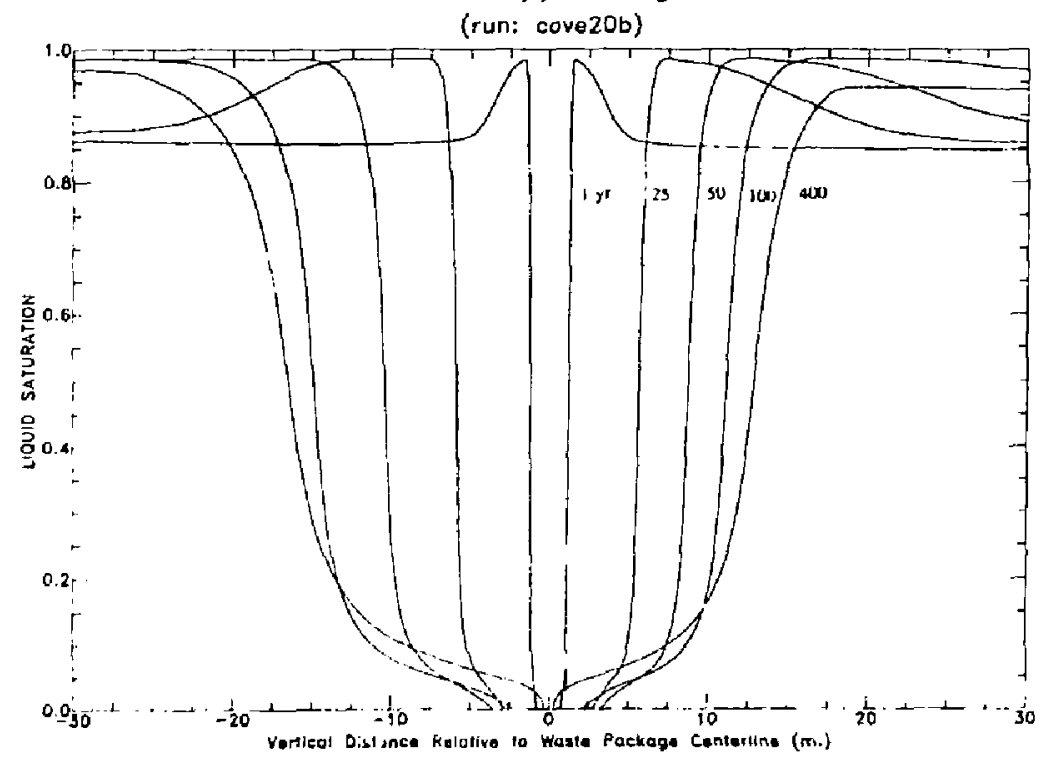

Figure 22. Licuid Saturation Protiles along Vertical through Waste Package, $0.1 \mathrm{~mm} / \mathrm{yr}$ 
LIQUID SATURATION PROFILES ALONG VERTICAL LINE THROUGH WASTTE PACKAGE CENTER

$0.1 \mathrm{~mm} / \mathrm{yr}$ rechorgo

(run: cove20b)

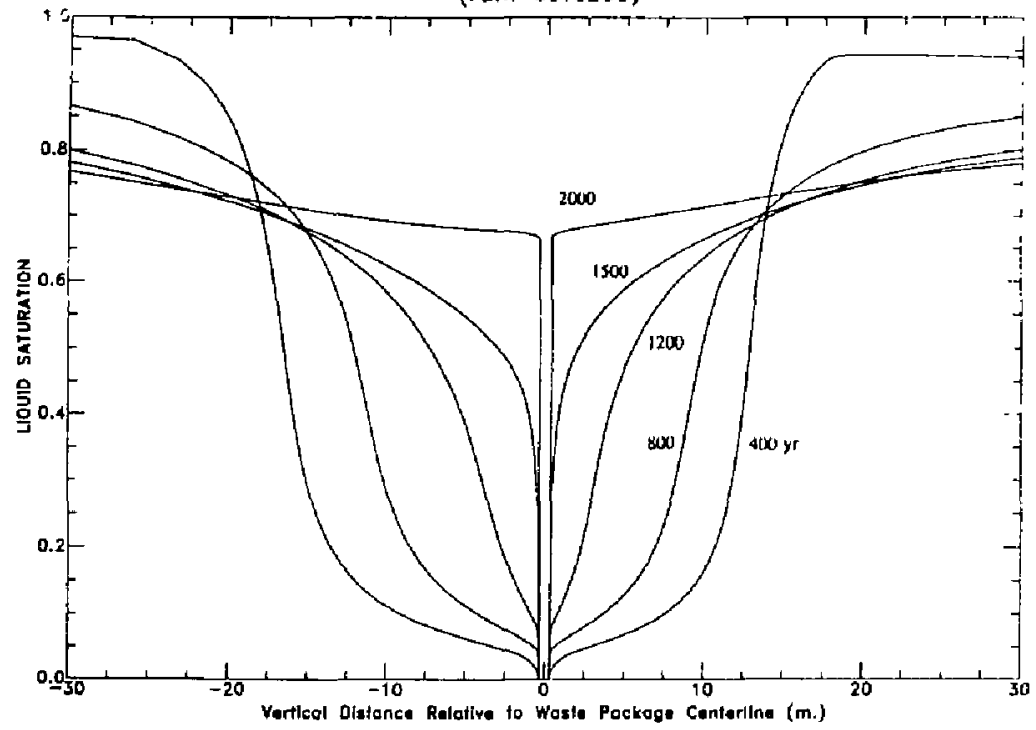

Figure 23. Liquid Saturation Profiles glong Vertical through Waste Package, $0.1 \mathrm{~mm} / \mathrm{yr}$

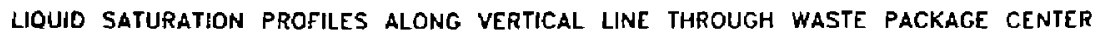
$0.5 \mathrm{~mm} / \mathrm{yr}$ recharge

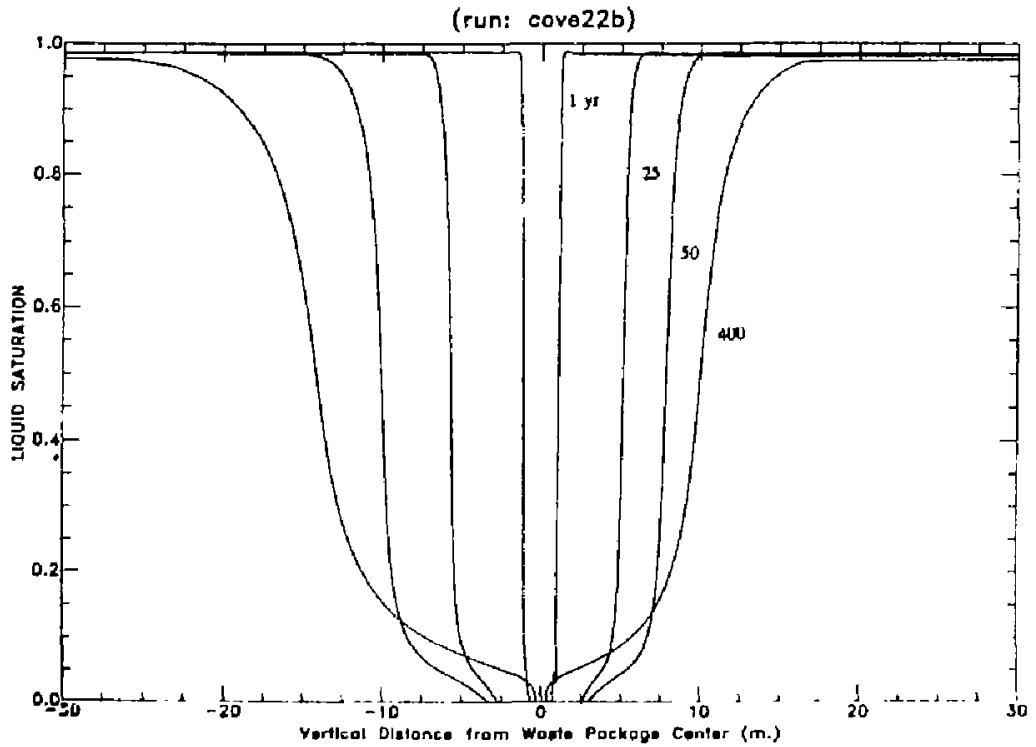

Figure 24. Liquid Saturation Profiles along Vertical through Waste Package, $0.5 \mathrm{~mm} / \mathrm{yr}$ 
$-55-$

LIQUIO SATURATION PRofiles along Vertical line through waste package center $0.5 \mathrm{~mm} / \mathrm{yr}$ rechorgo

(run: cove22b)

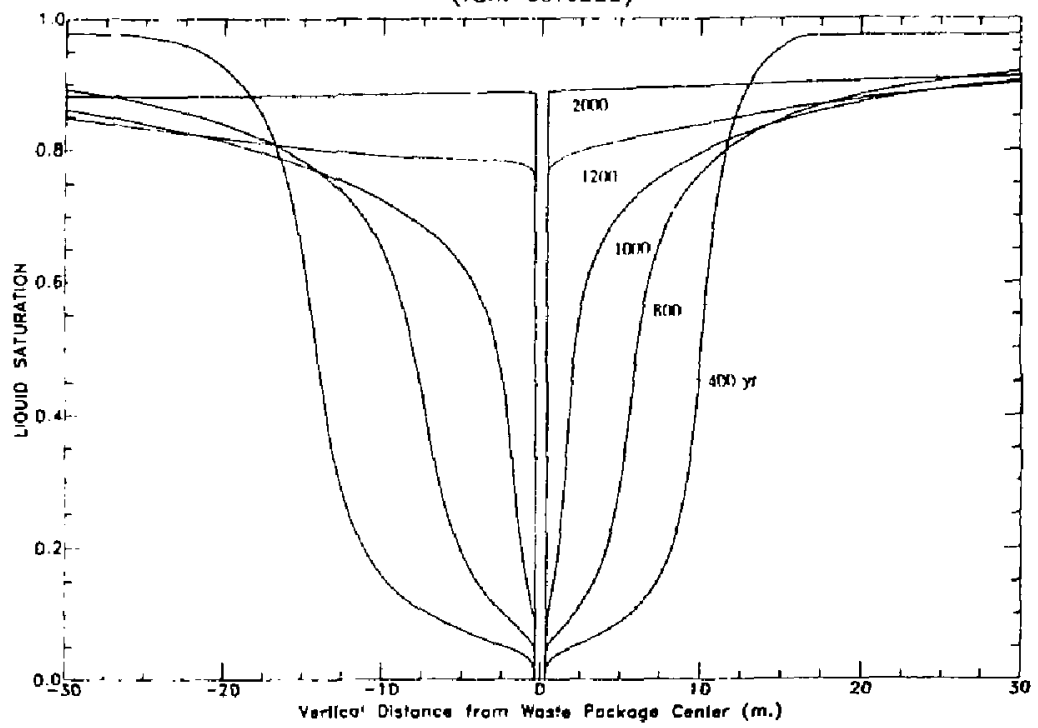

Figure 25. Liquid Saturation Profiles along Vertical through Waste Package, $0.5 \mathrm{~mm} / \mathrm{yr}$

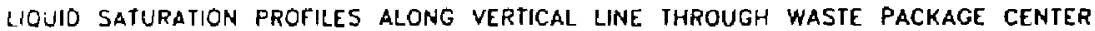
$1.0 \mathrm{~mm} / \mathrm{yr}$ recharge

(run: cove21b)

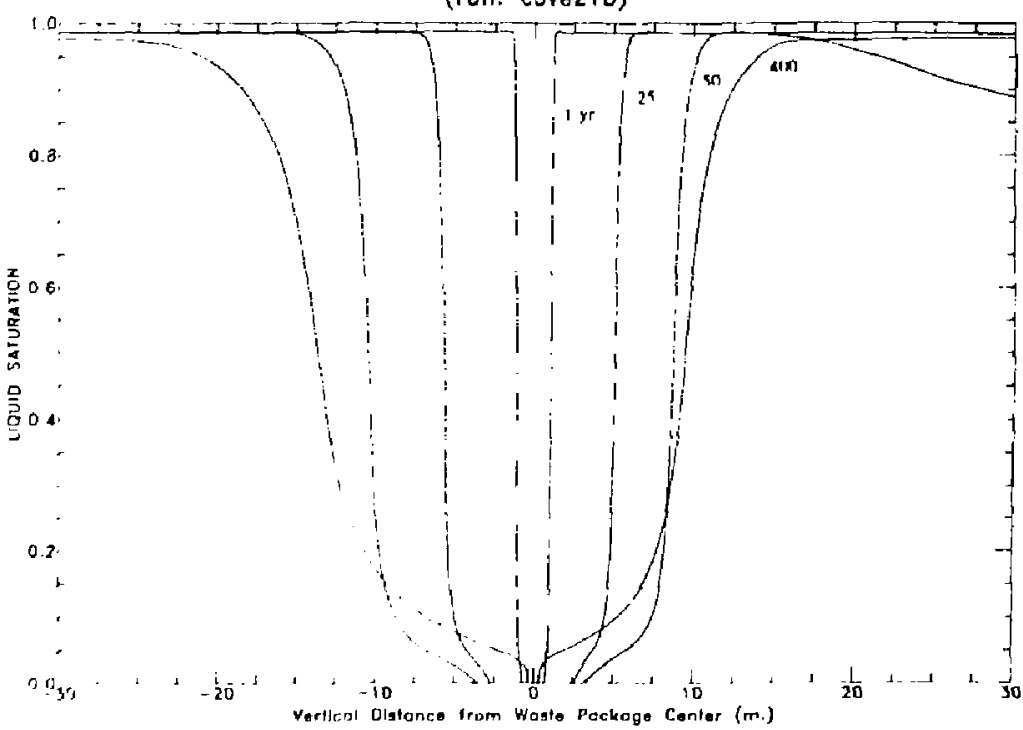

Figure 26. Liquid Saturation Profiles along Vertical tirough Waste Package, $1.0 \mathrm{~mm} / \mathrm{yr}$ 
LIOUID SATURATION PROFILES along VERTICAL LINE through WASTE PACKAGE CENTER $1.0 \mathrm{~mm} / \mathrm{yr}$ rechorge

(run: cove21b)

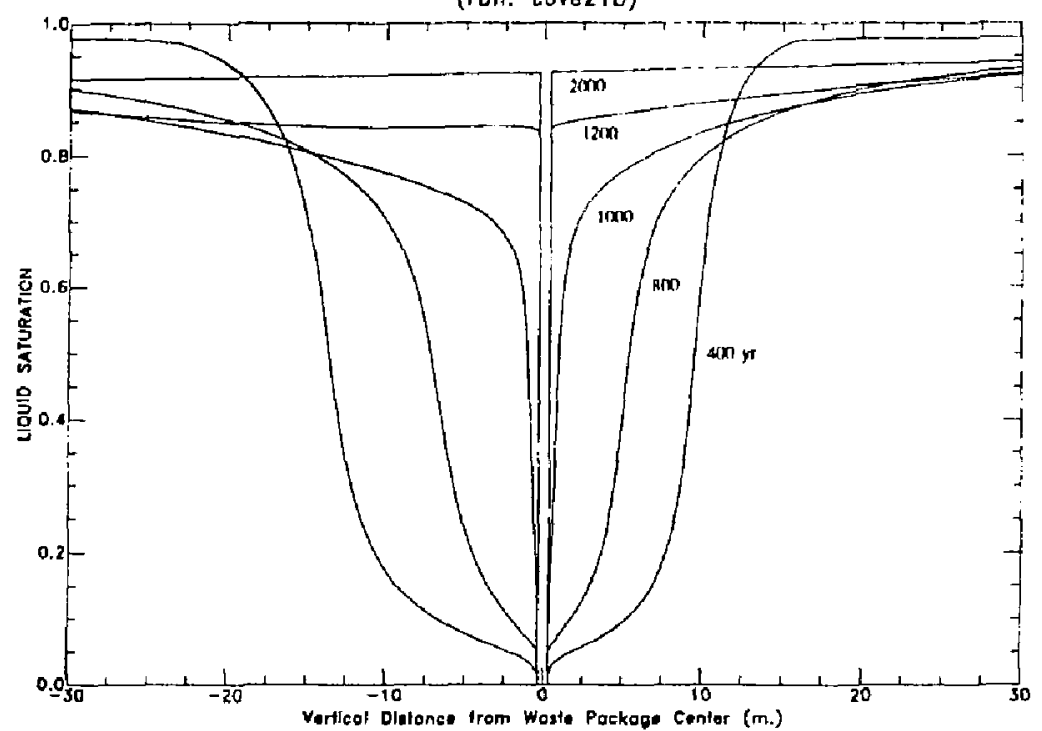

Figure 27. Liquid Saturation Profiles along Vertical through Waste Package, $1,0 \mathrm{~mm} / \mathrm{yr}$

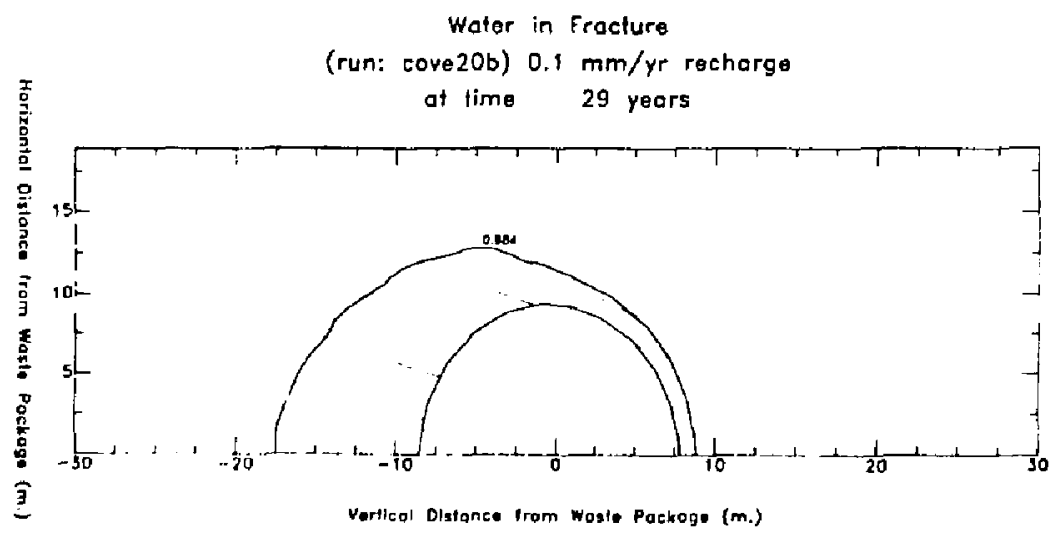

Figure 28. Water in Fracture at 29 years, $0.1 \mathrm{~mm} / \mathrm{yr}$ 


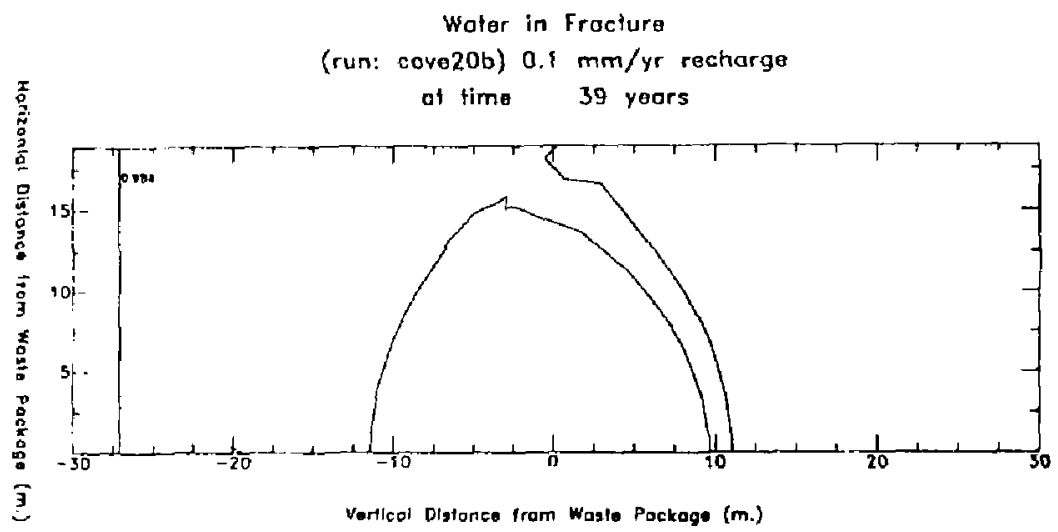

Figure 29. Waler in Fracture at 39 years, $0.1 \mathrm{~mm} / \mathrm{yr}$

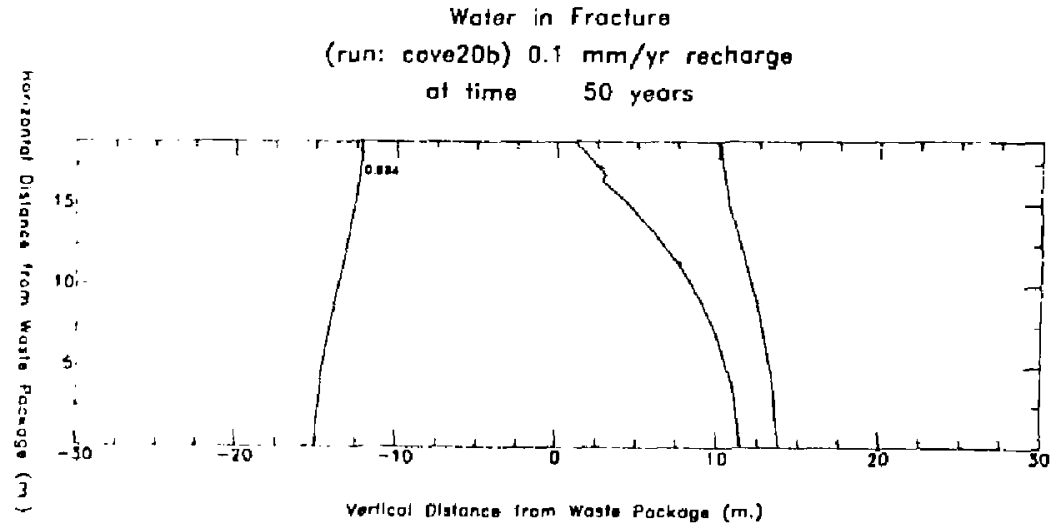

Fïgure 30. Walter in Fracture at 50 years, $0.1 \mathrm{~mm} / \mathrm{yr}$ 


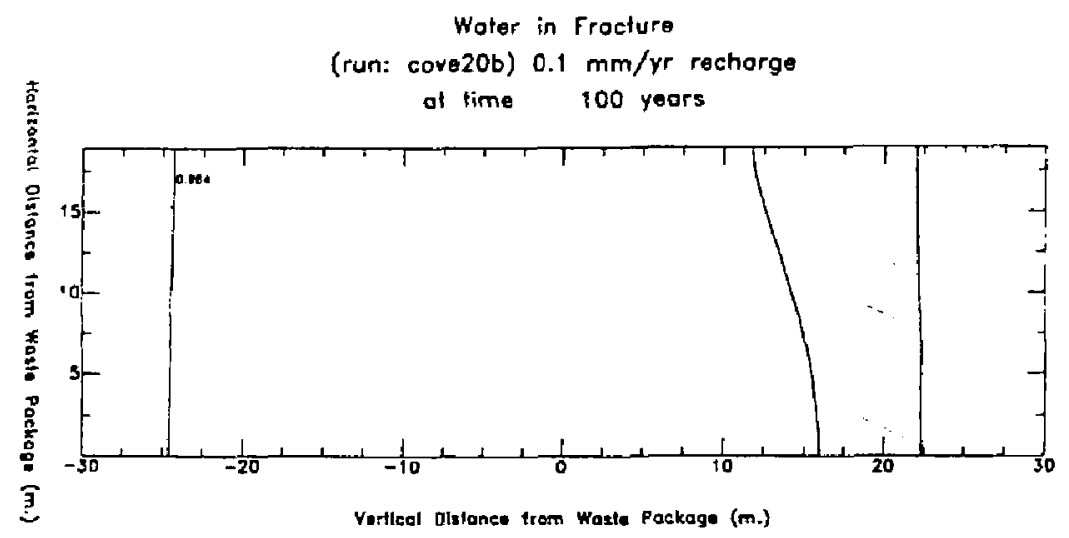

Figure 31. Water in Fracture at 100 years, $0.1 \mathrm{~mm} / \mathrm{yr}$

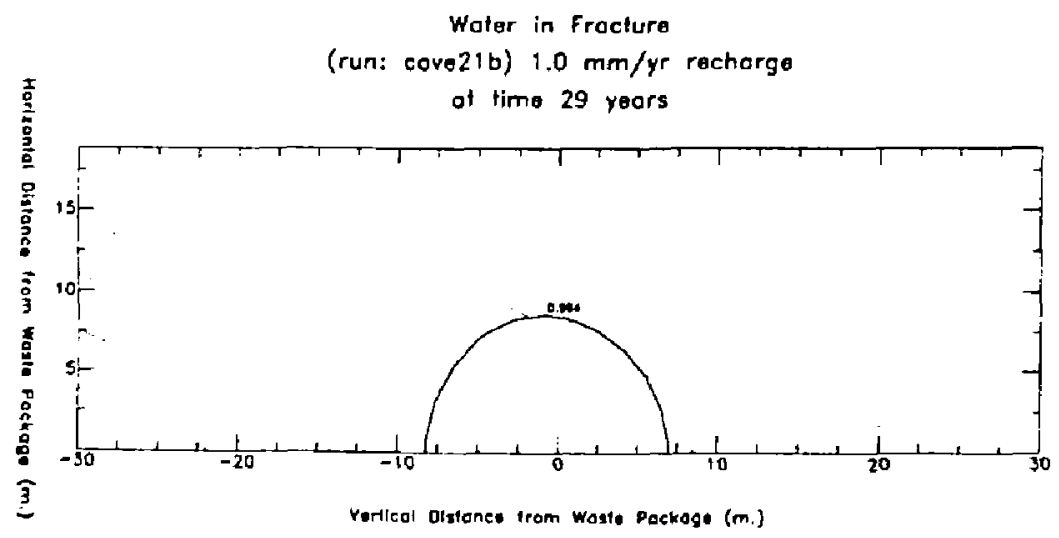

Figure 32. Water in Fracture at 29 years, $1.0 \mathrm{~mm} / \mathrm{yr}$ 


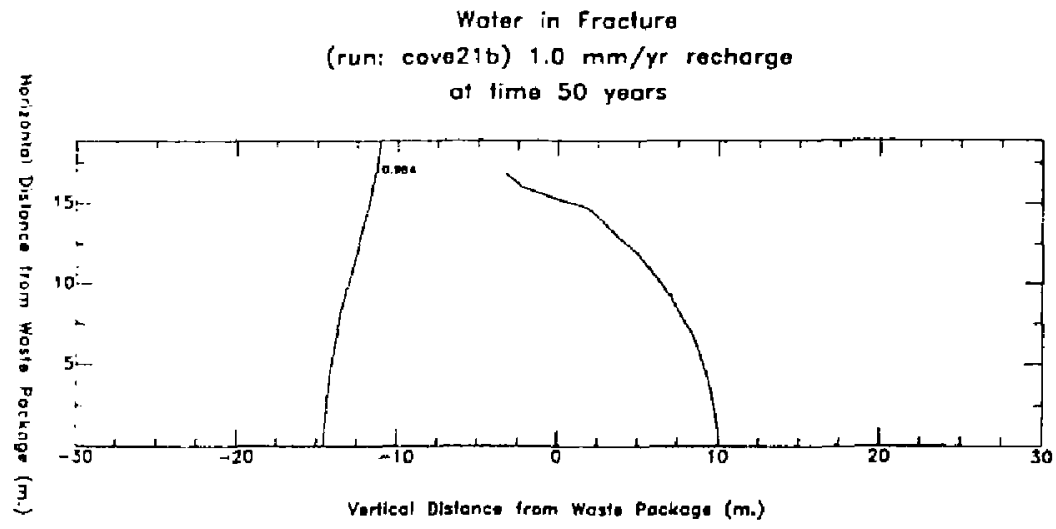

Figure 33. Water in Fracture at 50 years, $1.0 \mathrm{~mm} / \mathrm{yr}$

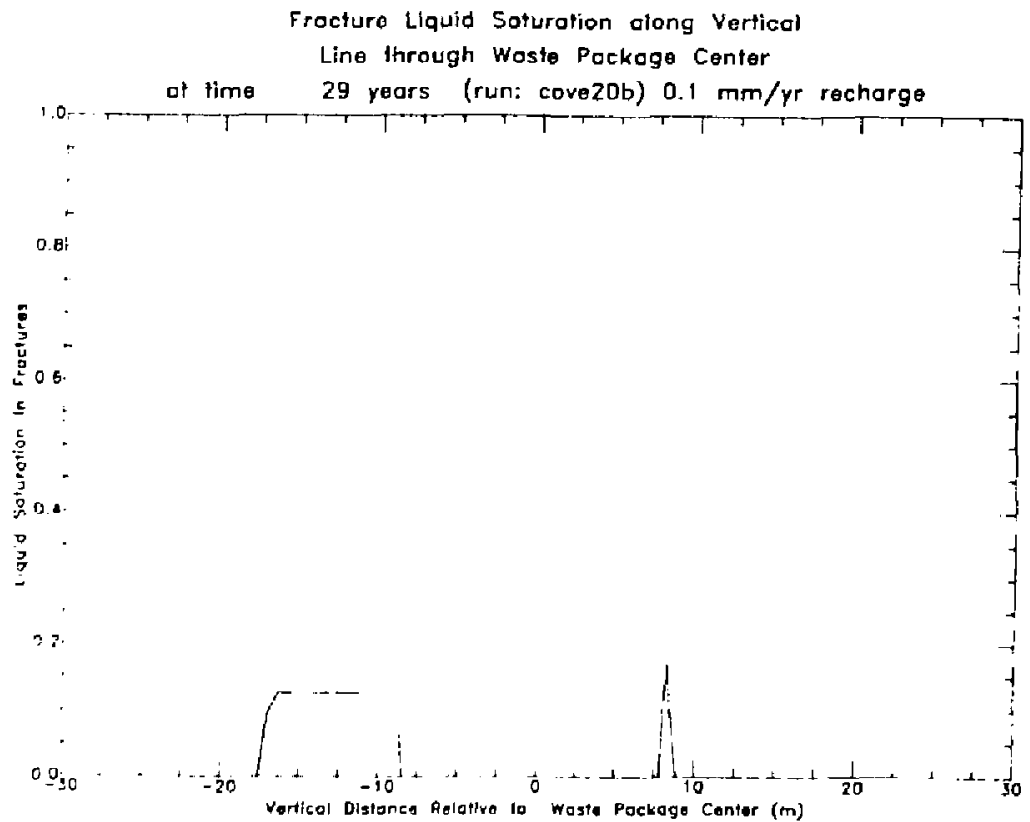

Figure 34. Fracture Liquid Saturation along Verticul line through Waste l'ackagre Center, 29 years 
$-60-$

Fracture Liquid Saturation along Vertical

Line through Woste Package Conter

at time 39 years (run: cove20b) $0.1 \mathrm{~mm} / \mathrm{yr}$ recharge

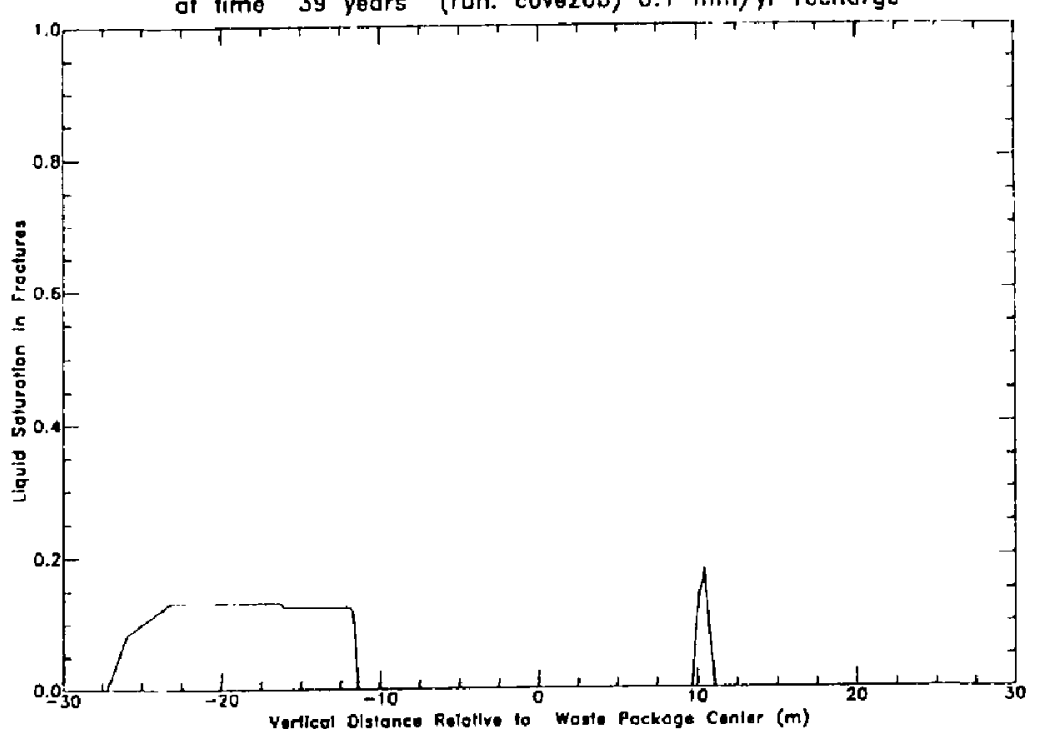

Figure 35. Fracture Liquid Saturation along Vertical Line through Waste Package Center, 39 years

Fracture Liquid Soturation along Verlicat Line through Waste Package Center of time 100 yeors (run: cove20b) $0.1 \mathrm{~mm} / \mathrm{yr}$ rechorge

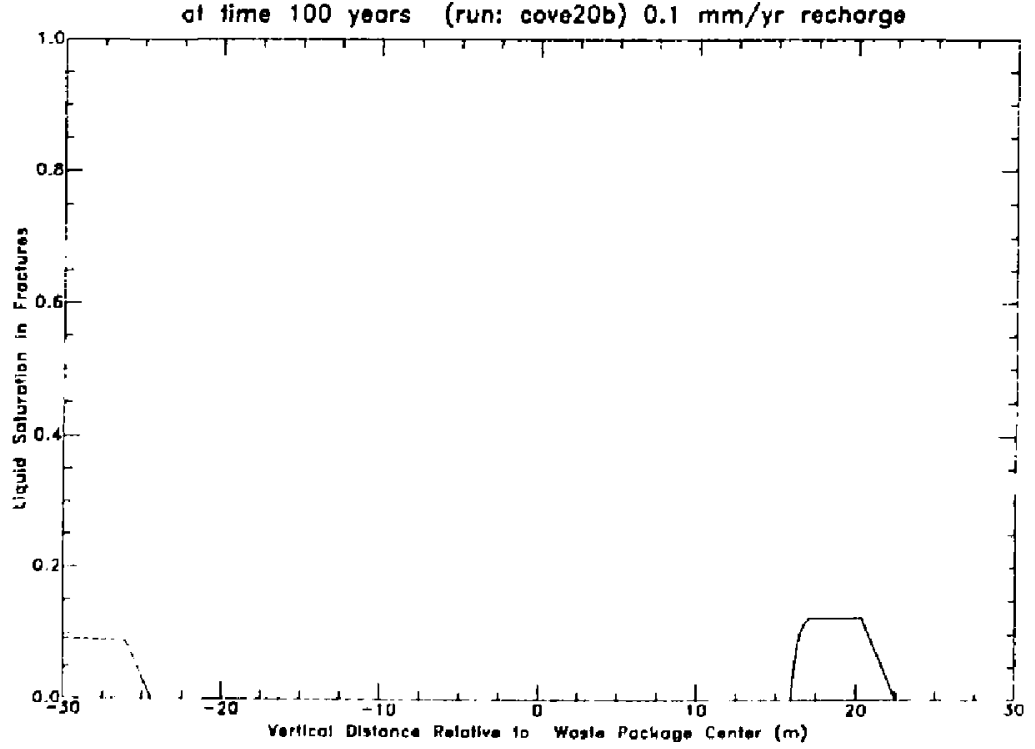

Higure 36. Fracture Liquid Saturation along Vertical I.ine through Waste Package Center, 100 years 


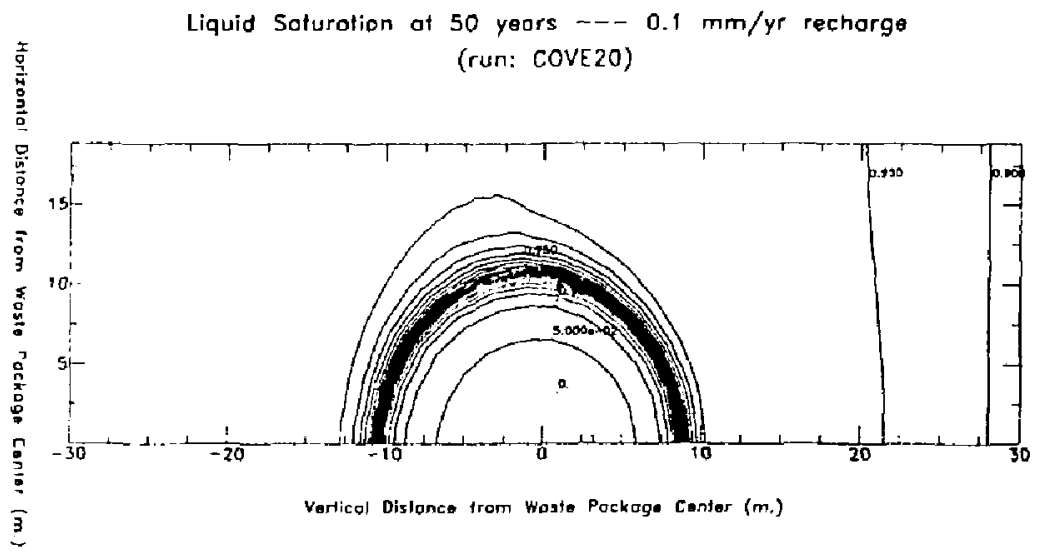

Figure 37. Liquid Saturation Contours at 50 years, $0.1 \mathrm{~mm} / \mathrm{gr}$

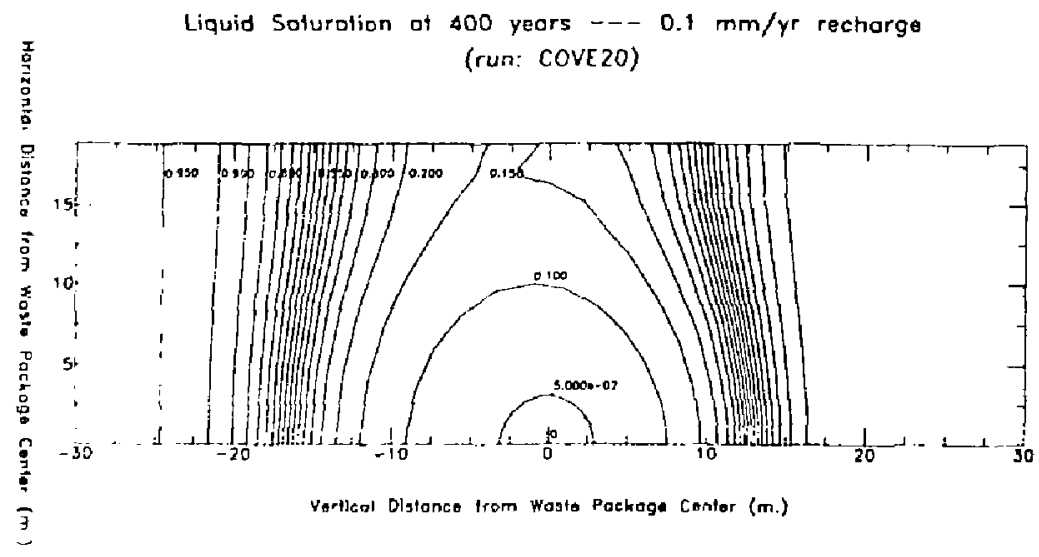

Figure 38. Liquid Saturation Contours at $\$ 00$ years, $0.1 \mathrm{~mm} / \mathrm{yr}$ 


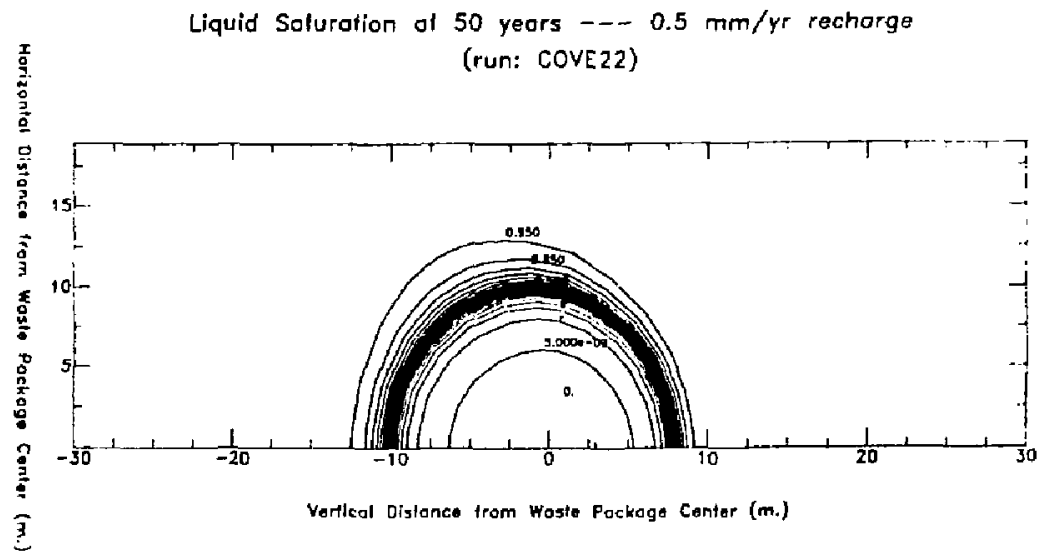

Figure 39. Liquid Saturation Contours at 50 years, $0.5 \mathrm{~mm} / \mathrm{yr}$

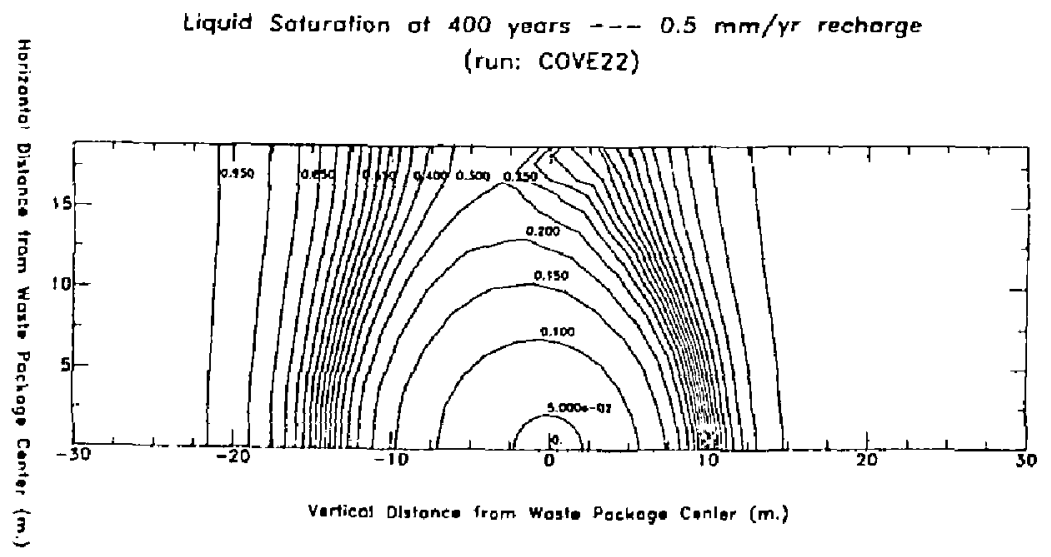

Figure 40. Liquid Saturation Contours at 400 years, $0.5 \mathrm{~mm} / \mathrm{yr}$ 


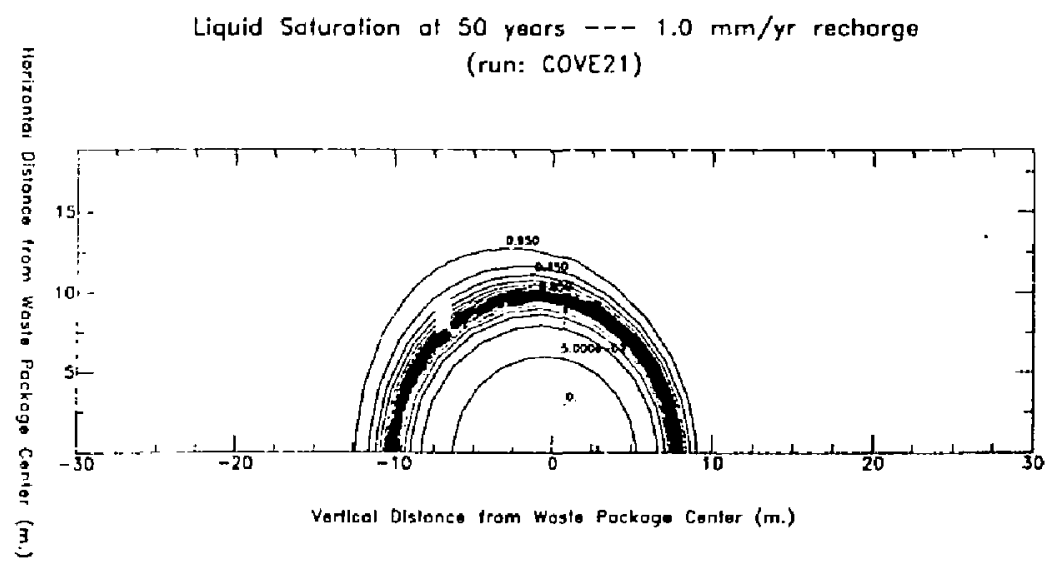

Figure 41 . Liquid Saturation Conlours at 50 years, $1.0 \mathrm{~mm} / \mathrm{yr}$

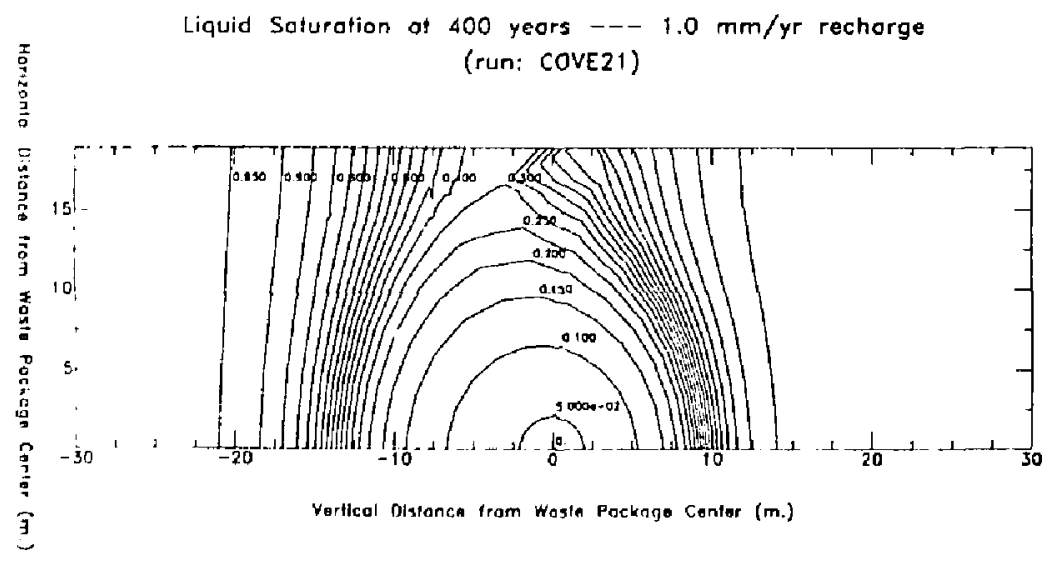

Figure 42, Liquid Saturation Contours at 400 years, $1.0 \mathrm{~mm} / \mathrm{yr}$ 
$-64-$

Comparison of Water Vapor Moss Fracllons At Borehola Wall

$0.1 \mathrm{~mm} / \mathrm{yr}, 0.5 \mathrm{~mm} / \mathrm{yr}$, and $1.0 \mathrm{~mm} / \mathrm{yr}$

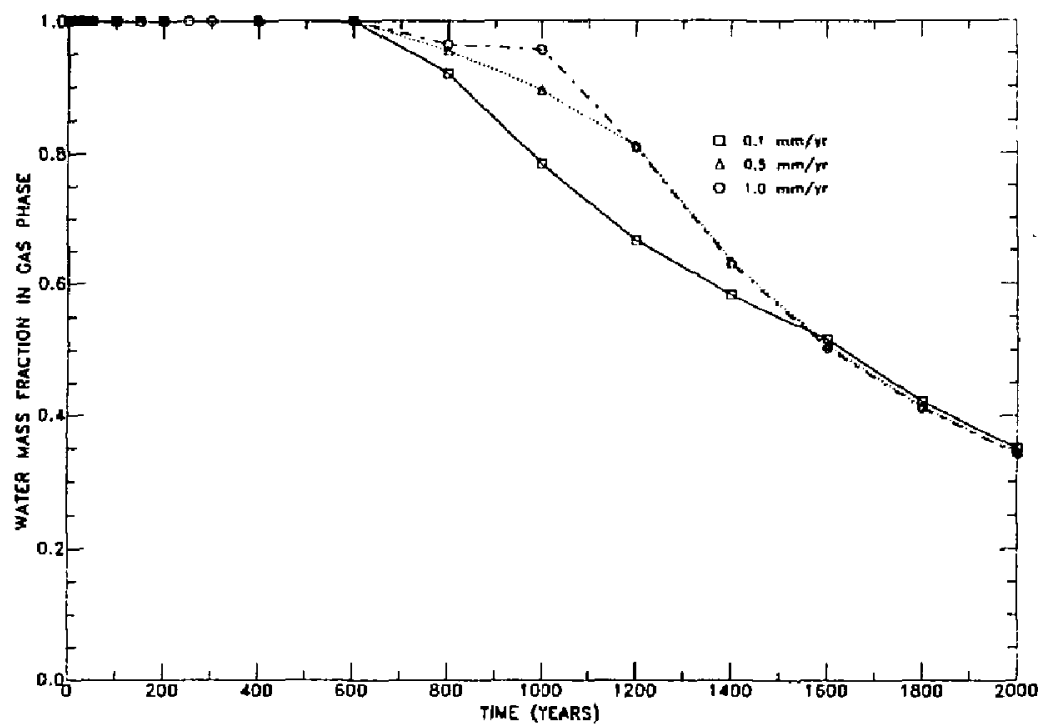

Figure 43. Water Vapor Mass Fractions versus Time at Borehole Wal!

WATER VAPOR MASS FRACTION ALONG VERTICAL LINE THROUGH WASTE PACKAGE DURING HEATUP $\rightarrow-0.1 \mathrm{~mm} / \mathrm{yr}$ rechorge

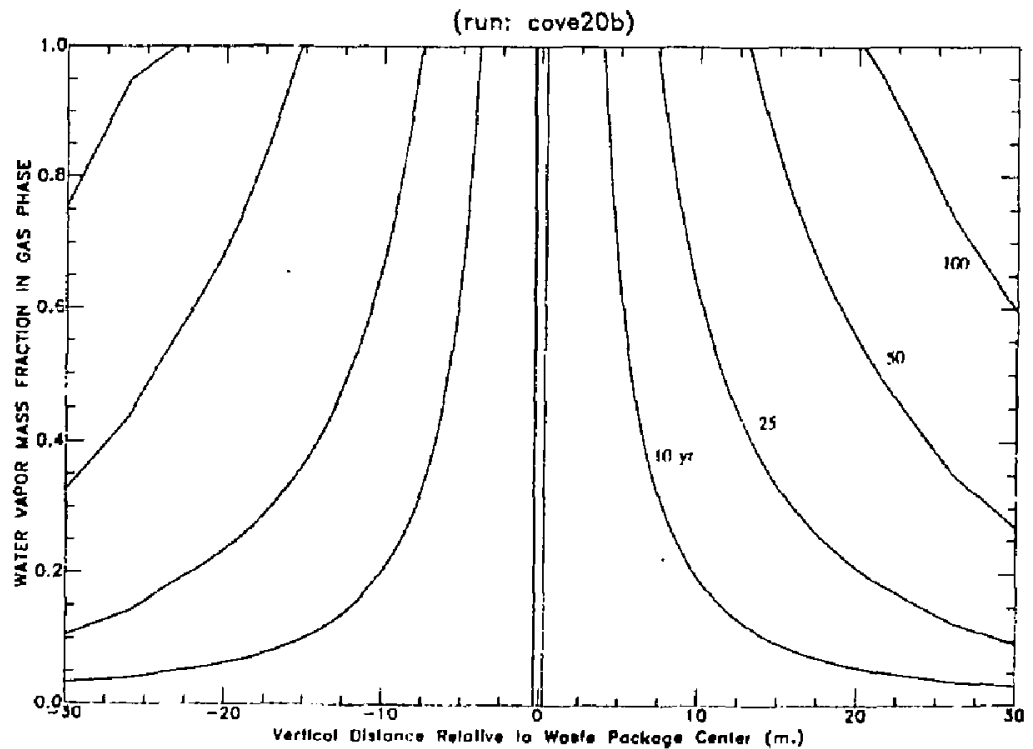

Figure 44. Wutcr Yapor Mass Fraction I'rotiles along Vertical tlorough Wuste Packuge Center, $0.1 \mathrm{~mm} / \mathrm{yr}$ 
$-65-$

Water VAPOR MaSS FRACTION ALONG VERTICAL LINE THROUGH WASTE PACKage DURING COOLDOWN - - $0.1 \mathrm{~mm} / \mathrm{Yr}$ recharge

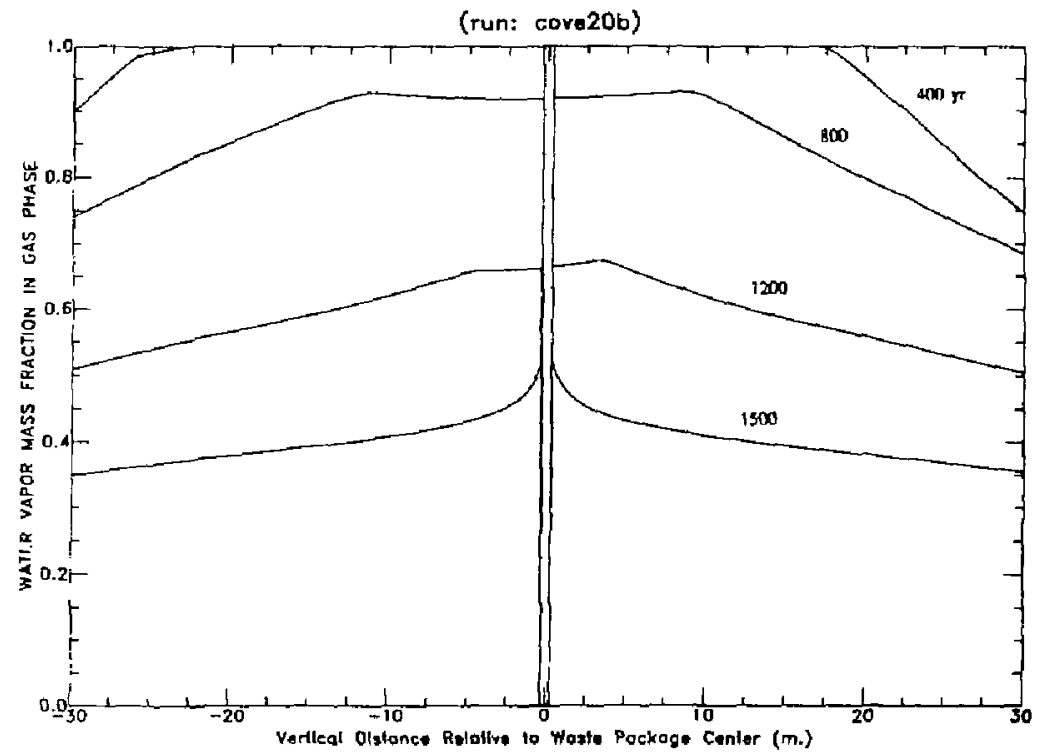

Figure 45. Water Vapor Mass Fraction Profiles phong Vertical through Waste Package Center, $0.1 \mathrm{~mm} / \mathrm{yr}$

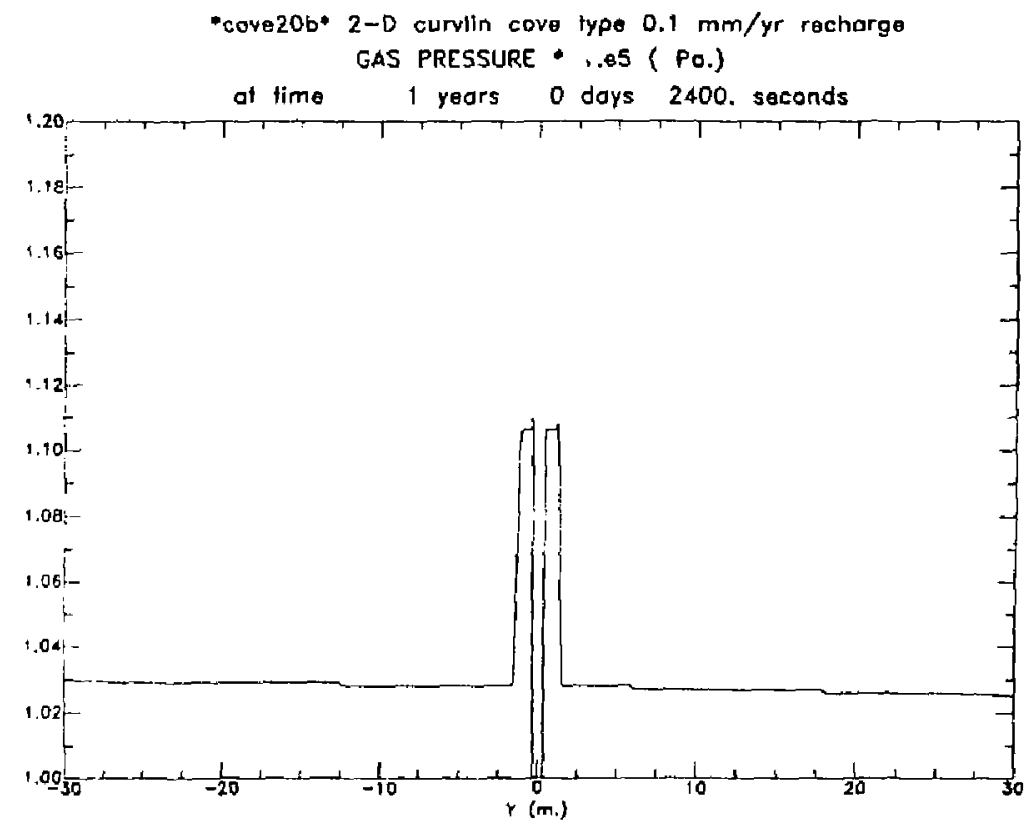

Figure 46. Gas Phase Pressure Profile at 1 year 
$-66-$

"cove20y* 2-D curvlin cove type $0.1 \mathrm{~mm} / \mathrm{yr}$ recharga

GAS PRESSURE * 1.05 ( $\mathrm{Pa}$.)

at time 100 years 2 days 67200 . secands

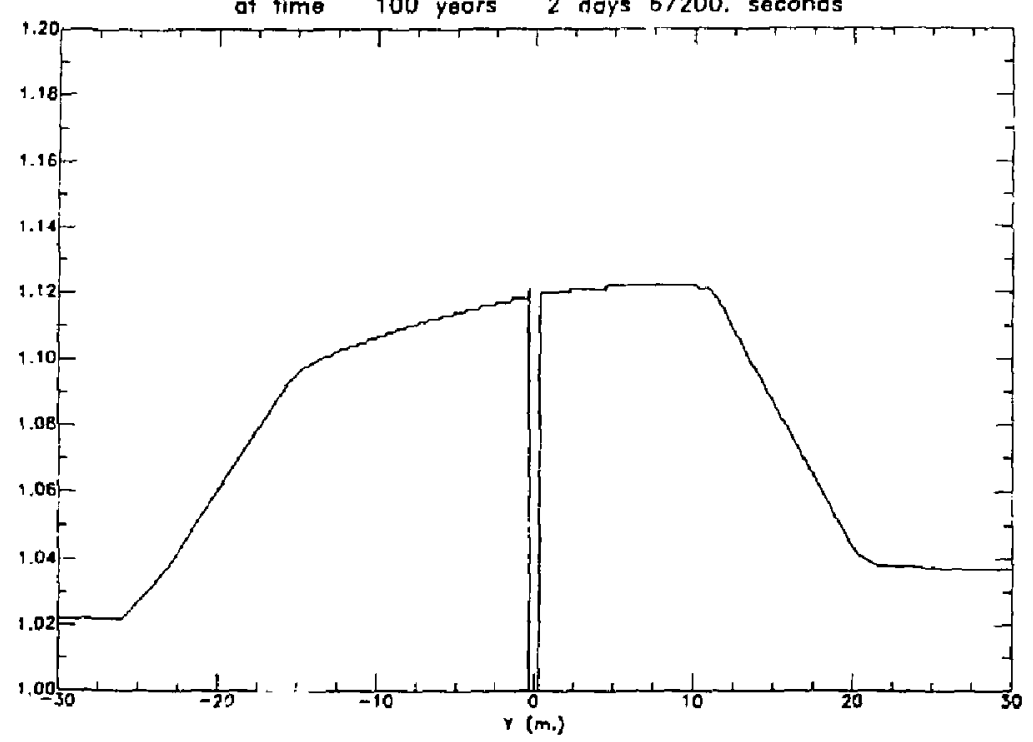

Figure 47. Gas Phase Pressure Profile at 100 years

"cove20b" 2-D curvlin cove typo $0.1 \mathrm{~mm} / \mathrm{yr}$ recharge gas PRESSURE * 1.05 (PO.)

at fime 399 years 364 doys 67552 . seconds

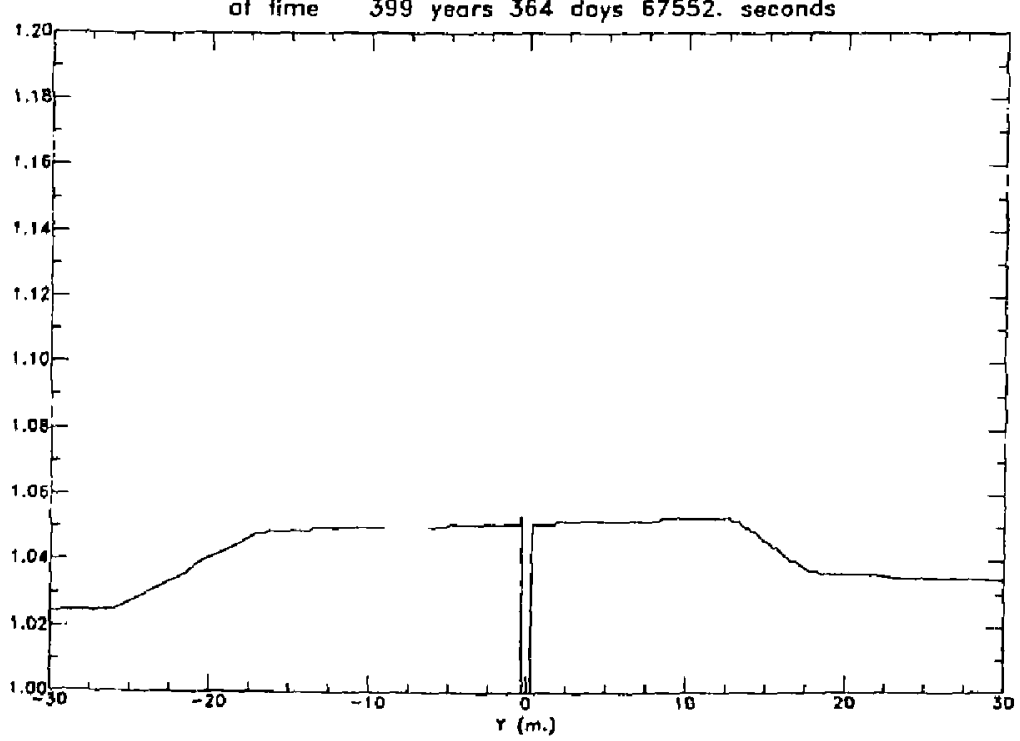

Figure 48. Gas Phase Pressure Profile at 400 years 
.67

Gas Phose Darcy Velocities of 400 years

$0.1 \mathrm{~mm} / \mathrm{yr}$ recharge

(cove20d)

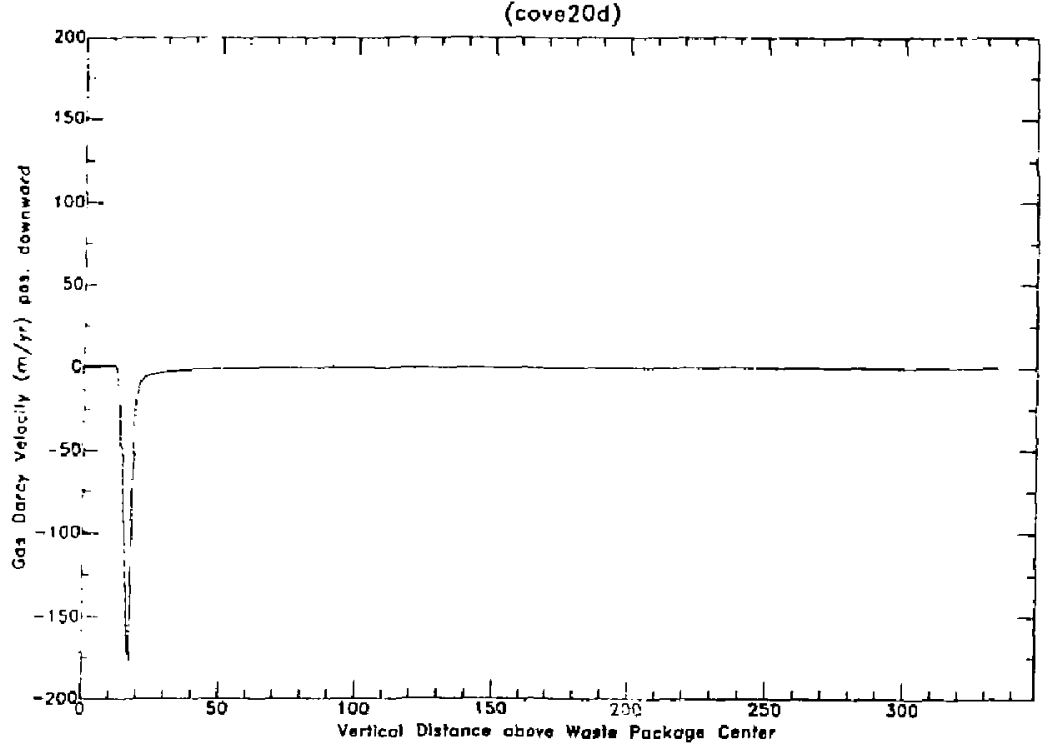

Figure 49. Gas Phase Darcy Velocities at 400 years, $0.1 \mathrm{~mm} / \mathrm{yr}$

Gos Phose Daray Velocities at 1500 years

$0.1 \mathrm{~mm} / \mathrm{yr}$ rechorge

(cove20d)

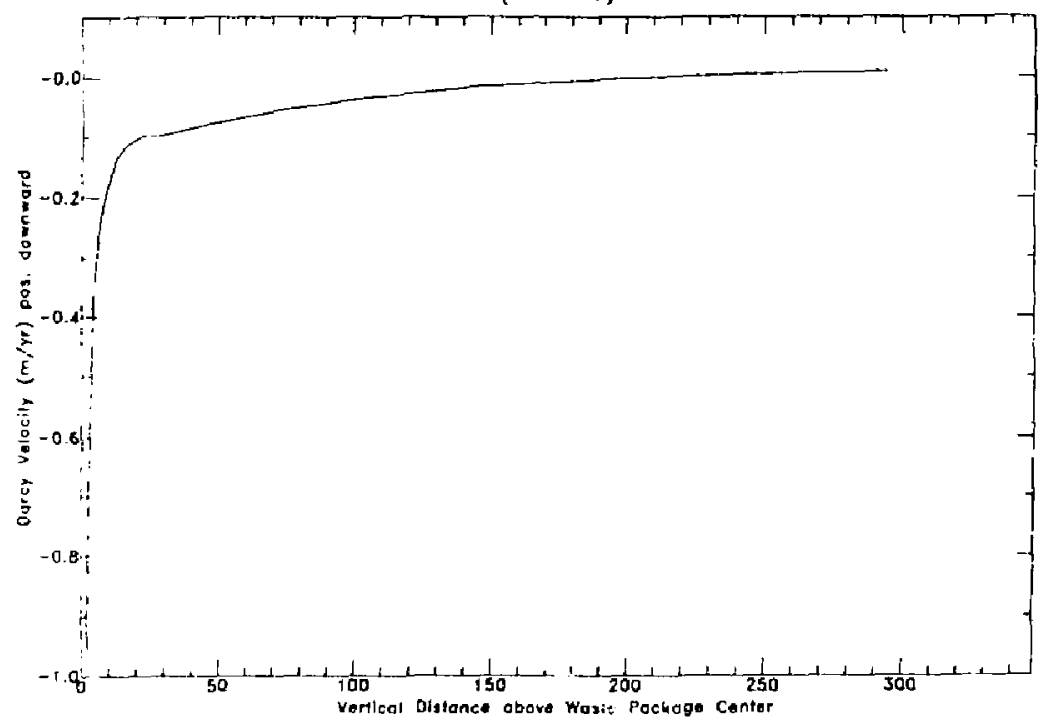

Figure 50. Gas Phase Darcy Velicities at 1500 years, $0.1 \mathrm{~mm} / \mathrm{yr}$ 
-68 -

Gos Phase Darcy Valocllies at 2000 years

$0.1 \mathrm{~mm} / \mathrm{yr}$ recharge

(cove20d)

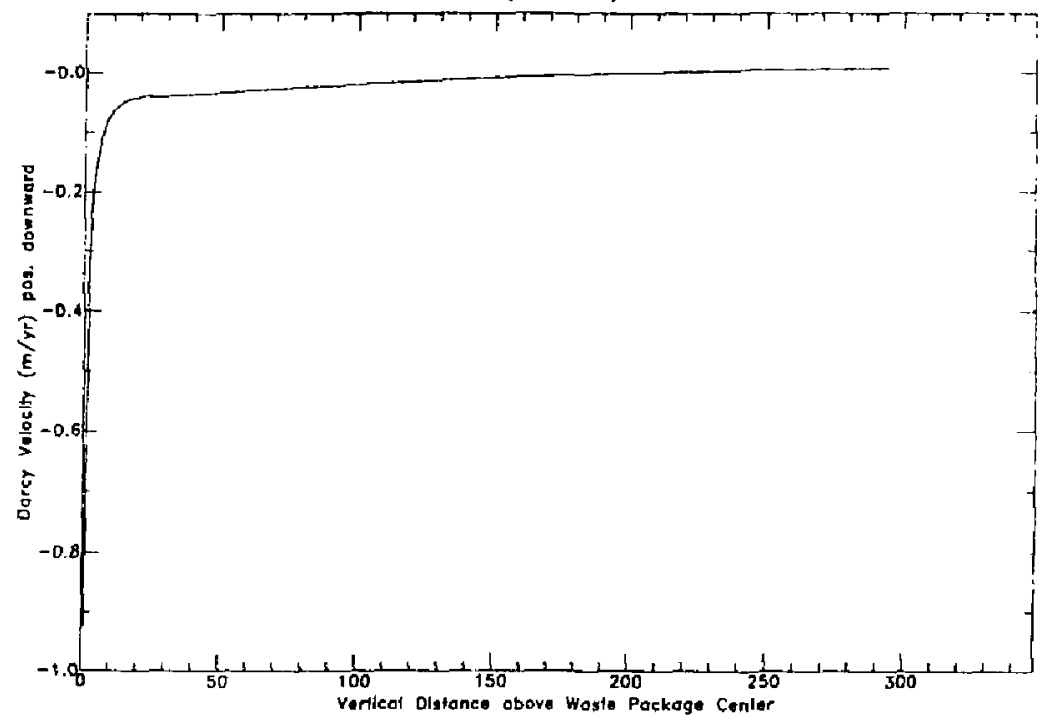

Figure 51. Gas Phase Darcy Velocities at 2000 years, $0.1 \mathrm{~mm} / \mathrm{yr}$

Liquid Darcy Velocities of 400 yeors

$0.1 \mathrm{mrr} / \mathrm{yr}$ recharge

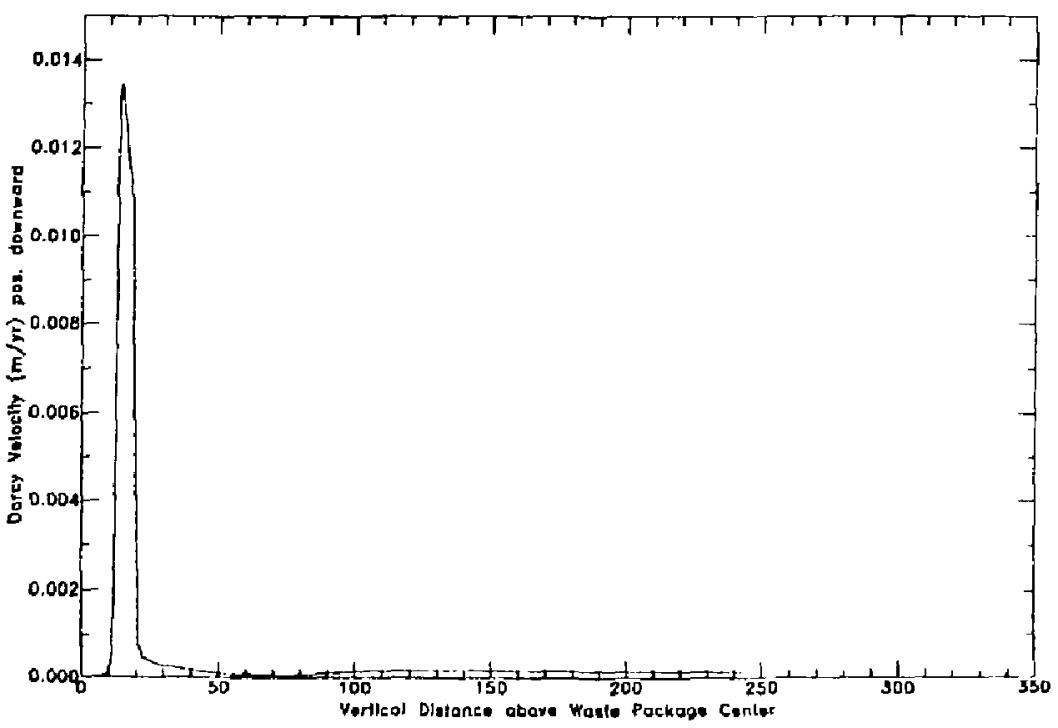

Figure 52. Liquid Phase Darcy Velocilies at 400 years, $0.1 \mathrm{~mm} / \mathrm{yr}$ 
-69.

Liquid Dorcy Velocities at 400 years

$0.1 \mathrm{~mm} / \mathrm{yr}$ racharge

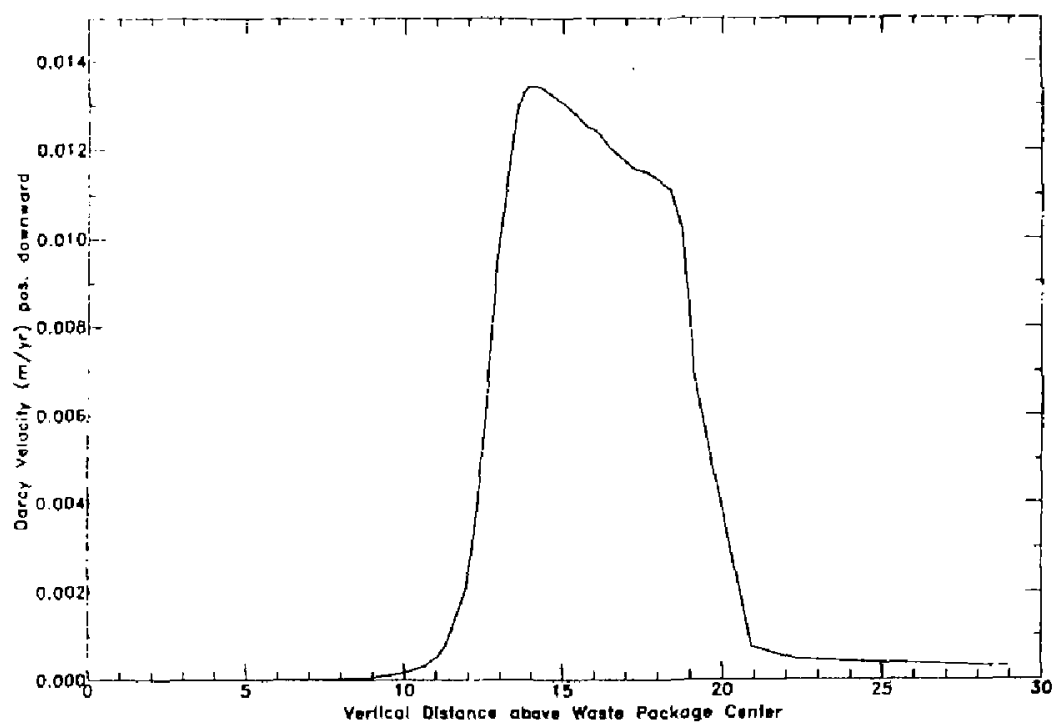

Figure 53. Liquid Phase Darcy Velocities at 400 years, $0.1 \mathrm{~mm} / \mathrm{yr}$

Liquid Phase Dorcy Velocities of 1500 yeors

$0.1 \mathrm{~mm} / \mathrm{yr}$ rechorge

(Cove20d)

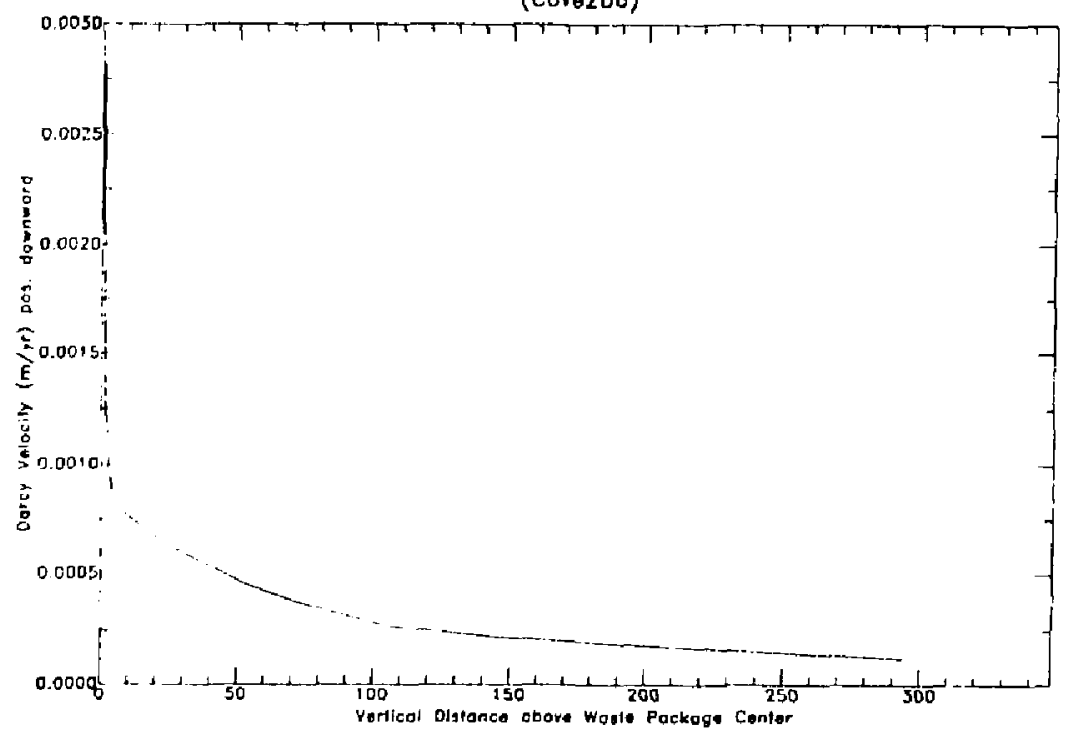

Figure 54. Liquid Phase Darcy Velocities at 1500 years, $0.1 \mathrm{~mm} / \mathrm{yr}$ 
$-70-$

Liquid Phose Dorcy Velocifies of 2000 years

$0.1 \mathrm{~mm} / \mathrm{pr}$ rechorge

(Cave200)

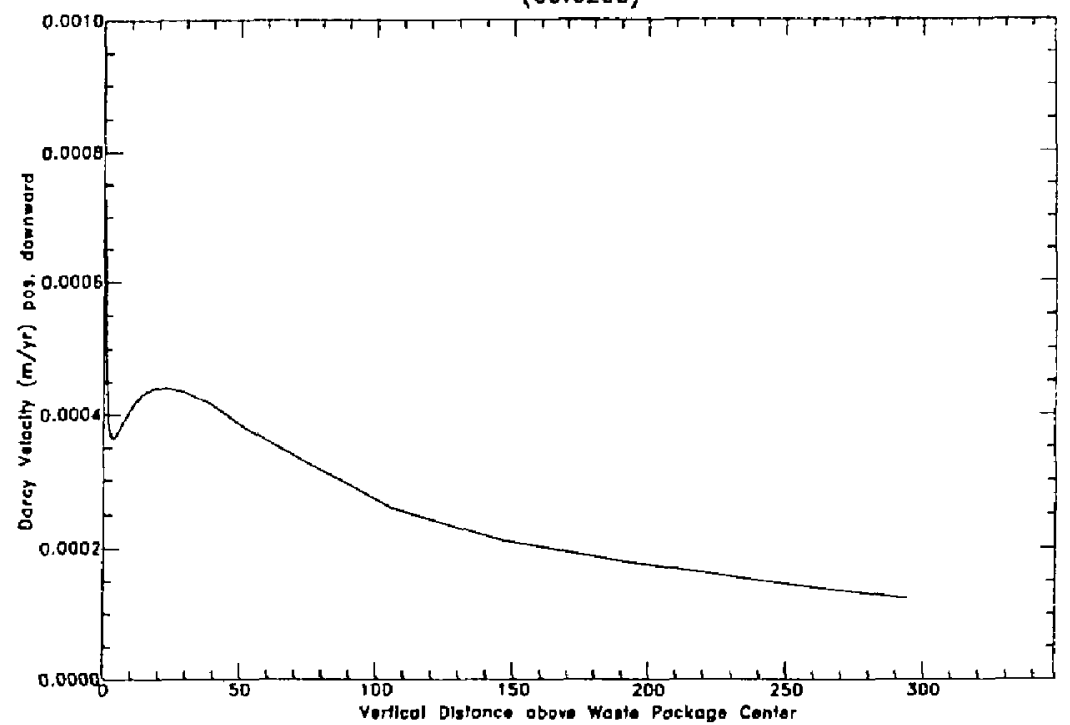

Figure 55. Liquid Phase Darcy Veiocities at 2000 years, $0.1 \mathrm{~mm} / \mathrm{yr}$

Ratio of Waler Vapar Mass Flow Rate to Liquid Mass Flow Rate

of 100 years

$0.1 \mathrm{~mm} / \mathrm{yr}$ recharge

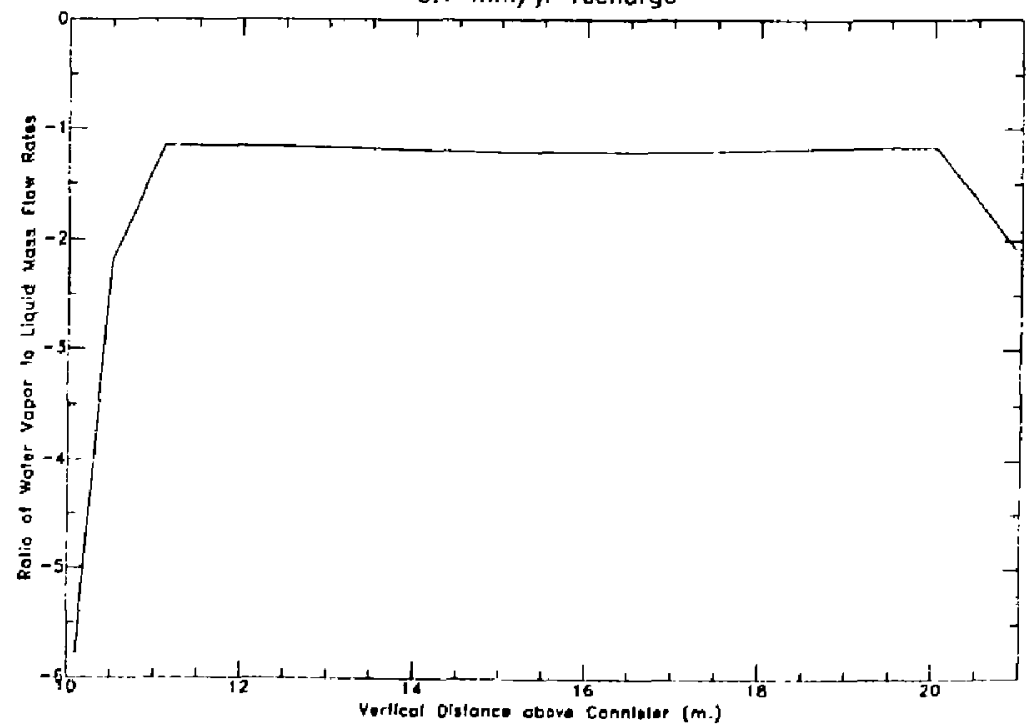

Figure 56. Ratio of Water Vapor Mass Flow Rate to Liquid Mass Flow Rate at 100 years, $0.1 \mathrm{~mm} / \mathrm{yr}$ 
$.71-$

Rotio of Water Vapor Moss Flow Rate to Liquid Moss Flow Rate at 400 years

$0.1 \mathrm{~mm} / \mathrm{yr}$ rechorge

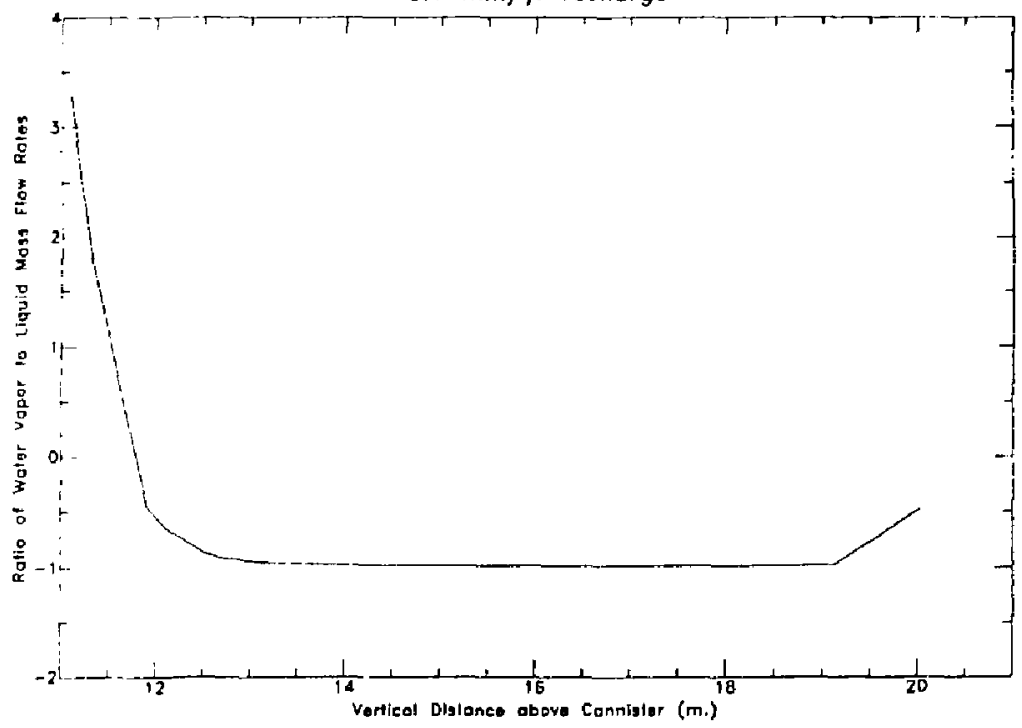

Figure 57. Ratio or Water Vapor Mass Flow Rate to Liquid Mass Flow Rate at 400 years, $0.1 \mathrm{~mm} / \mathrm{yr}$

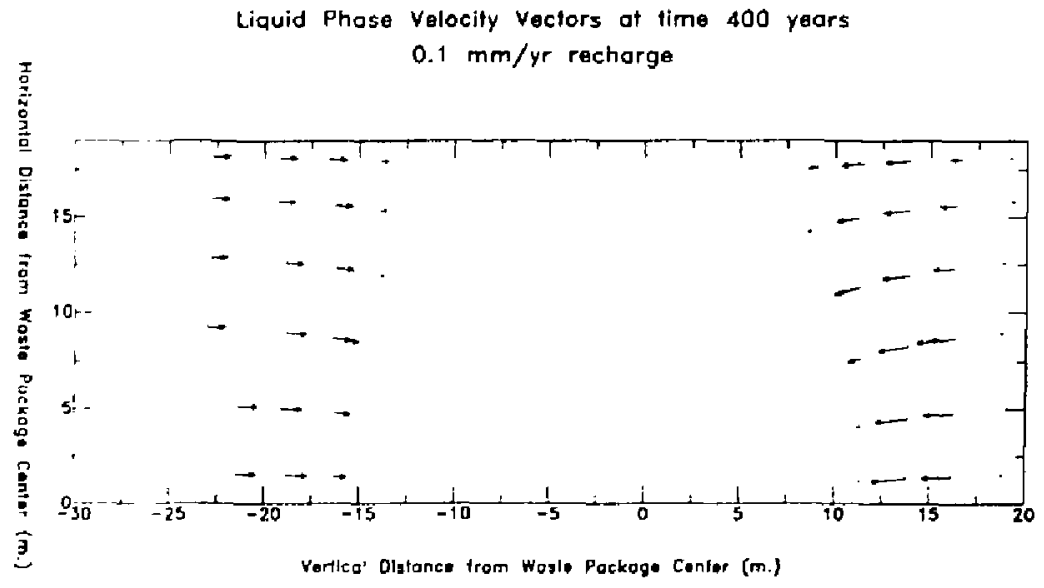

Pigure 58. Liquid Plase Velecily Vecturs at 400 years, $0.1 \mathrm{~mm} / \mathrm{yr}$ 


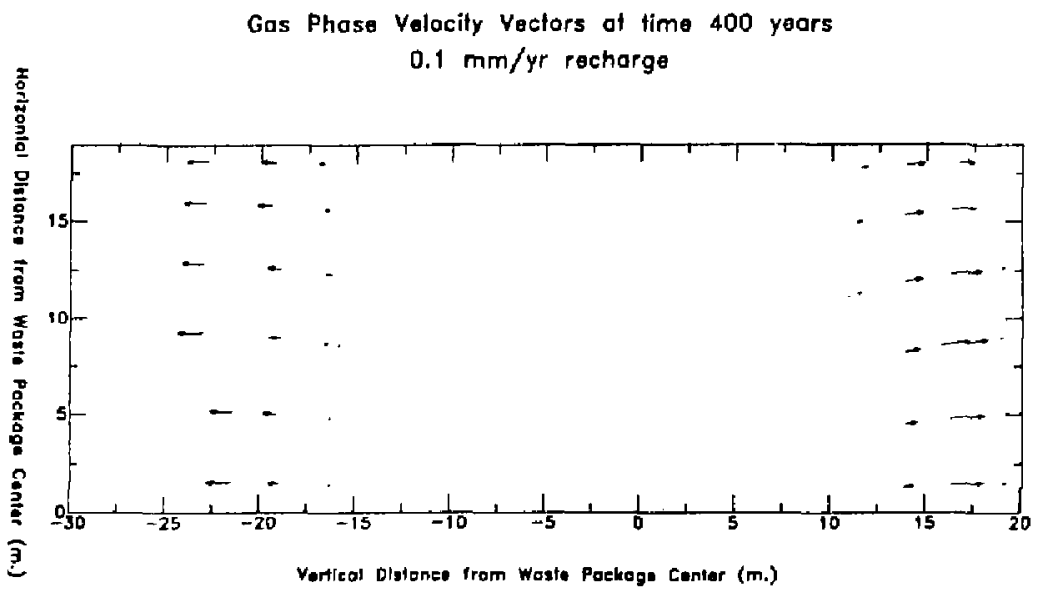

Figure 59. Gas Phase Velocity Vectors at 400 years, $0,1 \mathrm{~mm} / \mathrm{yr}$ 